\title{
Paternal impact on genetic integrity in newborns.
}

Citation for published version (APA):

Linschooten, J. O. (2012). Paternal impact on genetic integrity in newborns. [Doctoral Thesis, Maastricht University]. Datawyse / Universitaire Pers Maastricht. https://doi.org/10.26481/dis.20120620jol

Document status and date:

Published: 01/01/2012

DOI:

10.26481/dis.20120620jol

Document Version:

Publisher's PDF, also known as Version of record

\section{Please check the document version of this publication:}

- A submitted manuscript is the version of the article upon submission and before peer-review. There can be important differences between the submitted version and the official published version of record.

People interested in the research are advised to contact the author for the final version of the publication, or visit the DOI to the publisher's website.

- The final author version and the galley proof are versions of the publication after peer review.

- The final published version features the final layout of the paper including the volume, issue and page numbers.

Link to publication

\footnotetext{
General rights rights.

- You may freely distribute the URL identifying the publication in the public portal. please follow below link for the End User Agreement:

www.umlib.nl/taverne-license

Take down policy

If you believe that this document breaches copyright please contact us at:

repository@maastrichtuniversity.nl

providing details and we will investigate your claim.
}

Copyright and moral rights for the publications made accessible in the public portal are retained by the authors and/or other copyright owners and it is a condition of accessing publications that users recognise and abide by the legal requirements associated with these

- Users may download and print one copy of any publication from the public portal for the purpose of private study or research.

- You may not further distribute the material or use it for any profit-making activity or commercial gain

If the publication is distributed under the terms of Article $25 \mathrm{fa}$ of the Dutch Copyright Act, indicated by the "Taverne" license above, 
PATERNAL IMPACT ON GENETIC INTEGRITY IN NEWBORNS 
ISBN 978-90-8891-436-2

(C) copyright Joost O. Linschooten, Maastricht 2012.

Omslag en opmaak: Richard Verbruggen

Omslagrealisatie en druk: proefschriftmaken.nl / Universitaire Pers Maastricht
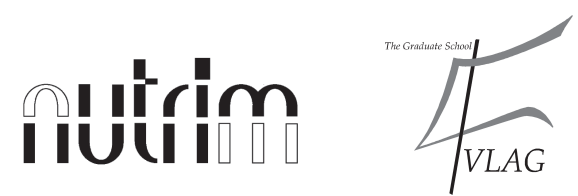

The studies presented in this thesis were performed within NUTRIM School for Nutrition, Toxicology and Metabolism which participates in the Graduate School VLAG (Food Technology, Agrobiotechnology, Nutrition and Health Sciences), accredited by the Royal Netherlands Academy of Arts and Sciences. 


\section{PATERNAL IMPACT ON GENETIC INTEGRITY IN NEWBORNS}

\section{PROEFSCHRIFT}

ter verkrijging van de graad van doctor aan de Universiteit Maastricht, op gezag van Rector Magnificus, Prof. mr. G.P.M.F. Mols, volgens het besluit van het College van Decanen,

in het openbaar te verdedigen

op woensdag 20 juni 2012 om 14:00 uur

door

Joost Olaf Linschooten

Geboren te Apeldoorn op 31 Augustus 1982 


\section{Promotor}

Prof. dr. F.J. van Schooten

\section{Co-promotor}

Dr. R.W.L. Godschalk

\section{Beoordelingscommissie}

Prof. dr. J.G.R. de Mey (voorzitter)

Dr. J. van Benthem (RIVM)

Prof. dr. G. Schoeters (VITO, België)

Prof. dr. M.P. Zeegers 


\section{CONTENTS}

$\begin{array}{lll}\text { Chapter } 1 & \text { General Introduction } & 7\end{array}$

Chapter 2 Use of spermatozoal mRNA profiles to study gene-environment 21 interactions in human germ cells

Chapter 3 In vitro evaluation of baseline and induced DNA damage in human sperm exposed to benzo[a]pyrene or its metabolite benzo[a]pyrene-7,8-diol-9,10-epoxide, using the comet assay

Chapter 4 Incomplete protection of genetic integrity of mature spermatozoa 59 against oxidative stress

Chapter $5 \quad$ New methods for assessing male germline mutations in humans and genetic risks in their offspring

Chapter 6 Evaluation of Randomly Amplified Polymorphic DNA (RAPD)- 91 PCR as methodology to assess mutation frequencies

Chapter 7 Paternal lifestyle as a potential source of germline mutations transmitted to offspring

Chapter 8 General Discussion \& Conclusion

Samenvatting en algemene discussie

Dankwoord

Curriculum vitae 139

List of publications 



\section{CHAPTER $\left.1\right|^{7}$ GENERAL INTRODUCTION}


The prevalence of children suffering from childhood diseases is increasing world-wide [1]. Although survival rates improved strongly over the past decades, there has also been an acceleration in the trend of cancer incidences during childhood [2]. The reason for this increase in childhood diseases might be a result of the wide application of improved diagnostic capabilities, but several types of cancer have gradually increased in specific parts of the world. An overall incidence of childhood cancer of 14 cases per 100,000 was reported and with these low numbers it is difficult to collect meaningful epidemiological evidence for this trend, even for the most common malignancies [3]. The biological reason for the early onset of cancer in children remains unclear, but there might be a link with exposure to genotoxic carcinogens present in the environment and diet. Since the newborn children develop these diseases early in life, it might be possible that they were already at higher risk through prenatal exposure via the parental diet and environment. Epidemiological data have indeed shown that parental exposure to environmental carcinogens and tobacco smoke, including passive smoking, increase the risk for severe health issues in the offspring already at early ages [4, 5]. Many studies have indicated that maternal exposure during pregnancy increases the risk for the offspring to specific types of cancer, because the developing fetus is via the placenta exposed to potentially genotoxic compounds that are present in the peripheral circulation of the mother [6]. Until recently, investigations of developmental defects after parental exposure to genotoxic compounds have mainly focused on these maternal factors [7]. However, upon fertilization the father contributes for $50 \%$ to the new genome and the role of paternal exposure on the onset of childhood diseases is far less intensively studied. Therefore, more studies are needed to provide information about the fathers' role in the development of diseases in their offspring. Since it is difficult to assess the impact of paternal exposure on occurrence of certain diseases with a low prevalence in the offspring, we have developed and applied new methodologies and biomarkers, focusing on the genetic integrity of spermatozoa and the offspring after paternal exposure to genotoxic compounds. These biomarkers are subsequently used as a proxy for a possible increased health risk in the offspring, as it is now generally accepted that DNA damage by genotoxic compounds is an important initial step in the onset of cancer $[8,9]$. Since $50 \%$ of the newborn's genome comes from the father, our studies first focused on DNA damage in male germ cells. From many genotoxic compounds it is known that they can decrease overall sperm quality, resulting in fertility problems [10]. Although it is often known that these compounds also compromise the genetic integrity of mature spermatozoa, it is often unclear whether this will also affect genetic integrity in the offspring, leading to transgenerational genomic instability $[11,12]$. Therefore, the second part of this thesis will focus on genetic effects in the offspring after paternal exposure.

\section{DNA damage in male germ cells}

Since the discovery of spermatozoa by Anthony van Leeuwenhoek in 1677, much research has been carried out to describe morphology, physiology and biochemistry of the male germ cells in more detail [13]. We now know that the sperm cells are responsible for a correct delivery of the male part of the genome to the female germ cell at fertilization. However, the correctness of the male DNA that is delivered to the oocyte is affected by paternal exposures to genotoxic compounds, that can reach the testis and thus also the developing germ cells. Indeed, many compounds have been identified that can induce damage to our germline DNA, leading to a variety of potential adverse events in the offspring, if this damage is not properly repaired. So far, most of the knowledge is acquired by studies on laboratory rodents, but spermatogenesis in rats and mice is 
dissimilar from the process in man. Therefore, the focus of research has shifted to the development of methods to measure effects of genotoxic compounds directly in exposed humans and their offspring. The first step would be to investigate whether compounds that were found to be genotoxic to germ cells in rodent models, can also induce damage to the DNA in mature sperm cells of men. If so, how does the cell cope with this damage and are there any protective mechanisms to prevent any health risks for the child? As these questions are the main topic of investigation in the next chapters, it is important to discuss the process of sperm cell maturation and at which stages the DNA can be damaged, how the damage may lead to effects in offspring, and how putative DNA damage can be prevented.

\section{Normal spermatogenesis and spermiogenesis}

For a better understanding of how damage may occur in spermatozoa, as discussed in chapter 2, 3 and 4, it is important to know at which stages of the spermatogenesis the various progenitor cells are most susceptible and how associated cell types in the testis are involved. The production of the male germ cells is located in the testes, which consist of a network of so-called seminiferous tubules. The walls of these seminiferous tubules are formed by the Sertoli cells that support and protect developing germ cells during all stages of spermatogenesis. The connections between Sertoli cells form the blood-testis barrier and protect the germ cells from direct contact with potentially harmful compounds present in blood. During spermatogenesis, germ cells undergo several modifications under influence of both mitotic and meiotic cell divisions to end as mature spermatozoa [14]. It takes several steps and major modifications to produce mature spermatozoa, starting with spermatogonial stem cells that are located close to the basal membrane that surrounds the seminiferous tubules. The duration of the spermatogenesis (as illustrated in figure 1) in human is about 64 - 74 days and can be subdivided into three major phases: 1) the proliferative phase, 2) the meiotic phase and 3) differentiation of the haploid spermatids (also known as spermiogenesis) [14-16]. At birth the primordial germ cells are the first cells involved in the production of male germ cells. They proliferate in utero into undifferentiated type A spermatogonial stem cells. During initiation and maintenance of spermatogenesis at puberty, these type A stem cells mitotically divide into two type A spermatogonia, of which one remains in a quiescent state as stem cell (called: the dark type A spermatogonium). The other pale type A spermatogonium develops into differentiating type B spermatogonia and these represent the onset of germ cell development. After the last mitotic division, these type B spermatogonia are transformed in pre-leptotene primary spermatocytes and these cells enter the meiotic stage of spermatogenesis.

The meiotic phase takes approximately 24 days in humans, of which 10-12 days are needed for the prophase. Optimal environmental conditions for meiotic cell division and post-meiotic development are created by the Sertoli cell barrier (or blood-testis barrier). After the entrance of primary spermatocytes into the prophase of meiosis, they pass the blood-testis barrier into the adluminal compartment. Upon transport of primary spermatocytes through the blood-testis barrier, the cells are connected to each other via cytoplasmic bridges. These cytoplasmic bridges are maintained throughout most spermatogonial and spermatocytic stages and dissolve only in advanced phases of spermatid development. In the adluminal compartment the primary spermatocytes continue with further prophase stages; the zygotene, pachytene and the diplotene stages. In the prophase, chromosome condensation, pairing of homologous chromosomes and homologous crossing-over takes place. Primary spermatocytes are still diploid and have two sets of 
chromosomes, but after the first meiotic division only one set of chromosomes is retained and these secondary spermatocytes rapidly divide into two haploid spermatids. In a process called spermiogenesis, the spermatids undergo maturation towards spermatozoa.

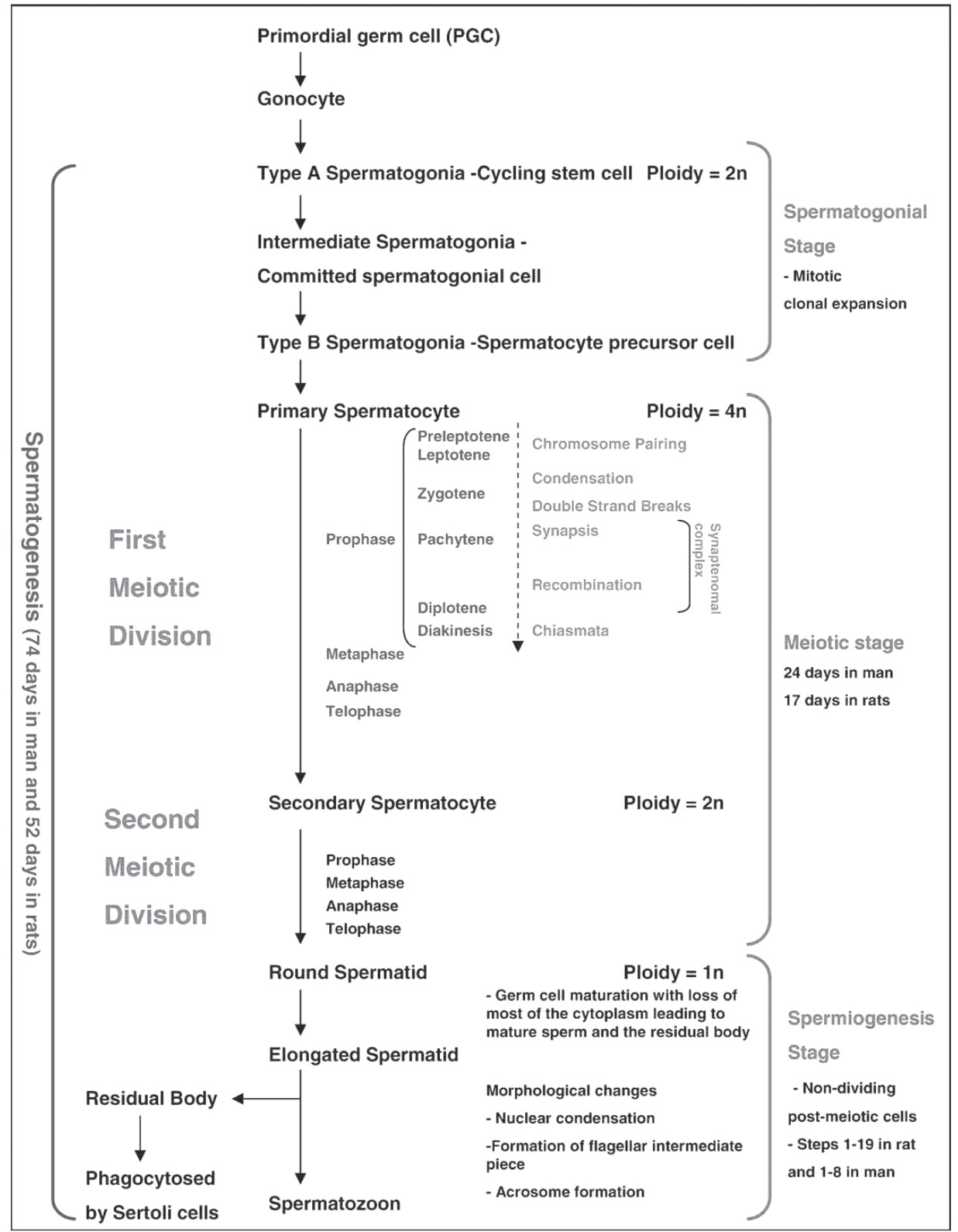

Figure 1: schematic overview of all steps involved in spermatogenesis (adapted from Olsen et al. [17])

During spermiogenesis, several structural changes take place: 1. the condensation of nuclear chromatin to about one tenth of the volume of an immature spermatid, which is achieved by the replacement of histones by transition proteins and subsequently pro- 
tamines, which can bind to each other with extensive disulfide cross-links, resulting in a compact chromatin structure. At this point transcriptional activity is largely silenced, as the DNA is no longer accessible for the transcription machinery (please note that not the full genome is compacted by protamines; part remains attached to histones and retains a relative open structure). 2. during spermiogenesis, an enzyme-filled cap-like structure is derived from the Golgi apparatus, called the acrosome. Upon fertilization, the enzymes of the acrosome are released to break down the zona pellucida, allowing the haploid sperm nucleus to join with the haploid nucleus of the ovum [18]. 3. the final important process during spermiogenesis is the development of flagellum structures and their implantation to provide the cells the ability to move [14].

Altogether, spermatids are transformed via several structural changes into spermatozoa that are ready for release into the seminiferous tubular lumen and transport to the seminal vesicles. Noteworthy is that the number of malformed spermatozoa is extremely high and also the variety of malformations is large; for instance affecting the acrosome, the nucleus or flagellum or a combination of these factors. Development of most of the malformed spermatozoa is aborted via apoptosis or arrest of spermatogenesis at the stage of primary spermatocytes and these cells disintegrate. At 100\% healthy testicular conditions, up to $75 \%$ of the developed spermatozoa are lost by apoptosis or disintegration, leaving $25 \%$ of the germ cells that will reach the ejaculate [14]. Still, more than half of these cells escaped from apoptosis and can be malformed, resulting in only $12 \%$ that is available for reproduction. According to $\mathrm{WHO}$-guidelines a normal ejaculate should contain 20 million spermatozoa per milliliter, but after all only one spermatozoon is necessary for fertilization.

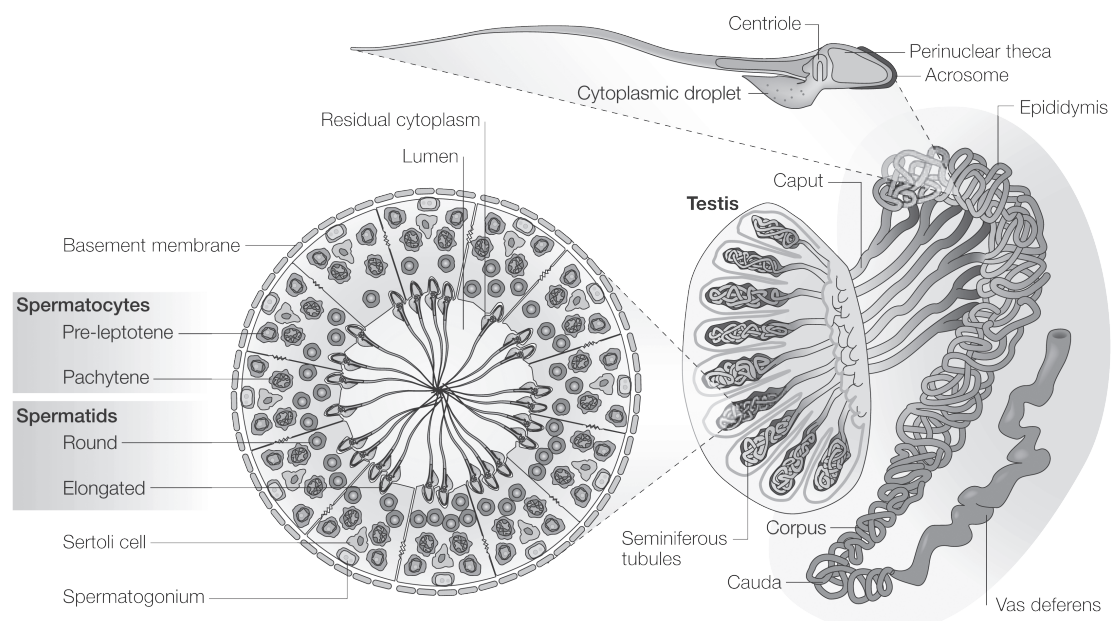

Figure 2: Schematic overview of the anatomy of the seminiferous tubules in which the Sertoli cells are located and from a mature sperm cell [19].

Thus, normal spermatozoa exist of a condensed nucleus, covered by an acrosome for establishing contact to the female gamete and a flagellum for movement (see figure 2). The head diameter of a mature spermatozoon is $4-5 \mu \mathrm{M}$, the diameter of the flagellum is $1-2 \mu \mathrm{M}$ and the total length of the spermatozoon measures $60 \mu \mathrm{M}$. The flagellum is responsible for sperm motility and is composed of two major components. The midpiece is located close to the nucleus, which contains the mitochondria that generate the energy needed for motility. The lower part of the flagellum, or principal and terminal pieces, is 
necessary in propelling the spermatozoon forward.

During transport of spermatozoa through the epididymis until ejaculation [13], they are still infertile and incapable of progressive movement, but the cells gain these properties during transport. This process requires 12 to 21 days in man, which can be accelerated by frequent ejaculations. However, too frequent ejaculations may thus lead to poorly fertile, immature spermatozoa. On the other hand, more than 7 days of abstinence causes aging of the spermatozoa that also lead to less fertile cells. An optimal period of abstinence for men is 3 to 4 days, resulting in fertile, healthy spermatozoa in sufficient amounts, according to WHO guidelines $[13,20]$.

Sperm production in the testes is a continuous process with an average production of 6 to $21 \times 10^{9}$ cells per day, so large numbers of mature cells are stored in the cauda epididymis. Half of these cells are never ejaculated and are removed by various mechanisms, as reviewed by Zaneveld et al. [13].

In the end, this process will lead to healthy ejaculates which should meet the following WHO guidelines criteria [20], to be classified as fertile:

- $\quad$ Semen volume: $1.5 \mathrm{ml}$ (range: $1.4-1.7 \mathrm{ml}$ );

- Total sperm number: 39 million per ejaculate (range 33-46 million per ejaculate);

- Sperm concentration: 15 million per ml (range 12-16 million per ml);

- Vitality: 58\% live (range 55-63\%);

- Progressive motility: 32\% (range 31-34\%);

- Total (progressive + non-progressive) motility: 40\% (range 38-42 \%);

- Morphologically normal forms: 4.0\% (range 3.0-4.0\%).

All samples used in chapters 2, 3 and 4 were analyzed according to these parameters in order to determine the potential fertility of the samples. It is remarkable that none of these parameters are linked to the genetic integrity of the sperm cells, which means that any type of DNA damage measured in these samples, is present in sperm in healthy ejaculate, if the $\mathrm{WHO}$ criteria are met.

\section{Susceptibility of male germ cells to genotoxins at various developmental stages}

Altogether, several stages can be identified at which the developing spermatozoa are most susceptible for exposures to genotoxic compounds. During spermatogenesis they undergo a number of structural changes, in order to conserve the male DNA for proper delivery of the paternal genetic material to the oocyte; during the first stages of the spermatogenesis cells divide mitotically, which means that DNA repair is still effective. If toxic compounds are able to pass the blood-testis barrier [14], the damage induced by these exposures can theoretically still be repaired. However, after transformation of the type B spermatogonia into primary spermatocytes, cells divide meiotically and most DNA repair pathways are silenced [17]. Although it is unclear what possible effects this might have on further development of the spermatocytes, this might lead to increased levels of DNA damage in mature sperm [21]. One important structural modification with respect to the DNA integrity of the mature spermatozoon is the condensation of the chromatin structure and loss of cytoplasm. At this stage, histones are replaced with protamines which lead to a more compact chromatin structure. This modification is not only necessary to fit the complete chromatin structure into the tight sperm nucleus; it makes the DNA also less accessible for DNA polymerases and genotoxic compounds. However, also the DNA repair machinery may be impaired in reaching the DNA, and loss of cytoplasm may lead to a concomitant loss of DNA repair enzymes that are usually present in cytoplasm and translocate to the nucleus only in case of activation by DNA damage. Thus, loss of cy- 
toplasm and compaction of the DNA does not only silence transcription, but also affects DNA repair. On the other hand, due to its compact structure, the DNA in spermatozoa is probably also protected from genotoxic compounds that would introduce DNA damage. Moreover, loss of cytoplasmic enzymes also leads to a decreased capacity to metabolically activate genotoxic compounds, which can be considered as an additional protective measure, but the close proximity of metabolically active Sertoli cells will theoretically make transport of active metabolites to sperm possible.

Secondly, an increased number of sperm cells with high levels of DNA damage might be the result of the exposure to reactive oxygen species (ROS). These ROS are able to interact directly with the DNA, although it is tightly packed, leading to oxidative DNA damage. However, mature spermatozoa are to a certain level protected from exposure to ROS by the presence of anti-oxidants in the seminal plasma (mainly vitamin C) [22]. Increased levels of ROS and oxidative DNA damage are commonly observed in spermatozoa of infertile men [23]. Exposure to genotoxic agents might also lead to increased formation of ROS, as is shown in somatic cells, but there are also other factors that increase ROS formation in these cells. More information on the susceptibility of germ cells to genotoxic exposures and ROS induced DNA damage will be given in chapter 3 and 4.

Half of the volume mature spermatozoa remain unejaculated, since longer periods of abstinence will lead to removal of mature spermatozoa in the epididymis during maturation [13]. Genotoxic exposure however, might lead to DNA damage in the mature spermatozoa and this might subsequently influence the proper initiation of sperm cell removal. If this disintegration of mature spermatozoa is aborted, more cells containing increased levels of DNA damage will be present in the ejaculate. The discovery of the presence of mRNA in spermatozoa [24] derived from ejaculates opened new possibilities for the assessment of gene expression profiles that can be relevant for germ cell exposure and subsequent health effects in the offspring. Since transcription is silenced in mature spermatozoa it is suggested that gene expression profiles reflect important processes that occurred earlier during spermatogenesis when transcription was still active. During transport through the Sertoli cells, spermatocytes are connected to each other via cytoplasmic bridges and most mRNA is lost when the cells disconnect from each other and the residual bodies, containing most cytoplasm, are removed. However, it should be noted that the contents of the sperm are released into the oocyte upon fertilization, including various transcription factors and types of RNA [19]. A response of sperm cells to a certain exposure could affect the type and quantity of RNA that is delivered to the oocyte. It has been shown that also RNA in sperm may have an effect on the offspring, probably via epigenetic processes [25], and therefore this may form an additional important aspect in paternally transmitted effects to the offspring by genotoxic compounds.

\section{Germline mutagenicity}

Since it is known that exposure to genotoxic compounds can induce damage to DNA in the paternal germ cells, the next step would be to find out to what extent this damage has an effect on the developing offspring. Therefore, germline effects of paternal exposures to chemical compounds require further investigation. In the end, the fathers' contribution to the next generation is half their genome [19] and the fathers' contribution to the epigenome can also be substantial. Thus, it is of great importance to understand the paternal contribution to discover its implications on early developmental processes and embryonic development. Genetic modifications already present at this stage, will eventually lead to onset of diseases in the children's early years [19]. Genetic diseases, 
such as cancer, are known to be induced by mutations in somatic cells. However, when these mutations occur in the genetic material of the germ cells, these mutations can be transferred to next generations and thereby increasing the risk of childhood diseases [26], as illustrated in figure 3.

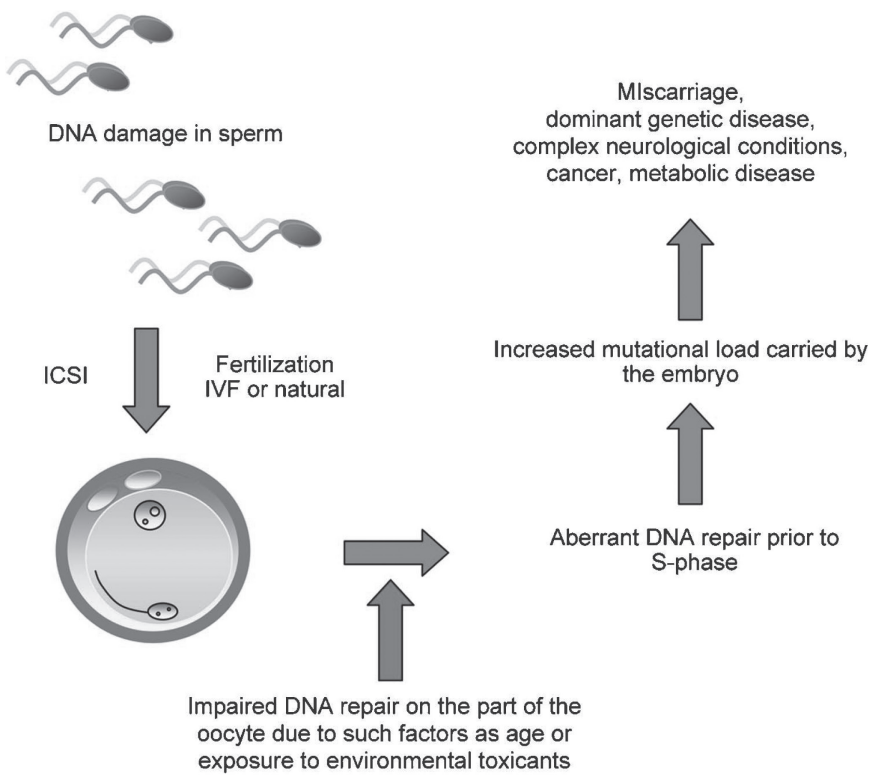

Figure 3: DNA damage in sperm might possibly have impact on the health and genetic integrity of the offspring via this suggested mechanism (by Aitken and Koppers [27]). Upon fertilization limited DNA repair is possible, but mutations can be introduced due to genotoxic exposure inhibiting this process. These mutations will subsequently remain present in the offspring genome and thereby increasing susceptibility for certain genetic diseases during childhood.

Several types of parental genotoxic exposure have already been associated with fertility problems, which might be an effect of decreased genetic integrity in the germ cells [28]. Furthermore, there is also increasing evidence for the association between parental exposure and childhood cancer and developmental defects. Although the source of the exposure can be very different between studies, the effects show that there is evidently an effect on the offspring, as described in the following paragraphs.

\section{Dietary exposure}

One of the main sources of genotoxins to which we are regularly exposed is our diet. There is increasing evidence for the negative reproductive health effects of several specific dietary components, such as ethanol [29]. On the other hand, most women alter their lifestyle as soon as they know they are pregnant and this will unavoidably also affect the type and amount of exposure. Although exposure to for instance alcohol can be simply minimized by not consuming alcoholic beverages, some exposures are unavoidable. In some parts of Europe a very common method of meal preparation is to grill meat products, which might lead to the formation of polycyclic aromatic hydrocarbons (PAHs). In other parts of Europe, it is very common to consume large amounts of baked and fried 
food products, leading to a possible high consumption of acrylamide or heterocyclic amines. Although there are ample studies on the effects of maternal diet on the offspring, it remains unclear how these dietary components affect sperm DNA quality and the offspring's health via exposure of the father. Upon fertilization the, possibly damaged, paternal heritable genetic package is delivered to the oocyte and from that moment the fathers' influence on the growing fetus is limited.

Exposure to genotoxic compounds has been shown to induce DNA damage in somatic cells, also after moderate levels of consumption. Only few data is available in which the relation between paternal dietary exposure and its effects on the offspring is studied. For instanced for acrylamide; it has been shown that it is able to decrease sperm count and increase sperm abnormalities in mice. Furthermore, after paternal exposure, a decrease in fertility was observed [30]. Another component that is able to decrease sperm quality [29] and therefore a potential risk for offspring, is ethanol as present in alcoholic consumptions. However, no adverse effects on the development of childhood germ cell tumors were found after preconceptional parental alcohol drinking [31]. On the other hand, high maternal alcohol consumption (1 drink / day during pregnancy) was found to be associated with the development of childhood leukemia, but data on effects of paternal consumption are marginal [32]. On the contrary to ethanol, paternal exposure to PAHs was associated with increased risks of cancer during childhood [33]. Maternal exposure to PAH before conception or during pregnancy was not linked to any type of childhood brain tumors, but this study emphasizes the contribution of paternal preconceptional exposure to PAH on increased risk for the development of these type of tumors [34].

\section{Parental smoking and childhood diseases}

Paternal exposure to PAHs has already been linked to a potentially increased childhood cancer risks, and one of the main sources of exposure to this compound is cigarette smoking. Smoking has been shown to increase oxidative damage in sperm cells [35], as well as decrease sperm quality and fertility [36]. Furthermore, several studies have investigated the effect of maternal and paternal cigarette smoking on the development of childhood cancer, in which maternal passive smoking is also of great importance [37]. In several studies, paternal preconception smoking was associated with significantly elevated risk of childhood cancers, even after correction for maternal smoking [37-39]. In contrast to the studies that observed positive correlations, there are also several studies indicating that there is no effect of prenatal exposure to parental smoking on the induction of genetic damage or development of germ cell tumors in the offspring [31, 40, 41].

Animal studies have shown that genetic damage after paternal smoking accumulates in the spermatogonial stem cells. These data also indicate that mutations in sperm are passed on to offspring, causing permanent changes in the newborns' genetic composition and can even persist in future generations [42]. Regarding exposure to cigarette smoke, it will be investigated whether this will have both an effect on the genetic integrity in the germ cells, as discussed earlier in this introduction, but also on the offspring's' DNA (see Chapter 7).

\section{Other types of exposure and risk for childhood diseases}

Exposure to smoking or genotoxic dietary components during daily life is very common. However, many other types of exposure present in our environment have been identified that may have large effects on the offspring, such as polluted air or extraordinary levels of radioactivity. Although such exposure may be rare and analysis of human populations is not as easy as animal studies, these environmental factors can induce DNA damage. 
After extrapolation of the results to humans, people living close to industrial areas might be at risk for developing mutations in the germline, as a result of inhalation of polluted air. In areas close to steel mills, the air is polluted and animal studies have indeed shown that this can increase germline mutation frequencies in herring gulls [11], as well as in mice $[12,43]$. Evaluation of the heritable genetic effects of environmental chemicals in human studies is more difficult; not only exposure to high levels of genotoxins is uncommon in humans, mutations are also rare, leading to the requirement of large populations when comparing exposed and non-exposed groups. Furthermore, humans are often not exposed to one specific compound, but to a complex mixture of chemicals, making it more difficult to relate exposure and mutation rates [44].

Although it is difficult to investigate effects after parental exposure on human offspring, several specific types of exposure were studied in human populations. Considerate amount of attention was paid to paternal exposure to pesticides, which was suspected to lead to germ-cell mutagenesis. Chen et al. reviewed the effects of pesticides on the offspring and concluded that outcomes were inconsistent, regarding the capacity of pesticides to increase the risk of germ-cell tumors among offspring [45]. Another specific type of exposure is radiation, provided unintentionally for a large population after the Chernobyl nuclear accident. In several studies by Dubrova et al. elevated mutation frequencies were observed in offspring of exposed families as compared to a control group $[46,47]$. These results suggest that radiation might have an effect on the genomic stability in the offspring from irradiated parents, but controls and exposed families were from different areas and may thus differ in lifestyle. More work is thus needed on the effects of lifestyle factors on mutation frequencies in the germline.

\section{Determination of germline mutagenicity}

The different sources of genotoxic exposure and its various relationships with negative impact on parental and newborn health as described above, illustrate that there are many sources of environmental hazards for the offspring's health. The development of biomarkers that are able to determine these effects, even after moderate exposure levels, would be of great value in research to find other possible relationships. In this thesis several potential biomarkers were developed and tested to detect several types of genetic alterations in sperm and in the offspring after paternal exposure to genotoxins by lifestyle (as described in chapter 5, 6 \& 7).

\section{Aim \& outline}

This study was conducted within the European Union's 6th Framework Programme "NewGeneris". The objective of this large project was to investigate the role of prenatal and early-life exposure to genotoxic chemicals present in food and environment in the development of childhood cancer and immune disorders. Next to the investigation of effects of maternal pre-natal exposure, one of the main goals of NewGeneris was to determine the role of paternal exposure and to develop biomarkers that reflect exposure to chemicals, or biomarkers that reflect early effects of toxic chemicals. This study was especially justified since childhood cancer incidences are rising in the world, but most of the underlying reasons for this increase are still unknown. Part may be due to preconceptional paternal exposure to genotoxic compounds and some studies have already investigated that many types of environmental exposure may lead to decreased sperm quality. However, it is still unclear to what extent paternal exposure may lead to genetic changes in the developing fetus with subsequent negative health effects to the child. This 
lack of knowledge is partly due to a lack of appropriate techniques that can be applied in human populations. Therefore, it was the aim of this thesis to develop methodologies with which germ cell DNA integrity can be investigated and these techniques have subsequently been applied to human populations to test their applicability. These techniques focus both on DNA damage in the sperm nucleus, as well as paternal exposures that can lead to genetic alterations in sperm that can be transmitted to the child.

First, the effects of genotoxic exposures on mature spermatozoa were studied, focusing on DNA integrity and mRNA content. In Chapter 2, spermatozoal mRNA profiles were tested as potential biomarker for exposure to genotoxins. In this study, gene expression profiles of smokers and non-smokers were used to test whether differences could be detected in gene expression after exposure to cigarette smoke. Next, in Chapter 3 , we evaluated whether the major cigarette smoke derived genotoxin, benzo[a]pyrene, was able to induce damage to human sperm in vitro. In Chapter 4, we have investigated the effect of ROS on the genetic integrity of mature spermatozoa and the potential antioxidative protective mechanisms present in the environment of mature sperm. Altogether, this might lead to more knowledge about the effects of environmental exposures to genotoxicants on the genetic integrity in the paternal germ cells, which is delivered to the oocyte.

Nowadays, there are several methods to assess male germline mutations and the genetic risks in the offspring, but not all of them are of relevance with respect to our aim. In Chapter 5, some classical and some newly develop methods to detect these heritable gene mutations will be reviewed and, compared, to investigate which methods will be most suitable in studies involving humans. Based on the findings of chapter 5, we selected one method, the RAPD-PCR, to assess mutation frequencies in an in vitro model in which cells were exposed to BPDE to induce DNA damage. In Chapter 6, we discuss the outcomes of this study and evaluate the usefulness of the RAPD-PCR as suitable methodology. Another promising method to determine the effects of parental exposure on the offspring is the use of the analysis of minisatellites in the father, the mother and the child. In Chapter 7 we used this assay to investigate whether specific types of lifestyle exposure (e.g. diet, smoking behavior) were able to induce mutations at these minisatellite regions in the offspring. Finally, in Chapter 8, the main findings as described in this thesis are discussed and summarized. 


\section{References}

1. Merlo, D.F., C.P. Wild, M. Kogevinas, S. Kyrtopoulos, and J. Kleinjans, NewGeneris: a European study on maternal diet during pregnancy and child health. Cancer Epidemiol Biomarkers Prev, 2009. 18(1): p. 5-10.

2. Steliarova-Foucher, E., C. Stiller, P. Kaatsch, F. Berrino, J.W. Coebergh, B. Lacour, et al., Geographical patterns and time trends of cancer incidence and survival among children and adolescents in Europe since the 1970s (the ACCISproject): an epidemiological study. Lancet, 2004. 364(9451): p. 2097-105.

3. Pallapies, D., Trends in childhood disease. Mutat Res, 2006. 608(2): p. 100-11.

4. Perera, F.P., W. Jedrychowski, V. Rauh, and R.M. Whyatt, Molecular epidemiologic research on the effects of environmental pollutants on the fetus. Environ Health Perspect, 1999. 107 Suppl 3: p. 451-60.

5. Perera, F.P., V. Rauh, R.M. Whyatt, D. Tang, W.Y. Tsai, J.T. Bernert, et al., A summary of recent findings on birth outcomes and developmental effects of prenatal ETS, PAH, and pesticide exposures. Neurotoxicology, 2005. 26(4): p. 573-87.

6. Godschalk, R.W. and J.C. Kleinjans, Characterization of the exposure-disease continuum in neonates of mothers exposed to carcinogens during pregnancy. Basic Clin Pharmacol Toxicol, 2008. 102(2): p. 109-17.

7. Friedler, G., Paternal exposures: impact on reproductive and developmental outcome. An overview. Pharmacol Biochem Behav, 1996. 55(4): p. 691-700.

8. Dolan-Mullen, P., G. Ramirez, and J.Y. Groff, A meta-analysis of randomized trials of prenatal smoking cessation interventions. Am J Obstet Gynecol, 1994. 171(5): p. 1328-34.

9. Tang, D., D.H. Phillips, M. Stampfer, L.A. Mooney, Y. Hsu, S. Cho, et al., Association between carcinogen-DNA adducts in white blood cells and lung cancer risk in the physicians health study. Cancer Res, 2001. 61(18): p. 6708-12.

10. Marchetti, F. and A.J. Wyrobek, Mechanisms and consequences of paternally-transmitted chromosomal abnormalities. Birth Defects Res C Embryo Today, 2005. 75(2): p. 112-29.

11. Yauk, C.L., G.A. Fox, B.E. McCarry, and J.S. Quinn, Induced minisatellite germline mutations in herring gulls (Larus argentatus) living near steel mills. Mutat Res, 2000. 452(2): p. 211-8.

12. Somers, C.M., B.E. McCarry, F. Malek, and J.S. Quinn, Reduction of particulate air pollution lowers the risk of heritable mutations in mice. Science, 2004. 304(5673): p. 1008-10.

13. Zaneveld, L.J., The biology of human spermatozoa. Obstet Gynecol Annu, 1978. 7: p. 15-40.

14. Holstein, A.F., W. Schulze, and M. Davidoff, Understanding spermatogenesis is a prerequisite for treatment. Reprod Biol Endocrinol, 2003. 1: p. 107.

15. Grootegoed, J.A., M. Siep, and W.M. Baarends, Molecular and cellular mechanisms in spermatogenesis. Baillieres Best Pract Res Clin Endocrinol Metab, 2000. 14(3): p. 331-43.

16. Adler, I.D., Comparison of the duration of spermatogenesis between male rodents and humans. Mutat Res, 1996. 352(1-2): p. 169-72.

17. Olsen, A.K., B. Lindeman, R. Wiger, N. Duale, and G. Brunborg, How do male germ cells handle DNA damage? Toxicol Appl Pharmacol, 2005. 207(2 Suppl): p. 521-31.

18. Miyazaki, R., M. Fukuda, H. Takeuchi, S. Itoh, and M. Takada, Flow cytometry to evaluate acrosome-reacted sperm. Arch Androl, 1990. 25(3): p. 243-51.

19. Krawetz, S.A., Paternal contribution: new insights and future challenges. Nat Rev Genet, 2005. 6(8): p. 633-42.

20. Cooper, T.G., E. Noonan, S. von Eckardstein, J. Auger, H.W. Baker, H.M. Behre, et al., World Health Organization reference values for human semen characteristics. Hum Reprod Update, 2009. 16(3): p. 231-45.

21. Andersen, S.L. and J. Sekelsky, Meiotic versus mitotic recombination: two different routes for double-strand break repair: the different functions of meiotic versus mitotic DSB repair are reflected in different pathway usage and different outcomes. Bioessays, 2010. 32(12): p. 1058-66.

22. Fraga, C.G., P.A. Motchnik, M.K. Shigenaga, H.J. Helbock, R.A. Jacob, and B.N. Ames, Ascorbic acid protects against endogenous oxidative DNA damage in human sperm. Proc Natl Acad Sci U S A, 1991. 88(24): p. 11003-6.

23. Agarwal, A., R.K. Sharma, K.P. Nallella, A.J. Thomas, Jr., J.G. Alvarez, and S.C. Sikka, Reactive oxygen species as an independent marker of male factor infertility. Fertil Steril, 2006. 86(4): p. 878-85. 
24. Pessot, C.A., M. Brito, J. Figueroa, Concha, II, A. Yanez, and L.O. Burzio, Presence of RNA in the sperm nucleus. Biochem Biophys Res Commun, 1989. 158(1): p. 272-8.

25. Miller, D. and G.C. Ostermeier, Spermatozoal RNA: Why is it there and what does it do? Gynecol Obstet Fertil, 2006. 34(9): p. 840-6.

26. Colt, J.S. and A. Blair, Parental occupational exposures and risk of childhood cancer. Environ Health Perspect, 1998. 106 Suppl 3: p. 909-25.

27. Aitken, R.J. and A.J. Koppers, Apoptosis and DNA damage in human spermatozoa. Asian J Androl, 2011. 13(1): p. 36-42.

28. Agarwal, A. and T.M. Said, Role of sperm chromatin abnormalities and DNA damage in male infertility. Hum Reprod Update, 2003. 9(4): p. 331-45.

29. Sadeu, J.C., C.L. Hughes, S. Agarwal, and W.G. Foster, Alcohol, drugs, caffeine, tobacco, and environmental contaminant exposure: reproductive health consequences and clinical implications. Crit Rev Toxicol, 2010. 40(7): p. 633-52.

30. Sakamoto, J. and K. Hashimoto, Reproductive toxicity of acrylamide and related compounds in mice--effects on fertility and sperm morphology. Arch Toxicol, 1986. 59(4): p. 201-5.

31. Chen, Z., L. Robison, R. Giller, M. Krailo, M. Davis, K. Gardner, et al., Risk of childhood germ cell tumors in association with parental smoking and drinking. Cancer, 2005. 103(5): p. 1064-71.

32. Menegaux, F., M. Ripert, D. Hemon, and J. Clavel, Maternal alcohol and coffee drinking, parental smoking and childhood leukaemia: a French population-based case-control study. Paediatr Perinat Epidemiol, 2007. 21(4): p. 293-9.

33. Cordier, S., C. Monfort, G. Filippini, S. Preston-Martin, F. Lubin, B.A. Mueller, et al., Parental exposure to polycyclic aromatic hydrocarbons and the risk of childhood brain tumors: The SEARCH International Childhood Brain Tumor Study. Am J Epidemiol, 2004. 159(12): p. 1109-16.

34. Seltmann, M., M. Horsch, A. Drobyshev, Y. Chen, M.H. de Angelis, and J. Beckers, Assessment of a systematic expression profiling approach in ENU-induced mouse mutant lines. Mamm Genome, 2005. 16(1): p. 1-10.

35. Ji, B.T., X.O. Shu, M.S. Linet, W. Zheng, S. Wacholder, Y.T. Gao, et al., Paternal cigarette smoking and the risk of childhood cancer among offspring of nonsmoking mothers. J Natl Cancer Inst, 1997. 89(3): p. 238-44.

36. Soares, S.R. and M.A. Melo, Cigarette smoking and reproductive function. Curr Opin Obstet Gynecol, 2008. 20(3): p. 281-91.

37. Boffetta, P., J. Tredaniel, and A. Greco, Risk of childhood cancer and adult lung cancer after childhood exposure to passive smoke: A meta-analysis. Environ Health Perspect, 2000. 108(1): p. 73-82.

38. John, E.M., D.A. Savitz, and D.P. Sandler, Prenatal exposure to parents' smoking and childhood cancer. Am J Epidemiol, 1991. 133(2): p. 123-32.

39. Sorahan, T., R. Lancashire, P. Prior, I. Peck, and A. Stewart, Childhood cancer and parental use of alcohol and tobacco. Ann Epidemiol, 1995. 5(5): p. 354-9.

40. Infante-Rivard, C., M. Krajinovic, D. Labuda, and D. Sinnett, Parental smoking, CYP1A1 genetic polymorphisms and childhood leukemia (Quebec, Canada). Cancer Causes Control, 2000. 11(6): p. 547-53.

41. Secretan, B., K. Straif, R. Baan, Y. Grosse, F. El Ghissassi, V. Bouvard, et al., A review of human carcinogens-Part E: tobacco, areca nut, alcohol, coal smoke, and salted fish. Lancet Oncol, 2009. 10(11): p. 1033-4.

42. Yauk, C.L., M.L. Berndt, A. Williams, A. Rowan-Carroll, G.R. Douglas, and M.R. Stampfli, Mainstream tobacco smoke causes paternal germ-line DNA mutation. Cancer Res, 2007. 67(11): p. 5103-6.

43. Somers, C.M., C.L. Yauk, P.A. White, C.L. Parfett, and J.S. Quinn, Air pollution induces heritable DNA mutations. Proc Natl Acad Sci U S A, 2002. 99(25): p. 15904-7.

44. Yauk, C., Monitoring for induced heritable mutations in natural populations: application of minisatellite DNA screening. Mutat Res, 1998. 411(1): p. 1-10.

45. Chen, Z., P.A. Stewart, S. Davies, R. Giller, M. Krailo, M. Davis, et al., Parental occupational exposure to pesticides and childhood germ-cell tumors. Am J Epidemiol, 2005. 162(9): p. 858-67.

46. Dubrova, Y.E., V.N. Nesterov, N.G. Krouchinsky, V.A. Ostapenko, R. Neumann, D.L. Neil, et al., Human minisatellite mutation rate after the Chernobyl accident. Nature, 1996. 380(6576): p. 683-6.

47. Dubrova, Y.E., G. Grant, A.A. Chumak, V.A. Stezhka, and A.N. Karakasian, Elevated minisatellite mutation rate in the post-chernobyl families from ukraine. Am J Hum Genet, 2002. 71(4): p. 801-9 



\section{CHAPTER 2 USE OF SPERMATOZOAL MRNA PROFILES TO STUDY GENE-ENVIRONMENT INTERACTIONS IN HUMAN GERM CELLS}

Mutation Research (2009) Jul 10;667(1-2):70 - 76

Joost O. Linschooten

Frederik J. van Schooten Adolf Baumgartner

Eduardo Cemeli Joost van Delft

Diana Anderson Roger W.L. Godschalk 


\section{Abstract}

Paternal exposure to genotoxic compounds is thought to contribute to diseases in their offspring. Therefore, it is of importance to develop biomarkers of male germ cell exposure to genotoxins. Unfortunately, the testis cannot be reached for routine biomonitoring, but mRNA-profiles in spermatozoa may reflect the processes that have occurred in the testis after exposures to genotoxins, since spermatozoa are largely transcriptionally inactive. Therefore, mRNA profiles from sperm in ejaculates of cigarette smokers $(\mathrm{N}=4)$ were compared with non-smokers $(\mathrm{N}=4)$. Smoking behaviour was verified by assessing cotinine levels in seminal plasma. High expression of the germ cell specific gene protamine 2 (PRM2) was observed in spermatozoal mRNA isolates by Q-PCR, which was absent in reference mRNA isolates obtained from a pool of other organs. Gene-expression analysis was subsequently performed using microarray technology and a total of 781 genes were found to be differentially expressed in spermatozoa of smokers compared to non-smokers (fold change $>40 \% ; p<0.05$ ). To further limit the number of false positive results, genes were additionally selected on basis of the correlation between their expression levels with cotinine concentrations in seminal plasma ( $r>0.80$ as arbitrary cut-off value, $p<0.05)$, and a total of 200 transcripts remained, of which the germ cell specific transcription factor $S A L F$ was the highest up-regulated gene (5.4-fold) and the zinc finger encoding gene TRIM26 most down regulated (7.4-fold). Although no altered pathways could be identified for the differentially expressed genes, an enrichment was observed for NF-kB regulated genes ( $46 \%$ vs. $27 \%, p=0.004)$ playing a central role in stress response. Accordingly, subsequent analysis of transcription factor networks suggests that apoptosis was inhibited in smokers. These data show the feasibility of using gene-expression profiles in mature sperm to elucidate gene-environment interactions in male testis. 


\section{Introduction}

Childhood cancer incidences have increased over the last few decades [1], suggesting a prominent role of environmental exposures to the parents in disease aetiology. We all are exposed to a variety of environmental genotoxins, such as constituents of cigarette smoke, exhaust fumes, and food contaminants. Most research has focussed on the effects of such exposures on somatic cells [2], but far less research has been performed on the effect of exposures to genotoxins in relation to parental germline mutations and possible health effects in the next generation. Genotoxic effects in the germline have been described for ionising radiation [3], and there is growing evidence that environmental/dietary exposures to chemicals can also be involved in the induction of heritable mutations [4].

Epidemiological studies have shown that exposure to tobacco smoke and environmental tobacco smoke during pregnancy increases the risk of severe health impairments in the newborn children [5,6]. However, few studies have investigated the effect of cigarette smoking of the father [7] before conception. These studies have found no overall effect of paternal smoking, though some report a positive association between paternal smoking and the development of childhood cancer. Although the effect of parental exposures to chemical carcinogens seems to be small in general [8], it may still be particularly relevant for a susceptible subgroup of individuals [9].

Most germline mutations seem to arise after paternal exposure and indeed, several environmental and food contaminants are known to reach the testis in significant concentrations, such as polycyclic aromatic hydrocarbons (PAH) and the food-derived carcinogen acrylamide $[10,11]$. Further studies of the relationship between exposure to environmental genotoxins and the formation of germline mutations require a reliable assessment of the exposure in the testis and subsequent biological effects in the testis. Assessment of external exposures is probably insufficient, because many individual factors may affect the dose that actually reaches the male germ cells. Exposure to genotoxic agents may cause differences in gene expression in several tissues as compared to unexposed subjects. For example, expression of the cytochrome P450 proteins (CYP's) $1 \mathrm{~A} 1$ and $1 \mathrm{~B} 1$ is higher in subjects exposed to PAH [12]. The fact that exposure to genotoxins can affect the tissue-specific regulation of gene expression [13] suggests a possible use of gene expression profiles as biomarkers of exposure of that particular organ/tissue. Since many internal organs cannot be reached in a non-invasive manner, these studies rely on surrogate tissues, such as peripheral blood. In theory, the testis can also only be reached in an invasive manner. However, since the discovery of mRNA in mature spermatozoa, there is a growing interest in results obtained from these cells [14]. Ostermeier et al. described the absence of ribosomal subunits in the RNA obtained from spermatozoa, which suggests that spermatozoa are largely transcriptionally inactive and mRNA isolated from these cells will thus reflect processes that have taken place earlier in the testis [15]. Some genes are specifically transcribed in this tissue during spermatogenesis, for example genes involved in histone replacement, like protamine 1, 2 and 3, during spermatogenesis [16]. Together with a different expression of several sperm specific proteins, it was also reported that some cell specific transcription factors are expressed during spermatogenesis [17].

mRNA profiles in mature spermatozoa may thus reflect the testicular response to exposures to genotoxins, representing an interesting potential retrospective biomarker of exposure as spermiogenesis and sperm maturation in the epididymis lasts for approximately 45-50 days in men. The aim of this study is therefore to test whether gene expression profiles in spermatozoa can be considered as new biomarkers for exposure of the testis to genotoxic compounds. 


\section{Materials \& Methods}

\section{Study population}

After giving their informed consent, four healthy smoking and four healthy nonsmoking subjects provided an ejaculate by masturbation at Bradford University, UK. Smoking behavior was assessed by a questionnaire and by cotinine levels in seminal plasma (see below). Each semen sample was processed within $2 \mathrm{~h}$ and analyzed for volume, number of spermatozoa per ml, motility, pH and morphology according to WHO criteria (1999). Semen samples were snap-frozen in liquid nitrogen and subsequently stored in aliquots at $-80{ }^{\circ} \mathrm{C}$ until analysis.

\section{Cotinine assessment}

Sperm samples were thawed at room temperature and centrifuged at 10,000rpm for 5 min. Supernatants were transferred to clean tubes, and cell pellets were used for RNA isolation. Seminal plasma was stored at $-20{ }^{\circ} \mathrm{C}$ until cotinine levels were assessed by a radio-immuno assay according to the method described by van Vunakis et al. [18]. Cotinine levels in the seminal plasma were expressed in $\mathrm{ng} / \mathrm{ml}$.

\section{RNA isolation from spermatozoa and cDNA synthesis}

Before RNA isolation from spermatozoa, somatic cells in the ejaculate were lysed using SDS and Triton-X, as described in Goodrich et al. [19] with minor modifications. After first lysis of the somatic cells, a small amount of the cell suspension was transferred onto a slide and stained with Giemsa to check whether lysis of somatic cells was successful. Lysis was followed with a washing step in lysis buffer, and the cell pellets were subsequently resuspended in Trizol solution (Invitrogen, UK). RNA was isolated from these solutions using a RNeasy Minelute kit (Qiagen Westburg bv., Leusden, the Netherlands), according to the producers' manuals. mRNA quantity was measured spectrophotometrically using a Nanodrop spectrophotometer (Nanodrop technologies, Wilmington, USA) and stored at $-80{ }^{\circ} \mathrm{C}$ until use for microarray and real-time polymerase chain reaction (RT-PCR). The quality of the RNA was checked using an Agilent BioAnalyzer (Agilent Technologies, Breda, The Netherlands). In contrast to RNA from other cell types, the RNA isolated from sperm cells is fragmented and does not contain the $18 \mathrm{~S}$ and $28 \mathrm{~S}$ ribosomal subunits. Nonetheless, this RNA could be used for cDNA synthesis and microarray analysis. From each sample, 500 ng of RNA was used for cDNA synthesis in combination with the iScript cDNA Synthesis Kit (Bio-Rad Laboratories, Hercules, CA).

\section{Microarray}

The arrays were hybridised using two groups, smokers and non-smokers. All samples were compared to a common reference sample obtained from one extra non-smoking donor. Each smoking subject was comparable with a non-smoking subject with regard to age, caffeine intake and alcohol use. Arrays were performed using Agilent human $4 \times 44 \mathrm{~K}$ arrays (Agilent technologies), according to the manufacturers' instructions. The microarray slides were scanned on a GenePix 4000B (Molecular Devices, Sunnyvale, CA). Processing of array data was done as described by Staal et al. [20]. The images were processed with ImaGene 8.0.1 software (Biodiscovery, Los Angeles, CA) to quantify 
spot signals. Flagged spots, consisting of poor quality spots and negative and positive control spots, were excluded. Data from ImaGene were transported to GeneSight software version 4.1.6 (Biodiscovery) for transformations and normalisations. For each spot, median local background intensity was subtracted from the median spot intensity and spots from low expression genes (with a net intensity of $<10$ in both channels), were excluded from further analysis. The corrected median intensities were log base 2 transformed and normalized using the LOWESS algorithm. The gene expression ratios were imported into Excel (Microsoft Corporation, Redmond,WA) for further analysis, where genes with availability of $100 \%$ of the values per gene were used.

\section{Real-time PCR}

To validate a selection of genes from the microarray experiments, quantitative realtime polymerase chain reaction (RT-PCR) was performed. For cDNA synthesis, $200 \mathrm{ng}$ of each sample was used in combination with the iScript cDNA Synthesis Kit (Bio-Rad Laboratories, Hercules, CA). RT-PCR reactions were carried out using iQ SYBR Green Supermix, which contains iTaq DNA Polymerase, deoxynucleoside triphosphates, $\mathrm{MgCl}_{2}$ and SYBR Green I (Bio-Rad laboratories). The cDNA was 10 times diluted before analysis and an amount of $5 \mu \mathrm{l}$ sample was added to each reaction well, and all samples were measured in duplicate. Samples were analysed on a MyiQ Single-Colour RealTime PCR detection System (Bio-Rad laboratories), using the following parameters: 3 min at $95{ }^{\circ} \mathrm{C}, 40$ cycles at $95{ }^{\circ} \mathrm{C}$ for $15 \mathrm{~s}$ and at $60{ }^{\circ} \mathrm{C}$ for $45 \mathrm{~s}$. Expression of only a few genes could be verified, due to the limited amount of mRNA available from the spermatozoa. Several toxicologically relevant genes (including CYP1A1 and CYP1B1) were selected for validation by Q-PCR as potential biomarkers of exposure. To normalize the amount of mRNA's, the housekeeping gene B-actin was used, and each sample was tested in duplicate. Protamine 2, a sperm specific protein, was selected as potential additional housekeeping gene. This protein is involved in replacement of histones during spermatogenesis, and there is no current evidence that expression of this gene is altered after exposure to environmental factors. The normalized values from $\beta$-actin and PRM2 were used to define differences in gene expression levels in smokers and non-smokers.

\section{Statistical analysis}

Differences in gene expression were calculated and assessed as significant when the fold change was higher than $40 \%$ (i.e., 0.5 on a log base 2 transformed scale) and $p<0.05$, using Student's $t$-test. Thereafter, data of the significantly up- or downregulated genes were Pearson-correlated with the log-transformed cotinine levels in the seminal plasma, to limit the number of false-positive results, applying an arbitrary cut-off value for the correlation coefficient of at least 0.80 or -0.80 for inverse relationships. Fatigo+ was used for analysis of transcription factors, which can bind up to $1 \mathrm{~kb}$ upstream from the genes that were found to be modulated by smoking and of which the level of expression correlated with cotinine concentrations in seminal plasma. T-Profiler changes were scored using $t$ test's, in the average activity of predefined groups of genes, as described in Boorsma et al. [21]. Finally, MetaCore from GeneGo Inc. (http://www.genego.com) was used to study transcription factor networks with the available expression data. Each network analysis is based on one specific transcription factor that has target genes in the list of differentially regulated genes, together with genes from that same list that directly influence activation or inhibition of this particular transcription factor. The generated networks centered on one transcription factor, are subsequently interpreted in terms of GO-processes. 


\section{Results}

\section{Characteristics of study population}

Non-smoking $(\mathrm{N}=4)$ and smoking $(\mathrm{N}=4)$ subjects were compared to each other with regard to age, ethnicity and the weekly usage of alcohol or caffeine containing beverages. This latter comparison was necessary, since both caffeine and alcohol can affect sperm quality [22-26]. The characteristics of the subjects are presented in Table 1. According to WHO-criteria, the sperm count of smokers was lower than that of non-smokers, but this difference did not reach statistical significance. There were no significant differences in sperm motility and morphology. Smoking was assessed by questionnaire, but no detailed information was available on the amount of cigarettes smoked per day. Nonetheless, the cotinine levels in the seminal plasma showed a clear difference in exposure to nicotine, since these levels were over 30 times higher in the smoking subjects than in non-smoking volunteers.

Table 1: Characteristics of study population

\begin{tabular}{lll}
\hline & Smokers & Non-smokers \\
\hline $\mathrm{N}$ & 4 & 4 \\
Age (years) & $38.8 \pm 4.9^{\mathrm{a}}$ & $35.8 \pm 3.9^{\mathrm{a}}$ \\
Cotinine in seminal plasma $(\mathrm{ng} / \mathrm{ml})$ & $276.8 \pm 107.2^{\mathrm{a}}$ & $8.3 \pm 0.5^{\mathrm{b}}$ \\
Sperm concentration $\left(\times 10^{6} \mathrm{cells} / \mathrm{ml}\right)$ & $19.4 \pm 1.3^{\mathrm{a}}$ & $42.6 \pm 14.9^{\mathrm{a}}$ \\
$\mathrm{pH}$ & 8 & 8 \\
Motility & $40 / 32 / 5 / 23$ & $59 / 13 / 6 / 22$ \\
Morphology (\% normal) & $72.5 \pm 7.5$ & $81.3 \pm 2.4$ \\
Alcohol intake (consumptions) & $1-10$ drinks per week & $1-10$ drinks per week \\
Caffeine intake (consumptions) & $1-5$ cups per day & $1-5$ cups per day \\
\hline
\end{tabular}

a Average values \pm S.E. of the mean are shown.

${ }^{b}$ Difference in cotinine levels in seminal plasma proved to be significant $(p<0.05)$ using Student's $t$-test.

${ }^{c}$ Motility format: $3 / 2 / 1 / 0$ in average percentages, with $3=$ fast-progressive; 2 = slow-progressive; $1=$ nonprogressive, but tail movement; 0 = immobile, no tail movement.

\section{RNA quantity and quality control}

The amount of mRNA isolated from the semen samples was low, which was expected since these cells contain less mRNA compared to somatic cells (approximately 2000 times lower) [27]. For this reason it is of great importance that somatic cells were removed before the spermatozoa were lysed to release the mRNA, since this could negatively influence gene expression data. To check whether lysis of these cells was successful, a small amount of each sample was microscopically checked. It appeared that hardly any somatic cells were still present and therefore it is expected that the contribution of somatic cell RNA is « $1 \%$ to the total amount of RNA isolated. The BioAnalyzer data showed that the spermatozoal mRNA is highly fragmented and the $18 \mathrm{~S}$ and $28 \mathrm{~S}$ ribosomal subunits are absent, which is typical for this cell type (as illustrated in figure 1). 

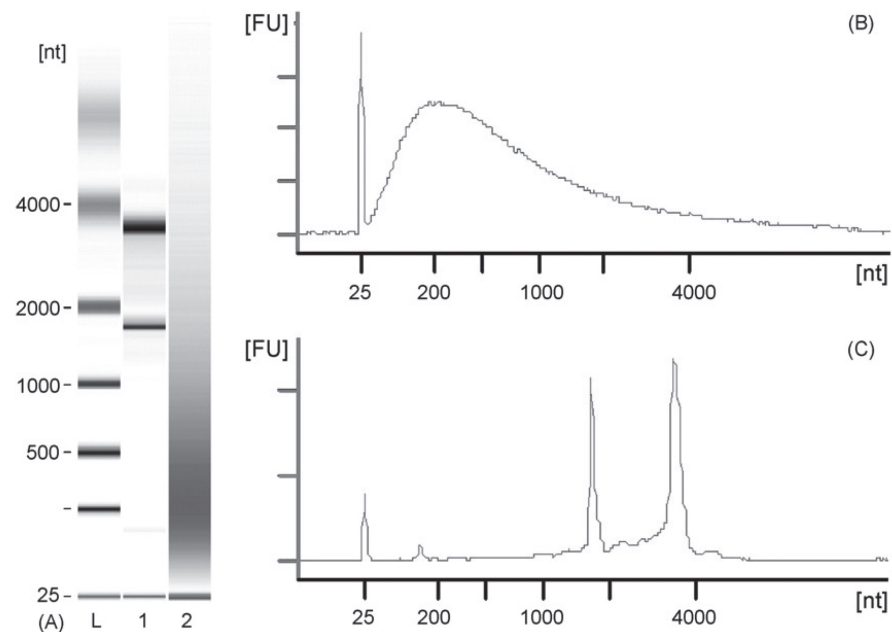

(B)

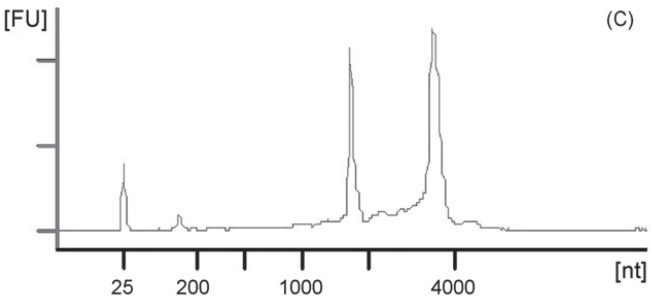

Figure 1: BioAnalyzer results showing the presence (lane 1) and absence (lane 2) of 18S and 28S ribosomal subunits (A), and the chromatograms of a sperm sample (B) with fragmented mRNA and a lung RNA sample containing the $18 \mathrm{~S}$ and $28 \mathrm{~S}$ ribosomal subunits $(\mathrm{C})$.

\section{Microarray analysis}

The data discussed in this publication have been deposited in NCBI's Gene Expression Omnibus [28] and are accessible through GEO Series accession number GSE13600 (http://www.ncbi.nlm.nih.gov/geo/query/acc.cgi?acc=GSE13600). Of the 44,000 genes on the slides, 13,994 were detected on all eight arrays. These data showed that a total of 781 genes were differentially expressed in smokers compared to non-smokers (fold change $>40 \% ; p<0.05$ ). This list of genes was correlated to the log-transformed cotinine values in seminal plasma, which resulted in a large variation in correlation coefficients, ranging from 0.48 up to 0.99 . Of the 781 differentially regulated genes, 200 showed a significant correlation of $r>0.80$ with the cotinine levels (for complete lists see supplementary data) and only 21 showed a correlation coefficient higher than $r>0.90$ (these 21 genes are presented in Table 2). SALF, a germ cell specific transcription factor, showed the highest fold change, in combination with the highest correlation with log-transformed cotinine levels in the seminal plasma. The most strongly down-regulated gene was found to be the tripartite motif-containing gene TRIM26, which encodes three zinc-binding domains. 
Table 2: Overview of significantly regulated genes that also showed a high correlation $(R>0.90)$ with logtransformed cotinine levels in seminal plasma of smokers and non-smokers.

\begin{tabular}{l|l|l|c|c}
\hline Gene name & UniGenelD & Proposed biological function & $\begin{array}{c}\text { Fold } \\
\text { change }\end{array}$ & $\begin{array}{c}\text { R with } \\
\text { cotinine }\end{array}$ \\
\hline SALF & Hs.44385 & Germline specific transcription factor & 5.474 & $0.986^{*}$ \\
UBE4B & Hs.386404 & Ubiquitination factor E4B & -1.993 & -0.976 \\
TRIM26 & Hs.485041 & Zinc finger protein & -7.356 & -0.950 \\
FADS2 & Hs.502745 & Fatty acid desaturase & -1.959 & -0.944 \\
ARMC1 & Hs.269542 & Signal transduction, development, cell adhesion & 2.118 & 0.941 \\
ACTL6A & Hs.435326 & And mobility, tumor initiation and metastasis & & \\
NBPF15 & Hs.512037 & Neuroblastoma breakpoint family & 3.209 & 0.940 \\
& Hs.143408 & Unknown & 1.848 & 0.937 \\
NBPF14 & Hs.515947 & Neuroblastoma breakpoint family & 2.220 & 0.935 \\
SMYD4 & Hs.514602 & SET and MYND domain; Transcriptional regulation & -4.265 & -0.929 \\
LRRC51 & Hs.317243 & Leucine rich repeat containing 51 & -2.101 & -0.925 \\
FLJ40852 & Hs.17589 & Hypothetical protein & 1.734 & 0.915 \\
C3orf48 & Hs.585048 & Chromosome 3 open reading frame 48 & 1.853 & -0.915 \\
TEAD1 & Hs.568169 & Transcription enhancer factor & 1.552 & 0.909 \\
SH2D5 & Hs.166270 & Intracellular signaling & -2.468 & -0.908 \\
& Hs.530461 & Unknown & -4.581 & 0.908 \\
LOC644246 & Hs.463231 & Hypothetical protein & 1.923 & -0.906 \\
SRPK1 & Hs.443861 & Phosphorylation of SR proteins & 1.737 & 0.906 \\
RNF125 & Hs.458449 & Negative regulator of IFN production & -4.898 & -0.905 \\
GALK2 & Hs.125434 & Unknown & -2.423 & -0.900 \\
\hline
\end{tabular}

* Remains statistically significant when fold changes are correlated with cotinine levels in smokers only $(p<0.05$; $R>0.90)$

\section{Analysis of pathways and transcription factors}

The list of 13,994 genes without missing values on all 8 arrays was uploaded into T-Profiler, a pathway analysis tool that focuses on shifts in total gene expression profiles, not only in that of differentially expressed genes [21]. The analysis showed that modulated genes are typical of testis/germ cell related processes, which provides evidence for the specificity of the spermatozoal RNA. Unfortunately, no differentially regulated pathways were detected by this tool. Accordingly, no exposure-related pathways were identified by several other 'pathway finding' programmes that focus only on the differentially regulated genes, like Fatigo+ [29] and Metacore (http://www.genego.com).

However, the analysis of hypothetical transcription factor binding sites up to $1 \mathrm{~kb}$ upstream (using Fatigo [29]) of the group of differentially regulated genes with a correlation coefficient of 0.90 or higher between their level of expression and cotinine levels in smoking subjects, showed that a higher percentage of these genes were regulated by NF-kB as compared to all genes that were significantly differentially expressed (46.3\% vs. $26.9 \%, p=0.004)$. A similar effect was found for forkhead transcription factors like FOX (18.5\% vs. 6.6\%, $p=0.005)$ and transcription factor YY1 (5.6\% vs. 0.9\%, $p=0.03)$. These transcription factors remained enriched after the cut-off value for the correlation with cotinine was increased from $r>0.90$ to $r>0.95$ (see figure 2). 


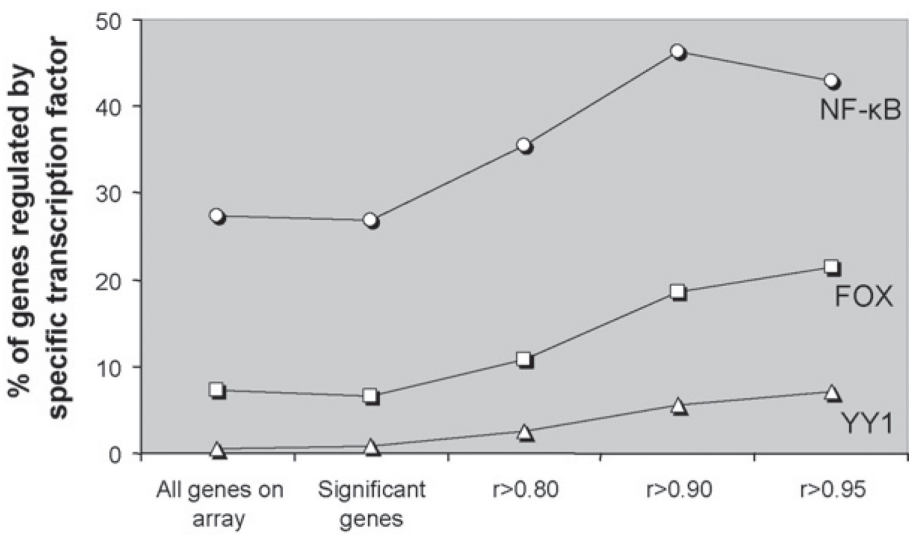

\section{Cut-off value for correlation with cotinine}

Figure 2: The differentially expressed genes that also showed a correlation with cotinine concentrations in the seminal plasma were more often regulated by NF-kB, FOX or YY1 than all other genes on the array or compared to those genes that were significantly affected by smoking, but did not strongly correlate with seminal cotinine concentrations (significant genes). The percentage of genes potentially regulated by one of these transcription factors even increased when the correlation cut-off value with the cotinine levels is set stricter.

Since some genes that are regulated by specific transcription factors seemed differentially regulated, a transcription factor network analysis was performed (using MetaCore). Anti-apoptosis proved to be the main significant process in the gene list, which was confirmed by the down regulation of genes involved in the induction of proliferation and apoptosis in smokers, whereas anti-apoptotic genes were up regulated (see Table 3). 
Table 3: Overview of genes involved in the regulation of apoptosis (according to their GO-terms) of which the expression was affected by cigarette smoking. Analysis of transcription networks indicated a possible anti-apoptotic response. Indeed, most pro-apoptotic genes were down regulated and anti-apoptotic genes were up regulated, indicated in the final column as (+). Gene expression with putative pro-apoptotic effects are indicated by (-).

\begin{tabular}{llll}
\hline Gene name & Fold change & $P$-value & Effect \\
\hline Pro-apoptotic & & & + \\
CCND3 & -3.057 & 0.00795 & + \\
FASLG & -2.993 & 0.02406 & + \\
HIPK2 & -2.926 & 0.01616 & + \\
NUTD2 & -2.388 & 0.00910 & + \\
TNFSF9 & -2.387 & 0.03098 & + \\
HIP1 & -2.363 & 0.03570 & + \\
CCND1 & -2.243 & 0.04162 & + \\
TNFAIP8 & -2.225 & 0.00772 & + \\
CDK5R1 & -2.078 & 0.00327 & + \\
UBE4B & -1.993 & 0.00007 & + \\
ERCC2 & -1.905 & 0.04268 & + \\
LGALS12 & -1.891 & 0.04084 & + \\
TNFAIP8L3 & -1.786 & 0.03336 & + \\
P2RX1 & -1.665 & 0.00466 & + \\
PLG & 1.486 & 0.04067 & + \\
INHBA & 1.718 & 0.03960 & + \\
ITGB3BP & 2.061 & 0.02555 & + \\
Anti-apoptotic & & & + \\
RAB6IP2 & 2.309 & 0.02061 & + \\
AZI2 & 1.123 & 0.00204 & + \\
IL7 & 1.894 & 0.02234 & + \\
PHB & -1.792 & 0.00974 & + \\
RIPK2 & & 0.04676 & + \\
MYBL2 & & & + \\
\hline & & & + \\
\hline
\end{tabular}

\section{Real-time PCR}

High expression of the sperm specific gene protamine 2 (PRM2) was observed in spermatozoal mRNA by Q-PCR, which was absent in reference mRNA obtained from a pool of mRNA from 10 different human cell lines (Stratagene, La Jolla, CA, cat.nr. 750500), which can be regarded as further evidence that the RNA was isolated from spermatozoa. Since SALF was highly differentially regulated, according to microarray data, this gene was also selected to be validated on Q-PCR. The expression of this germ cell specific transcription factor indeed shows the same direction of regulation on both microarray and real-time PCR (see Table 4).

The cytochromeP450 enzymes $1 A 1$ and $1 B 1$ known to be up regulated by exposure to aryl hydrocarbon (Ah) receptor agonists like PAH (PAH are constituents of cigarette smoke) and were therefore included in the validation by real-time PCR. From the microarray data, it could be expected that these genes were not significantly up or down regulated. Indeed, using real-time PCR, these genes show only a marginal increase in 
gene expression.

Table 4: Real-time PCR validation data; fold change as compared to non-smokers (NS as reference $=1.00$ )

\begin{tabular}{lll}
\hline Gene name & Fold change Q-PCR & Fold change array \\
\hline PRM-2 & $1.01 \pm 0.37$ & 0.88 \\
Cyp1A1 & $1.26 \pm 0.31$ & 1.08 \\
Cyp1B1 & $1.77 \pm 1.04$ & 1.39 \\
SALF & $2.29 \pm 2.61$ & 5.48 \\
\hline
\end{tabular}

Values are corrected using the geometrical average of $\beta$-actin and protamine 2 as reference genes.

\section{Discussion}

In human biomonitoring studies it is practically and ethically very difficult to use samples of internal organs such as testis. Therefore, it is necessary to use alternative cells or tissues to study germline effects. The discovery of the presence of mRNA in mature spermatozoa obtained from an ejaculate [14] open new possibilities for the assessment of gene expression profiles that can be relevant for germ cell exposure and subsequent health effects in the offspring. In the present work, we showed that it is possible to isolate mRNA from spermatozoa which represents germ cell and testis related processes. Gene-environment interactions largely depend on the activation of specific transcription factors that mediate stress responses after exposure to toxic and genotoxic compounds [30]. Thus, studying the activation of transcription factors in certain organs may reflect the actual exposure of that particular organ to genotoxic compounds. Therefore, it is assumed that gene expression profiles represent better biomarkers than the mere assessment of exogenous levels of exposure (for instance, number of cigarettes per day). Accordingly, we showed that several transcription factors can indeed be identified as regulators in the stress response after exposure to cigarette smoke and the toxins therein.

In our study, cigarette smokers were used as a model of exposure to environmental genotoxins, since cigarette smoke is the source of a variety of toxic and genotoxic compounds [31]. Although the direct effects of this type of exposure on sperm quality have been intensively studied [26,32], the evidence is still not very strong for transgenerational effects. There is some evidence for a higher risk of childhood leukaemia after paternal smoking in the preconceptional period [33], but these data are not consistent in the scientific literature [34]. Boffetta et al. [8] performed a meta-analysis in which epidemiological studies were reviewed of paternal smoking and the possible development of specific types of childhood cancer; a positive correlation was performed between paternal smoking in the preconceptional period and elevated risks of several childhood cancers [7]. In vitro studies do indeed indicate that cigarette smoke condensate can induce mutations that are typically analysed in sperm (tandem repeats) [35]. Moreover, it has been shown that cigarette smoke derived compounds can reach the testis and semen, and are able to bind to DNA in these cells [22]. As it is illustrated in figure 3, spermatids and mature spermatozoa in the testis are thought to be exposed to exogenous genotoxins in three different ways during spermatogenesis [36]. First, the exogenous substances can pass the blood-testis barrier, which is a physical barrier between the blood vessels and the seminiferous tubules in the testis formed by tight junctions between the Sertoli cells. Secondly, after transport via the Sertoli cells, contaminants may be able to induce damage in spermatids and maturate spermatogonia. Finally, genotoxic compounds could reach the lumen via the Sertoli cells and reach the mature spermatozoa, but in this case it is not yet known to what level these agents are able to induce damage to the DNA, because it is tightly packed in the sperm nucleus. For instance, Gallagher et al. [37] isolated DNA from 
sperm cells of smoking and non-smoking subjects, but were not able to detect smokingrelated DNA adducts. Nonetheless, with a different detection method Zenzes et al. [38] did show increased DNA adduct levels in sperm after cigarette smoking. As the sperm still have to pass through the epididymis after being released into the testicular lumen of the seminiferous tubules, genotoxins could have an effect on the sperm during the epididymal maturation. However, as mature sperm is transcriptionally silenced, this route of exposure is expected to have no effect on mRNA profiles.

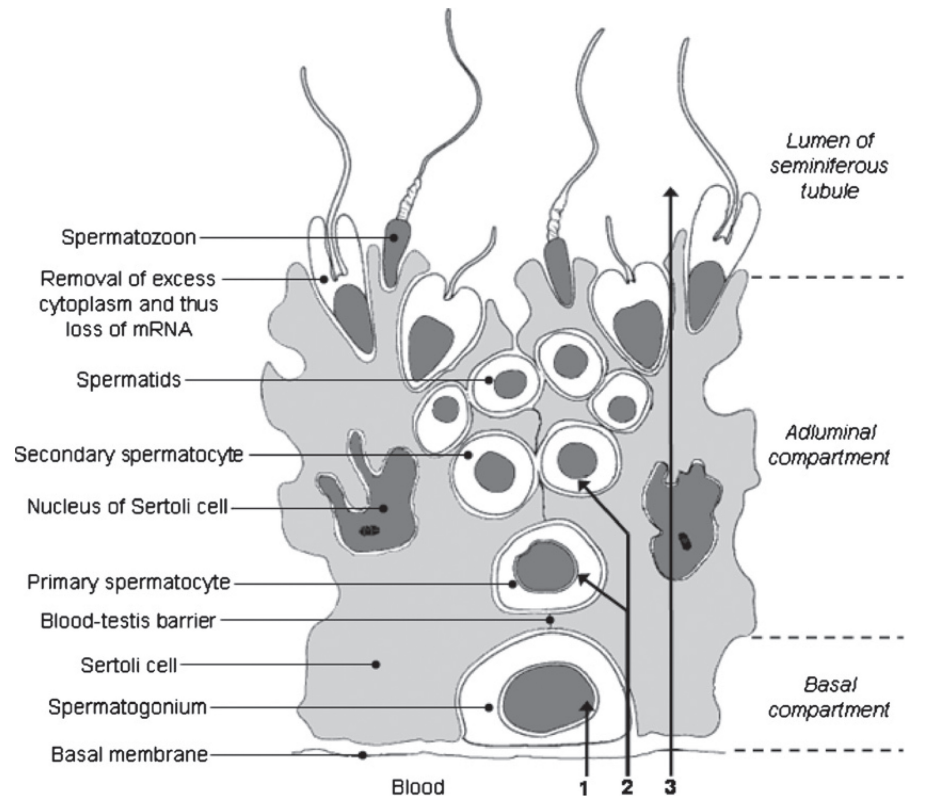

Figure 3: Three different routes of exposure of germ cells to exogenous substances that could ultimately influence mRNA profiles in sperm. Arrows indicate the exposure route to exogenous compounds, 1: directly fromthe blood into the basal compartment, 2: via the Sertoli cell into the adluminal compartment, or 3: through the Sertoli cell directly into the lumen of the seminiferous tubule. Figure adapted from Holstein et al. [36].

During spermiogenesis, protamines replace histones in order to pack the DNA more compactly [16], making the male genome small enough to fit into the spermatid nucleus (the nucleus of a mature spermatozoon is six times smaller than that of somatic cells) [39]. This high level of 'packaging' of DNA in spermatozoa also affects the transcription in developing germ cells. Spermatozoa are assumed to be transcriptionally silenced for a large part of the genome during maturation, with some exceptions (such as transcription in mitochondria and transcription in parts of the genome that have not been packaged by protamines but by histones). It was therefore postulated that the RNA present in the ejaculated spermatozoa is most likely residual and non-functional [40], and may be a reflection of gene expression during earlier stages of spermatogenesis [41]. Another observation supporting this idea is the absence of the ribosomal subunits $18 \mathrm{~S}$ and $28 \mathrm{~S}$ in the spermatozoal RNA (also in this study, see figure 1) [19]. Thus, mRNA profiles in sperm provide a retrospective view into processes that have taken place during earlier stages of spermatogenesis, and could also reflect the processes that occur after exposure to toxins and genotoxins in the testis. Moreover, there is also evidence that spermatogenesis-related gene expression profiles can also be used in clinical assessments of sperm quality [42]. 
Several genes were differentially expressed in smokers' spermatozoa than in nonsmokers, including $S A L F$, a germ cell specific transcription factor, which also showed the highest correlation with cotinine levels in seminal plasma (which are considered to be good indicators of exposure to cigarette smoke). SALF is especially expressed in pachytene spermatocytes and haploid spermatids [43]. Pathway analysis of all the genes that were differentially regulated in smokers as compared to non-smokers did not reveal any enriched pathway. Part of this inability to detect altered pathways may be related to the degradation of mRNA in spermatozoa (see figure 1), and as a result signals of genes with relatively low levels of expression may be lost, making pathway analysis incomplete. However, the remaining detectable genes can still provide information regarding the pathways that were activated / inhibited by analyzing the transcription factors that have recognition sequences in the upstream sequences of genes (up to $1 \mathrm{~kb}$ ). The transcription factors that were identified to play a role in the transcription of differentially regulated genes by exposure to cigarette smoke were NF-kB, forkhead transcription factors (FOX) and $Y Y 1$. These transcription factors are known regulators in stress responses. For instance, NF-kB is known to be a key regulator in the inflammatory response, but has also been linked to the control of apoptosis, cell cycle, differentiation and cell migration [30]. NF-kB can be activated by various stressors, including bacteria, viruses, oxidative stress and certain chemicals. Forkhead proteins are a family of transcription factors with more than 100 members of functionally diverse transcription factors that have commonly been associated with the regulation of foetal development. FOX genes were found to be involved in the regulation of NF-kB activity [44] (via transcription of its inhibitor IKK) and also DNA damage inducible genes (e.g. GADD45). Finally, YY1 has fundamental roles in differentiation, replication, and cellular proliferation [45]. Oei and Shi [46] noted a physical interaction between $Y Y 1$ and poly(ADP-ribose) polymerase (PARP is a nuclear enzyme involved in DNA repair and transcription). Moreover, YY1 seems to be a cofactor for MDM2 in the regulation of p53 homeostasis. The transcription factor network analysis showed that apoptosis appeared to be the most significantly influenced process (downregulation in smokers), which means that damaged cells in smoking subjects may not be stopped during the cell cycle. This would predict that ejaculates of smokers would contain more spermatozoa with damaged DNA. Indeed, sperm of smokers showed more genetic abnormalities, like aneuploidy [25]. These findings suggest that cigarette smoke components actually reach the testis and the developing germ cells. However, it is not yet clear to what extent environmental genotoxins can reach the testis to induce damage in spermatozoa.

mRNA in spermatozoa is delivered to the oocyte together with the DNA during fertilisation [47], and some studies show that this RNA may have a significant impact on the developing foetus [48]. The role of this mRNA is still not clear, but it has been suggested that it plays an important role during early embryogenesis [49]. Nonetheless, it is not yet possible to determine the effect on the health of newborns up to adult ages.

Two well-known genes that are up-regulated after exposure to Ah-receptor agonists, like polycyclic aromatic hydrocarbons and dioxins, are CYP1A1 and CYP1B1, and therefore the expression of these genes can be used as biomarker for exposure to these compounds [50]. PAH are important genotoxins in cigarette smoke, but we did not observe altered expression of CYP1A1 or 1B1 in spermatozoal mRNA. It is of course possible that parts of the compounds that reach the testis are metabolised by the Sertoli cells and that the germ cells do not have to metabolise the compounds themselves. Nonetheless, the mRNA of both genes was detectable in all subjects by microarray analysis as well as Q-PCR, indicating that germ cells may have the ability to produce these cytochrome P450's to subsequently metabolise environmental genotoxins. The spermatozoal specific enzyme protamine 2 (PRM2) was included as reference gene in 
these Q-PCR experiments on spermatozoal mRNA, since it was not differentially regulated after exposure to cigarette smoke in the microarray results. As it is known that PRM2 expression can be abnormal in infertile men [16], PRM2 should be used as reference gene with care. Still, our data (microarray and real-time quantitative PCR) show that there is no differential gene expression of all three protamines (PRM1, PRM2 and PRM3) as a result of smoking.

The main goal of this study was to examine the feasibility of using gene expression profiles in mRNA from spermatozoa as biomarkers of exposure. The germ cell specific transcription factor SALF appeared to be such a biomarker in subjects exposed to cigarette smoke, where the exposure resulted in different gene expression profiles. It might be possible that this shift in gene expression can result in decreased sperm quality. Further studies are needed to further validate this biomarker, also for other important environmental and dietary contaminants. It remains to be elucidated whether these changes in spermatozoal mRNA can induce or reflect (negative) health effects in the next generation.

\section{Acknowledgements}

The authors would like to thank Ralph Gottschalk and Lou Maas for technical assistance. This work was supported by the Cefic Long-Range Research Initiative Innovative Science award 2004 to R.W.L.G.; as well as by the EU Integrated Project NewGeneris, 6th Framework Programme, Priority 5: Food Quality and Safety (Contract no. FOOD-CT-2005-016320). NewGeneris is the acronym of the project 'Newborns and Genotoxic exposure risks' http://www.newgeneris.org.

\section{Appendix A. Supplementary data}

Supplementary data associated with this article can be found, in the online version, at doi:10.1016/j. mrfmmm.2008.12.014. 


\section{References}

[1] E. Steliarova-Foucher, et al., Geographical patterns and time trends of cancer incidence and survival among children and adolescents in Europe since the 1970s (the ACCIS project): an epidemiological study, Lancet 364 (9451) (2004) 2097-2105.

[2] M.D. Shelby, et al., Fertility, reproduction, and genetic disease: studies on the mutagenic effects of environmental agents on mammalian germ cells, Environ. Health Perspect. 100 (1993) 283-291.

[3] Y.E. Dubrova, et al., Human minisatellite mutation rate after the Chernobyl accident, Nature 380 (6576) (1996) $683-686$

[4] C.L. Yauk, et al., Induced minisatellite germline mutations in herring gulls (Larus argentatus) living near steel mills, Mutat. Res. 452 (2) (2000) 211-218.

[5] F.P. Perera, et al., Molecular epidemiologic research on the effects of environmental pollutants on the fetus, Environ. Health Perspect. 107 (Suppl. 3) (1999) 451-460.

[6] F.P. Perera, et al., A summary of recent findings on birth outcomes and developmental effects of prenatal ETS, $\mathrm{PAH}$, and pesticide exposures, Neurotoxicology 26 (4) (2005) 573-587.

[7] B.T. Ji, et al., Paternal cigarette smoking and the risk of childhood cancer among offspring of nonsmoking mothers, J. Natl. Cancer Inst. 89 (3) (1997) 238-244.

[8] P. Boffetta, J. Tredaniel, A. Greco, Risk of childhood cancer and adult lung cancer after childhood exposure to passive smoke: a meta-analysis, Environ. Health Perspect. 108 (1) (2000) 73-82.

[9] R.W. Godschalk, J.C. Kleinjans, Characterization of the exposure-disease continuum in neonates of mothers exposed to carcinogens during pregnancy, Basic Clin. Pharmacol. Toxicol. 102 (2) (2008) 109-117.

[10] L. Gaspari, et al., Polycyclic aromatic hydrocarbon-DNA adducts in human sperm as a marker of DNA damage and infertility, Mutat. Res. 535 (2) (2003) 155-160.

[11] C. Bjorge, et al., A comparative study of chemically induced DNA damage in isolated human and rat testicular cells, Reprod. Toxicol. 10 (6) (1996) 509-519.

[12] S. Mollerup, et al., Sex differences in risk of lung cancer: expression of genes in the PAH bioactivation pathway in relation to smoking and bulky DNA adducts, Int. J. Cancer 119 (4) (2006) 741-744.

[13] D.M. van Leeuwen, et al., Cigarette smoke-induced differential gene expression in blood cells from monozygotic twin pairs, Carcinogenesis 28 (3) (2007) 691-697.

[14] C.A. Pessot, et al., Presence of RNA in the sperm nucleus, Biochem. Biophys. Res. Commun. 158 (1) (1989) 272-278.

[15] G.C. Ostermeier, et al., Spermatozoal RNA profiles of normal fertile men, Lancet 360 (9335) (2002) 772-777.

[16] D.T. Carrell, B.R. Emery, S. Hammoud, Altered protamine expression and diminished spermatogenesis: what is the link? Hum. Reprod. Update 13 (3) (2007) 313-327.

[17] P. Sassone-Corsi, Unique chromatin remodeling and transcriptional regulation in spermatogenesis, Science 296 (5576) (2002) 2176-2178.

[18] H. van Vunakis, H.B. Gijka, J.J. Langone, Radioimmunoassay for nicotine and cotinine, IARC Sci. Publ. 109 (1993) 293-299

[19] R. Goodrich, G. Johnson, S.A. Krawetz, The preparation of human spermatozoal RNA for clinical analysis, Arch. Androl. 53 (3) (2007) 161-167.

[20] Y.C. Staal, et al., Binary PAH mixtures cause additive or antagonistic effects on gene expression but synergistic effects on DNA adduct formation, Carcinogenesis 28 (12) (2007) 2632-2640.

[21] A. Boorsma, et al., T-profiler: scoring the activity of predefined groups of genes using gene expression data, Nucleic Acids Res. 33 (Web Server issue) (2005) W592-W595.

[22] S. Horak, J. Polanska, P. Widlak, Bulky DNA adducts in human sperm: relationship with fertility, semen quality, smoking, and environmental factors, Mutat. Res. 537 (1) (2003) 53-65.

[23] T.E. Schmid, et al., The effects of male age on sperm DNA damage in healthy non-smokers, Hum. Reprod. 22 (1) (2007) 180-187.

[24] R.J. Aitken, et al., Influence of caffeine on movement characteristics, fertilizing capacity and ability to penetrate cervical mucus of human spermatozoa, J. Reprod. Fertil. 67 (1) (1983) 19-27. 
[25] W.A. Robbins, et al., Effect of lifestyle exposures on sperm aneuploidy, Cytogenet. Genome Res. 111 (3-4) (2005) 371-377.

[26] D. Marinelli, et al., Mini-review of studies on the effect of smoking and drinking habits on semen parameters, Int. J. Hyg. Environ. Health 207 (3) (2004) 185-192.

[27] D. Miller, G.C. Ostermeier, S.A. Krawetz, The controversy, potential and roles of spermatozoal RNA, Trends Mol. Med. 11 (4) (2005) 156-163.

[28] R. Edgar,M. Domrachev, A.E. Lash, Gene expression omnibus: NCBI gene expression and hybridization array data repository, Nucleic Acids Res. 30 (1) (2002) 207-210

[29] F. Al-Shahrour, et al., BABELOMICS: a systems biology perspective in the functional annotation of genomescale experiments, Nucleic Acids Res. 34 (Web Server issue) (2006)W472-W476.

[30] X. Li, G.R. Stark, NFkappaB-dependent signaling pathways, Exp. Hematol. 30 (4) (2002) 285-296.

[31] R.W. Godschalk, et al., Differences in aromatic-DNA adduct levels between alveolar macrophages and subpopulations of white blood cells from smokers, Carcinogenesis 19 (5) (1998) 819-825.

[32] L. Gandini, et al., The in-vitro effects of nicotine and cotinine on sperm motility, Hum. Reprod. 12 (4) (1997) 727-733.

[33] J.S. Chang, et al., Parental smoking and the risk of childhood leukemia, Am. J. Epidemiol. 163 (12) (2006) 1091-1100.

[34] D. Pang, R. McNally, J.M. Birch, Parental smoking and childhood cancer: results from the United Kingdom Childhood Cancer Study, Br. J. Cancer 88 (3) (2003) 373-381.

[35] C.L. Yauk, et al., Mainstream tobacco smoke causes paternal germ-line DNA mutation, Cancer Res. 67 (11) (2007) 5103-5106.

[36] A.F. Holstein, W. Schulze, M. Davidoff, Understanding spermatogenesis is a prerequisite for treatment, Reprod. Biol. Endocrinol. 1 (2003) p107.

[37] J.E. Gallagher, et al., ${ }^{32}$ P-postlabeling analysis of DNA adducts in human sperm cells from smokers and nonsmokers, Cancer Epidemiol. Biomarkers Prev. 2 (6) (1993) 581-585.

[38] M.T. Zenzes, R. Bielecki, T.E. Reed, Detection of benzo(a)pyrene diol epoxide-DNA adducts in sperm of men exposed to cigarette smoke, Fertil. Steril. 72 (2) (1999) 330-335.

[39] J.A. Kramer, S.A. Krawetz, RNA in spermatozoa: implications for the alternative haploid genome, Mol. Hum. Reprod. 3 (6) (1997) 473-478.

[40] D. Miller, et al., A complex population of RNAs exists in human ejaculate spermatozoa: implications for understanding molecular aspects of spermiogenesis, Gene 237 (2) (1999) 385-392.

[41] G.C. Ostermeier, et al., Toward using stable spermatozoal RNAs for prognostic assessment of male factor fertility, Fertil. Steril. 83 (6) (2005) 1687-1694.

[42] H. Wang, et al., A spermatogenesis-related gene expression profile in human spermatozoa and its potential clinical applications, J. Mol. Med. 82 (5) (2004) 317-324.

[43] S.Y. Han, et al., TFIIAalpha/beta-like factor is encoded by a germ cell-specific gene whose expression is upregulated with other general transcription factors during spermatogenesis in the mouse, Biol. Reprod. 64 (2) (2001) 507-517

[44] C. Grant, et al., Foxp3 represses retroviral transcription by targeting both NFkappaB and CREB pathways, PLoS Pathog. 2 (4) (2006) e33.

[45] S. Gordon, et al., Transcription factor YY1: structure, function, and therapeutic implications in cancer biology, Oncogene 25 (8) (2006) 1125-1142.

[46] S.L. Oei,Y. Shi, Transcription factor YinYang 1 stimulates poly(ADP-ribosyl)ation and DNA repair, Biochem. Biophys. Res. Commun. 284 (2) (2001) 450-454.

[47] G.C. Ostermeier, et al., Reproductive biology: delivering spermatozoan RNA to the oocyte, Nature 429 (6988) (2004) 154.

[48] M. Rassoulzadegan, et al., RNA-mediated non-mendelian inheritance of an epigenetic change in the mouse, Nature 441 (7092) (2006) 469-474.

[49] S.A. Krawetz, Paternal contribution: new insights and future challenges, Nat. Rev. Genet. 6 (8) (2005) $633-642$.

[50] F. Lemm, M. Wilhelm, P.H. Roos, Occupational exposure to polycyclic aromatic hydrocarbons suppresses constitutive expression of CYP1B1 on the transcript level in human leukocytes, Int. J. Hyg. Environ Health. 207 (4) (2004) 325-335. 

IN VITRO EVALUATION OF BASELINE AND INDUCED DNA DAMAGE IN HUMAN SPERM EXPOSED TO BENZO[a] PYRENE OR ITS METABOLITE BENZO[a]PYRENE-7,8DIOL-9,10-EPOXIDE, USING THE COMET ASSAY

Ville E. Sipinen Julian Laubenthal Adolf Baumgartner

Eduardo Cemeli Joost O. Linschooten Roger W.L. Godschalk Frederik J. van Schooten Diana Anderson Gunnar Brunborg 


\section{Abstract}

Exposure to genotoxins may compromise DNA integrity in male reproductive cells, putting future progeny at risk for developmental defects and diseases. To study the usefulness of sperm DNA damage as a biomarker for genotoxic exposure, we have investigated cellular and molecular changes induced by benzo[a]pyrene $(\mathrm{B}[\mathrm{a}] \mathrm{P})$ in human sperm in vitro, and results have been compared for smokers and non-smokers. Sperm DNA obtained from five smokers was indeed more fragmented than sperm of six non-smokers (mean \% Tail DNA 26.5 and 48.8, respectively), as assessed by the alkaline comet assay $(p<0.05)$. $\mathrm{B}[\mathrm{a}] \mathrm{P}$-related DNA adducts were detected at increased levels in smokers as determined by immunostaining. Direct exposure of mature sperm cells to B[a]P (10 or $25 \mathrm{mM}$ ) caused moderate increases in DNA fragmentation which was independent of addition of human liver S9 mix for enzymatic activation of $\mathrm{B}[\mathrm{a}] \mathrm{P}$, suggesting some unknown metabolism of $\mathrm{B}[\mathrm{a}] \mathrm{P}$ in ejaculates. In vitro exposure of samples to various doses of $\mathrm{B}[\mathrm{a}] \mathrm{P}$ (with or without S9) did not reveal any significant differences in sensitivity to DNA fragmentation between smokers and non-smokers. Incubations with the proximate metabolite benzo[a] pyrene-r-7,t-8-dihydrodiol-t9,10-epoxide (BPDE) produced DNA fragmentation in a dosedependent manner (20 or $50 \mathrm{mM}$ ), but only when formamidopyrimidine DNA glycosylase treatment was included in the comet assay. These levels of DNA fragmentation were, however, low in relation to very high amounts of BPDE-DNA adducts as measured with ${ }^{32} \mathrm{P}$ postlabelling. We conclude that sperm DNA damage may be useful as a biomarker of direct exposure of sperm using the comet assay adapted to sperm, and as such the method may be applicable to cohort studies. Although the sensitivity is relatively low, DNA damage induced in earlier stages of spermatogenesis may be detected with higher efficiencies. 


\section{Introduction}

Environmental pollutants such as products of fossil fuel combustion and contaminants in food and water are - together with lifestyle factors - unquestionably linked to human health. One such compound is the polycyclic aromatic hydrocarbon (PAH), benzo[a] pyrene $(\mathrm{B}[\mathrm{a}] \mathrm{P})$, an ubiquitous environmental pollutant found in, e.g., cigarette smoke and grilled food. When ingested or inhaled, B[a]P can be transformed by phase I enzymes such as the CYP450 enzymes into several DNA-reactive metabolites, including the directly acting carcinogen benzo[a]pyrene-7,8-diol-9,10-epoxide (BPDE) (reviewed in refs $[1,2]$ ), which binds covalently to DNA [3]. BPDE can also act in synergy with other exposures e.g. ultraviolet light [4], ultimately increasing the risk of mutation, cancer or possibly other adverse effects [5-7]. B[a]P can also contribute to the genotoxic burden in cells by reaction via the aldo-keto reductase superfamily leading to oxidative stress (reviewed in ref. [8]). The oxidized quinones produced via this pathway may in addition revert to catechols, which can react with DNA and other biomolecules to form covalent adducts.

When mutations occur in male or female reproductive cells, future progeny may be at risk of hereditary predispositions to various developmental defects or disease including cancer. Studies suggest that exposure to PAHs is correlated with reduced semen quality and higher risk of infertility; men with idiopathic infertility and also abnormal sperm parameters (World Health Organization (WHO) criteria (1999)) were shown to have increased levels of urinary PAH metabolites compared to control groups [9]. Moreover, studies have shown that smoking men have higher levels of BPDE-DNA adducts than non-smokers and that the level of adducts in embryos from smoking couples seems to depend more on the smoking habit of the father than that of the mother, implying that the adducts in embryos could be more of paternal origin $[10,11]$. Sperm is a useful human biomaterial, being available from volunteering individuals and from sperm banks; sperm has a well-studied physiology and there are established methods for their characterization (WHO). For tissues such as white blood cells and mouth mucous cells, the application of the comet assay [12] has been useful in biomonitoring studies [13]. This assay traditionally detects DNA strand breaks and alkali-labile sites (e.g. baseless sites in DNA), is fast and sensitive and can readily be modified to achieve higher specificity for the detection of specific types of DNA lesions [14-18]. Analysis of human sperm using the comet assay (reviewed in [19] and [20]) provides information on DNA integrity in relevance to male fertility, and the method may supplement established techniques e.g. sperm chromatin structure assay and terminal deoxynucleotidyl transferase deoxyuridine triphosphate nick end labelling (TUNEL) assay. In addition to issues relating to fertility, DNA damage in the mature sperm may provide information about the genotoxic burden of the germline. In vivo, such DNA lesions may arise in dividing testicular stem cells or at varying stages during spermatogenesis and spermiogenesis. The susceptibility at the various stages to chemicals will depend on the ability of the cells to remove the damage by DNA repair [21-26], but it also relates to the packaging and restructuring of the chromatin at the various stages, including replacement of histones with protamines which occurs progressively during spermiogenesis (reviewed in refs [27,28]). Mature sperm could potentially have a great potential as biomarker for genotoxic exposure in vivo when assayed with the comet assay. This, however, requires that induced lesions are measurable in a sensitive and robust manner. If human sperm collected from healthy men is susceptible to DNA damage induction after chemical treatment in vitro, it is likely that mature sperm may also be damaged in situ at a late stage of maturation, i.e. in the epididymis. 
The present study was undertaken to evaluate the use of sperm DNA damage as a biomarker in population studies. Using B[a]P as an example of environmental exposure, semen samples were exposed to this compound or its proximate metabolite BPDE in vitro. Samples were obtained repetitively from one donor or from groups of donors representing smokers and non-smokers. The experiments were carried out in three laboratories, using the comet assay adapted to sperm; in addition, DNA adducts were analysed in some samples after exposure to $\mathrm{B}[\mathrm{a}] \mathrm{P}$ or BPDE in vitro, using ${ }^{32} \mathrm{P}$ postlabelling and immunostaining.

\section{Materials \& methods}

\section{Chemicals}

Benzo[a]pyrene-r-7,t-8-dihydrodiol-t9,10-epoxide [( \pm )anti-BPDE] was obtained from the National Cancer Institute (NCI), Chemical Carcinogen Reference Standard Repository at the Midwest Research Institute, Kansas City, MO, USA (0477 NCI\#: L0137\# Batch: 42 Lot.: 01262007-PSU). B[a]P (48564-SUPELCO) was obtained from Sigma-Aldrich $®$, Munich, Germany. SYBRGold ${ }^{\mathrm{TM}}$ was from Molecular Probes, Invitrogen, Paisley, UK; ethidium bromide was from Sigma, Gillingham, Dorset, UK. Proteinase K was from Hoffman-La Roche, Basel, Switzerland. Other chemicals were pro analysis grade from commercial suppliers.

Human liver fraction S9-mix and essential reagents Pooled human liver S9-mix (10 individuals, mixed gender) was obtained from In vitro Technologies, Cat. no. X008023 LOT RTO. Glucose-6-phosphate (G-6-P), glucose-6-phosphate dehydrogenase (G-6-P $\mathrm{DH}$ ), grade I from yeast and nicotinamide adenine dinucleotide phosphate (NADP) were obtained from Roche Diagnostics, Mannheim, Germany.

\section{Semen samples}

Semen samples were obtained from healthy volunteers after informed consent, at the University of Bradford after 3-5 days of sexual abstinence. Detailed information on age, ethnicity, sexual activity and children (and also other factors e.g. occupation, smoking and drinking habits, vitamin intake, existing urogenital pathologies, X-ray exposure, chemotherapy) was collected for other purposes but was not used for further analysis because of the small sample size. Smoking habits were confirmed by cotinine levels measured in seminal plasma (data not shown). The samples were labelled with date and time of collection and given an anonymous donor code. Routine analysis of semen quality was conducted within $2 \mathrm{~h}$ of collection using WHO criteria (1999) to provide details on colour, volume, viscosity, sperm concentration, $\mathrm{pH}$, motility and morphology; all samples were found to be normospermic. All samples were aliquoted, snap frozen in liquid nitrogen and then kept at $-80^{\circ} \mathrm{C}$. Treated samples (5, 10 and $25 \mu \mathrm{M} \mathrm{B}[a] \mathrm{P} \pm \mathrm{S} 9$ mix or 5, 20 and $50 \mu \mathrm{M}$ BPDE) from three separate experiments were frozen and shipped to the participating laboratories for ${ }^{32} \mathrm{P}$ postlabelling analysis. Ethical approval was obtained from the Research Ethics Sub-committee for Human Subjects at Bradford University in June 2005.

\section{Cell treatments}

Aliquots of 2-5 $\mu$ from a thawed sperm sample were incubated for $1 \mathrm{~h}$ in $1 \mathrm{ml}$ solutions of phosphate-buffered saline (PBS), $\mathrm{pH} 7.4$, with either 1, 5, 10 or $25 \mu \mathrm{M}$ of $\mathrm{B}[\mathrm{a}] \mathrm{P}$ dissolved 
in dimethyl sulfoxide (DMSO; end concentration 1\%), 1\% human liver fraction S9-mix or 5, 20 and $50 \mu \mathrm{M}$ BPDE (DMSO $1 \%$ ), at $32^{\circ} \mathrm{C}$. X irradiation was used as positive control and was calibrated using Fricke's ferrous sulphate chemical dosimetry. The reduced nicotinamide adenine dinucleotide phosphate regenerating system (NRS) and the S9mix $(S 9+N R S)$ were freshly prepared before each experiment as previously described [29]. When mixing the ingredients, the S9 fraction and the G-6-P DH were added at last to the mix, immediately before addition to the cells for exposure (NRS end concentrations: $33 \mathrm{mM}$ potassium chloride $(\mathrm{KCl}), 8 \mathrm{mM}$ magnesium chloride $\left(\mathrm{MgCl}_{2}{ }^{*} 6 \mathrm{H}_{2} \mathrm{O}\right), 5 \mathrm{mM}$ G-6-P, 3,75 U/ml G-6-P DH, $4 \mathrm{mM}$ NADP, $0.3 \times \mathrm{PBS})$. For immunostaining analysis, sperm aliquots were incubated as described above but with $40 \mu \mathrm{M}$ of $\mathrm{B}[\mathrm{a}] \mathrm{P}+\mathrm{S} 9$-mix or with vehicle alone.

\section{Alkaline comet assay}

Two different methods were applied to study comet formation in mature sperm after incubation with $\mathrm{B}[\mathrm{a}] \mathrm{P}$, and essential differences between protocols are mentioned in Table I. The two protocols were initially established to obtain relatively stable baseline levels of DNA damage of donor samples. They were then used as part of a large European Commission (EC) project (NewGeneris) to study various genotoxic and immunotoxic compounds using various end points including human sperm.

Table I: Differences in comet assay protocols 1 and 2

\begin{tabular}{|c|c|c|}
\hline Experimental conditions & Protocol 1 & Protocol 2 \\
\hline Layers & $\begin{array}{l}\text { 1. Layer : Normal slide with } 1 \% \text { NMP } \\
\text { 2. Layer : } 1: 1 \text { cells with } 2.0 \% \text { LMP } \\
\text { (end conc. } 1 \% \text { ) } \\
\text { 3. Layer : } 0.5 \% \text { LMP }\end{array}$ & $\begin{array}{l}\text { 1. Layer : GelBond® films using a } \\
\text { twelve-well format ( } 4 \times 3 \text { wells) } \\
\text { 2. Layer : } 1: 10 \text { cells with } 1.7 \% \\
\text { LMP (end conc. } 1.53 \%)\end{array}$ \\
\hline Lysis & $\begin{array}{l}\text { 1.Lysis : slides in lysis buffer with } 10 \\
\mathrm{mM} \mathrm{DTT} \text {, at } 4^{\circ} \mathrm{C} \text {, for } 60 \text { minutes } \\
\text { 2. Lysis : slides in lysis stock with } \\
0.05 \mathrm{mg} / \mathrm{ml} \text { Prot. } \mathrm{K} \text {, at } 4^{\circ} \mathrm{C} \text {, for } 60 \\
\text { minutes }\end{array}$ & $\begin{array}{l}\text { 1. Lysis: gel bond films in lysis } \\
\text { buffer at } 4^{\circ} \mathrm{C} \text {, over night } \\
\text { 2. Lysis: gel bond films in lysis } \\
\text { buffer with } 10 \mathrm{mM} \text { DTT, at } 4^{\circ} \mathrm{C} \text {, for } \\
60 \text { minutes } \\
\text { 3. Lysis: gel bond films in } 100 \mathrm{mM} \\
\text { Trizmaß buffer with } 4 \mathrm{mM} \text { lithium } \\
\text { diiodosalicyclate (LIS), pH } 7.6 \text {, } \\
\text { at ambient temperature, for } 90 \mathrm{~min}\end{array}$ \\
\hline Enzyme treatment & & $1 \mu \mathrm{g} / \mathrm{mL} F P G$ \\
\hline DNA unwinding & Electrophoresis buffer $\mathrm{pH}$ 13.2, $20 \mathrm{~min}$ & $\begin{array}{l}\text { Electrophoresis buffer } \mathrm{pH} 13.2 \text {, } \\
20 \mathrm{~min}\end{array}$ \\
\hline Electrophoresis & $\begin{array}{l}\text { Electrophoresis : } 25 \mathrm{~V}(0.78 \mathrm{~V} / \mathrm{cm}) \\
\text { and not exceeding } 300 \mathrm{~mA} \text { at } 4^{\circ} \mathrm{C} \text { for } \\
20 \mathrm{~min}\end{array}$ & $\begin{array}{l}\text { Electrophoresis : } 20 \mathrm{~V}(0.8 \mathrm{~V} / \mathrm{cm}) \\
\text { and } 300 \mathrm{~mA} \text { at } 8^{\circ} \mathrm{C} \text { for } 20 \mathrm{~min}\end{array}$ \\
\hline After electrophoresis & $\begin{array}{l}\text { pH Neutralization } \\
\text { Staining: Ethidium bromide }\end{array}$ & $\begin{array}{l}\text { pH Neutralization and fixation in } \\
\text { ethanol (>70\%) for } 90 \text { min, dried } \\
\text { and stored } \\
\text { Staining: SYBRGold }{ }^{T M}\end{array}$ \\
\hline
\end{tabular}




\section{Comet assay Protocol 1}

This protocol is based on Singh et al. [30], with modifications. Following exposure, sperm samples were centrifuged for $10 \mathrm{~min}$ at $450 \times \mathrm{g}$ at room temperature, resuspended in cold PBS and kept on ice until mixed 1:1 with $2 \%$ low melting point agarose. The samples were cast onto standard glass slides pre-coated with 1\% normal melting point agarose. Cell lysis was achieved through submerging the slides in two consecutive lysis solutions: (i) lysis buffer (2.5 M NaCl, $100 \mathrm{mM} \mathrm{Na2-ethylenediaminetetraacetic} \mathrm{acid} \mathrm{(EDTA),} 10 \mathrm{mM}$ Trizma ${ }^{\circledR}$ base, $1 \%$ Triton $X-100, \mathrm{pH} 10$ ) containing $10 \mathrm{mM}$ dithiothreitol (DTT) for $60 \mathrm{~min}$ at $4^{\circ} \mathrm{C}$ and (ii) lysis buffer containing $0.05 \mathrm{mg} / \mathrm{ml}$ proteinase $\mathrm{k}$ for $60 \mathrm{~min}$ at $4^{\circ} \mathrm{C}$. After lysis, the slides were incubated in electrophoresis buffer $\left(300 \mathrm{mM} \mathrm{NaOH}, 1 \mathrm{mM} \mathrm{Na}{ }_{2}\right.$ EDTA, pH 13.2) at $4^{\circ} \mathrm{C}$ for $20 \mathrm{~min}$ to unwind DNA and then subjected to electrophoresis at $25 \mathrm{~V}(0.8$ $\mathrm{V} / \mathrm{cm}$ on platform, $300 \mathrm{~mA}$ ) for $20 \mathrm{~min}$ at $4^{\circ} \mathrm{C}$. Prior to staining with ethidium bromide (20 $\mu \mathrm{g} / \mathrm{ml}$ ) for $10 \mathrm{~min}$, the slides were neutralized (0.4 M Trizma $\circledR$ base, $\mathrm{pH} 7.5)$ three times for 5 min each. Comet visualization and scoring was performed with a Leica fluorescence microscope equipped with a Charge Coupled Device (CCD) camera using the image analysis software 'Komet 4' from Kinetic Imaging Ltd.

\section{Comet assay Protocol 2}

The general comet assay protocol is also based on Singh et al. [30] but was performed as adapted for sperm [31], with some modifications: following exposure, sperm samples were centrifuged for $8 \mathrm{~min}$ at $700 \times \mathrm{g}$ at room temperature to avoid precipitation of $\mathrm{B}[\mathrm{a}] \mathrm{P}$, resuspended in $1 \mathrm{ml}$ of cold PBS and kept on ice until mixed 1:10 with $1.7 \%$ low melting

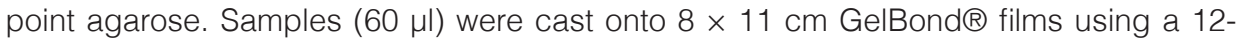
well format. Cell lysis was achieved through submerging the films in three consecutive lysis solutions: (i) lysis buffer: $2.5 \mathrm{M} \mathrm{NaCl}, 100 \mathrm{mM} \mathrm{Na} \mathrm{EDDT}_{2}, 10 \mathrm{mM}$ Trizma ${ }^{\circledR}$ base, $1 \%$ Triton $\mathrm{X}-100, \mathrm{pH} 10$, at $4^{\circ} \mathrm{C}$, overnight; (ii) lysis buffer with $10 \mathrm{mM} \mathrm{DTT}, \mathrm{pH} 10$, at $4^{\circ} \mathrm{C}$, for $60 \mathrm{~min}$ and (iii) $100 \mathrm{mM}$ Trizma $\AA$ buffer with $4 \mathrm{mM}$ lithium diiodosalicylate, $\mathrm{pH}$ 7.6, at ambient temperature, for $90 \mathrm{~min}$. After lysis, all films were equilibrated in enzyme buffer (40 mM HEPES, $100 \mathrm{mM} \mathrm{KCl}, 0.5 \mathrm{mM} \mathrm{Na}_{2}$ EDTA, pH 8) at $4^{\circ} \mathrm{C}$ for $60 \mathrm{~min}$, after which the films were incubated in pre-warmed enzyme buffer with $0.2 \mathrm{mg} / \mathrm{ml}$ bovine serum albumin at $37^{\circ} \mathrm{C}$ for $60 \mathrm{~min}$ with or without $1 \mu \mathrm{g} / \mathrm{ml}$ (sufficient for saturating cleavage of oxidative lesions induced in human lymphocytes by Ro 12-9786 + visible light; data not shown) formamidopyrimidine DNA glycosylase (FPG) crude extract (A.K. Olsen, personal communication). Enzyme treatment was followed by unwinding in electrophoresis buffer (300 $\mathrm{mM} \mathrm{NaOH}, 1 \mathrm{mM} \mathrm{Na}_{2} \mathrm{EDTA}$, adjusted to $\mathrm{pH} 13.2$ with $\mathrm{HCl}$ ) at $4^{\circ} \mathrm{C}$ for $20 \mathrm{~min}$, and electrophoresis at $20 \mathrm{~V}(0.8 \mathrm{~V} / \mathrm{cm}$ on platform, $300 \mathrm{~mA})$ at $8^{\circ} \mathrm{C}$ for $20 \mathrm{~min}$. After $3 \times 5$ minutes of neutralization in $0.4 \mathrm{M}$ Trizma $\circledR$ base, $\mathrm{pH} 7.5$, films were rinsed in water and fixed in ethanol (>70\%) for 90 min and dried. Gels were rehydrated and stained in Tris-EDTA buffer ( $1 \mathrm{mM} \mathrm{Na}{ }_{2}$ EDTA, $10 \mathrm{mM}$ Trizma® HCl, pH 8) with SYBERGold® (1:12 000 dilution) for 20 min. Comet visualization and scoring were performed using the image analysis software 'Comet assay IV' from Perceptive Instruments Ltd, Haverhill, Suffolk, UK, and an Olympus BX51 fluorescence microscope (Japan), with an A312f camera (Basler Vision Technologies, Ahrensburg, Germany).

\section{Immunodetection of monoclonal antibodies}

Semen aliquots were centrifuged for $10 \mathrm{~min}$ at $450 \times \mathrm{g}$, the supernatant was carefully discarded and the pellet was dissolved in $300 \mu \mathrm{l}$ PBS and again spun at $450 \times \mathrm{g}$ for $10 \mathrm{~min}$. This step was repeated twice to wash the sperm pellet thoroughly. The pellet was then resuspended in a 3:1 methanol-acetic acid solution (fixative); during continuous mixing on a vortex, the fixative was slowly dropped into the tube in $30 \mu \mathrm{l}$ steps to avoid clumping of the sperm followed by incubation for $30 \mathrm{~min}$. The fixed sperm were then applied in 50 
$\mu \mathrm{l}$ drops to glass slides and air-dried for $3 \mathrm{~h}$. The sperm were decondensed by incubating slides in ice-cold $10 \mathrm{mM}$ DTT in a Coplin jar for $30 \mathrm{~min}$, washing twice in $2 \times$ saline-sodium citrate buffer for 10 min each and dehydration in an ethanol series (70, 90 and 100\%) for 3 min each. Finally, slides were air-dried. The decondensed sperm were permeabilized with $0.5 \%$ Triton $X-100$ and then analysed under a light microscope to check the density and possible overdecondensation. With a hydrophobic PapPen ${ }^{\odot}$, an area with an optimal density and quality was then marked for hybridization [10,11].

Unspecific binding sites were first blocked with $10 \%$ goat serum in PBS, followed by application of $100 \mu \mathrm{l}$ 1:50 5D11 monoclonal antibody (Amersham, Piscataway, NJ, USA) in $1 \%$ goat serum. Clone 5D11 was reported to react directly with BPDE-DNA adducts as well as with diol epoxide-DNA adducts of different PAHs in a cross-reaction [32]. The slides were incubated in a moist chamber at $4^{\circ} \mathrm{C}$ for $16 \mathrm{~h}$ to allow slow and thorough recognition of DNA adducts by the antibody. After hybridization, the slides were washed three times in PBS for 10 min each, followed by adding $100 \mu \mathrm{l}$ of a solution containing the secondary goat anti-mouse antibody conjugated with biotin (DakoCytomation, Cambridge, UK). After incubation for $40 \mathrm{~min}$ at room temperature in a humid chamber, the slides were washed again three times in PBS for 10 min each, followed by application of $100 \mu \mathrm{l}$ of a solution containing Streptavidin conjugated to horseradish peroxidase (DakoCytomation) and incubation at room temperature for 40 min in a moist chamber. Slides were washed twice in PBS for 10 min and finally for 10 min in double distilled $\mathrm{H}_{2} \mathrm{O}$. The peroxidase reaction was developed with the 3.3'-diaminobenzidine enhanced liquid system (Sigma-Aldrich $®$ ). As a negative control, sperm from smokers were treated with $10 \%$ goat serum instead of the primary antibody, followed by application of the secondary antibodies and peroxidise reaction system. All slides were coded by co-workers and scored blindly. For the evaluation of staining intensity (STI), each sperm cell was scored as negative (STI 0), weak (STI 1), moderate (STI 2) or strong (STI 3) for a total of 100 sperm per semen donor. A staining intensity score (e.g. the sum of the products for the STI levels 0-3, with STI $0=1$ points, STI $1=2$ points, STI $2=3$ points, STI $3=4$ points) was calculated for each successfully hybridized sperm sample $(10,11)$. Images (figure 4) were obtained using a 100× Pan-NeoFluar objective and a CCD-camera.

\section{${ }^{32} \mathrm{P}$ postlabelling}

Spermatozoa obtained from frozen ejaculates were lysed overnight at $55^{\circ} \mathrm{C}$ using a buffer containing 20 mM Tris- $\mathrm{HCl}, 20$ mM EDTA, 200 mM NaCl, 80 mM DTT, 4\% sodium dodecyl sulphate and $250 \mu \mathrm{g} / \mathrm{ml}$ proteinase $\mathrm{K}$. DNA from the lysed spermatozoa was isolated using the DNeasy Tissue Kit (Qiagen Westburg bv., Leusden, The Netherlands) according to manufacturers' instructions with minor modifications: after the lysis of the cells, Buffer $\mathrm{AL}$ and $100 \%$ ethanol (EtOH) were added. This mixture was brought onto DNeasy Spin Columns and centrifuged. Thereafter, Buffer AW1 was added to the column and centrifuged and next, the column was washed with Buffer AW2. After centrifuging the column, the DNA was eluted in distilled water and stored at $-20^{\circ} \mathrm{C}$ until use. The ${ }^{32} \mathrm{P}$ postlabelling assay was subsequently performed as described [33]. Briefly, DNA was digested using micrococcal endonuclease and spleen phosphodiesterase. Unadducted nucleotides were dephosphorylated by Nuclease P1 treatment and the modified nucleotides were subsequently radiolabelled ( $50 \mu \mathrm{Ci}$ per sample) by incubation with T4 polynucleotide kinase and ${ }{ }^{32}{ }^{2}$ P-ATP. Radiolabelled adduct nucleotide biphosphates were separated by chromatography on polyethylenimine-cellulose sheets from Machery-Nagel (Düren, Germany). In each experiment, three standards of BPDE-modified DNA with known modification levels ( 1 adduct per $10^{7}, 10^{8}$ and $10^{9}$ nucleotides) were run in parallel for quantification purposes using phosphor-imaging technology (Molecular Dynamics ${ }^{\mathrm{TM}}$, Sunnyvale, CA, USA). 


\section{High-performance liquid chromatography analysis of metabolites after exposure of mature sperm to $\mathrm{B}[\mathrm{a}] \mathrm{P}$}

Sperm sample aliquots of $250 \mu$ were exposed under two different conditions, either unwashed in the presence of seminal plasma or washed in PBS. Washed samples were prepared by centrifugation at $9300 \times \mathrm{g}$ for $5 \mathrm{~min}$; the plasma above the cell pellets was removed and the pellets were resuspended and mixed thoroughly in $250 \mu \mathrm{l}$ PBS and centrifuged another $5 \mathrm{~min}$. The supernatant was then removed and the cell pellets were resuspended in a new $250 \mu \mathrm{l}$ PBS. A volume of $250 \mu$ ejaculate or washed sperm cells was exposed to $10 \mu \mathrm{M} \mathrm{B}$ [a]P dissolved in DMSO. All incubations were performed at $32^{\circ} \mathrm{C}$ for 1 or $24 \mathrm{~h}$. After incubation, the samples were extracted three times with $1 \mathrm{ml}$ ethyl acetate, which was subsequently evaporated under a continuous nitrogen flow. The residues were redissolved in 100\% methanol and analysed by reversed phase high-performance liquid chromatography (HPLC); the samples were injected onto a Supelco Hypersil 5 column $(250 \times 3 \mathrm{~mm})$. Elution was performed by using two mobile phases: Mobile phase A contained $100 \%$ methanol and Mobile phase B contained 40\% methanol and $60 \%(\mathrm{v} / \mathrm{v})$ water. A gradient elution programme, with a flow rate of $0.5 \mathrm{ml} / \mathrm{min}$, started with $30 \% \mathrm{~A}$ and $70 \%$ $\mathrm{B}$ for $5 \mathrm{~min}$, then gradually changed to $90 \% \mathrm{~A}$ in $25 \mathrm{~min}$, held at $90 \%$ for $5 \mathrm{~min}$, then back to $30 \% \mathrm{~A}$ in $2 \mathrm{~min}$ and held at 30\% A for 3 min before the next injection. Detection was performed by a Perkin Elmer model LS 30 fluorescence spectrometer with 257 and $>350$ $\mathrm{nm}$ as excitation and emission wavelengths, respectively.

\section{Statistics}

The comet assay sample differences were determined by one-way analysis of variance with a Dunnett's or Tukey's post-hoc test, using SPSS $17^{\circ}$. For immunostaining, all generated data were processed with Metlab ${ }^{\odot}$ software for the median and standard error. SPSS $15.0^{\odot}$ was used to measure asymmetry of the probability distribution and skewness and to measure if the results were peaked or flat relative to a normal distribution and kurtosis. All the immunostaining data were found to violate normality and therefore, nonparametric Mann-Whitney was used to test for significant differences. If not specified, the level of significance is $p<0.05$.

\section{Results}

\section{Comet assay analysis of sperm from non-smoking volunteers}

Comet assay experiments using Protocol 1 showed moderate but consistent increases in DNA strand breaks in sperm from three donors, exposed to 10 or $25 \mu \mathrm{M}$ of $\mathrm{B}[a] \mathrm{P}$ ( $p<$ 0.05; figure 1). These increases were found without addition of liver S9-mix. 


\section{Human sperm exposed to benzo[a]pyrene in vitro}

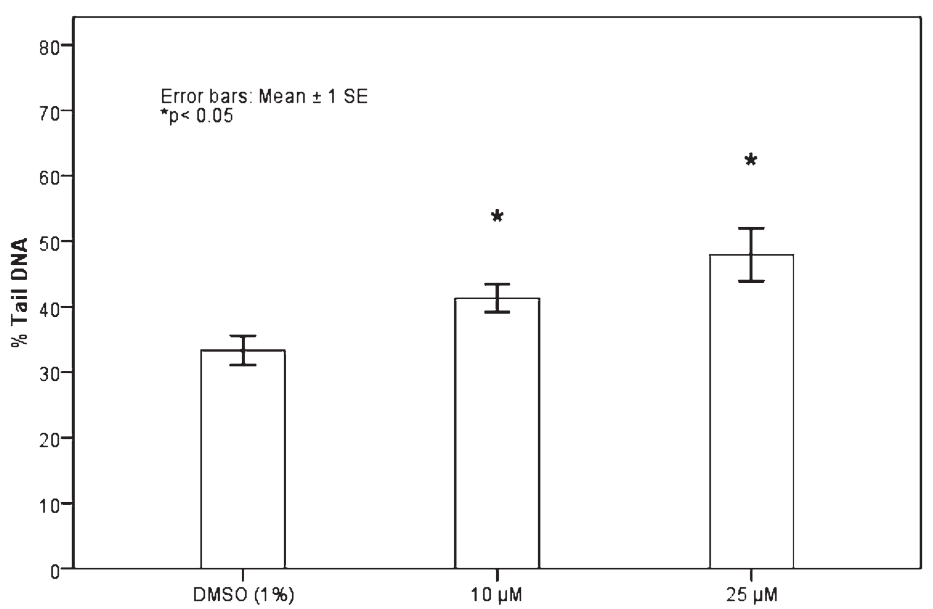

Figure 1: DNA damage in sperm exposed to 10 or $25 \mu \mathrm{M}$ B[a]P. Data was assessed by one-way ANOVA with a Dunnett's post-hoc test. The dose response is presented as mean \% Tail DNA \pm 1 SE. Each treatment group was compared to the control group ( $1 \% \mathrm{DMSO}$ ). ${ }^{*} p<0.05$,. Control group, $\mathrm{n}=10$, other treatments $\mathrm{n}=4$. Comet assay protocol 1.

In the in vitro experiments analysed by the comet Protocol 2, sperm aliquots from only one donor were used. Ejaculates were divided into several $50 \mu \mathrm{l}$ aliquots and frozen at $-80^{\circ} \mathrm{C}$ so that cells from the same ejaculate could be used repeatedly. During the 2-year course of the project, about 10 ejaculates from the same person were collected and used. No major difference in response to chemical treatment in vitro was observed between ejaculates, suggesting minor intra-individual differences during the project period.

Exposure to either $\mathrm{B}[\mathrm{a}] \mathrm{P}$ or $\mathrm{B}[\mathrm{a}] \mathrm{P}$ plus S9-mix showed no statistically significant increase in DNA strand breaks, and the inclusion of FPG treatment did not lead to $B[a]$ P-associated DNA damage (figure 2a). BPDE produced weakly increased levels of DNA damage at 20 and $50 \mu \mathrm{M}$, as compared to the control (figure $2 \mathrm{~b}$ ). These increases were significant only with FPG treatment $(p<0.05)$. These exposures were also repeated with samples from a second donor, giving highly similar results (data not shown). 
a) Human sperm exposed to benzo[a]pyrene \pm human S9 and analysed in the comet assay with or without FPG

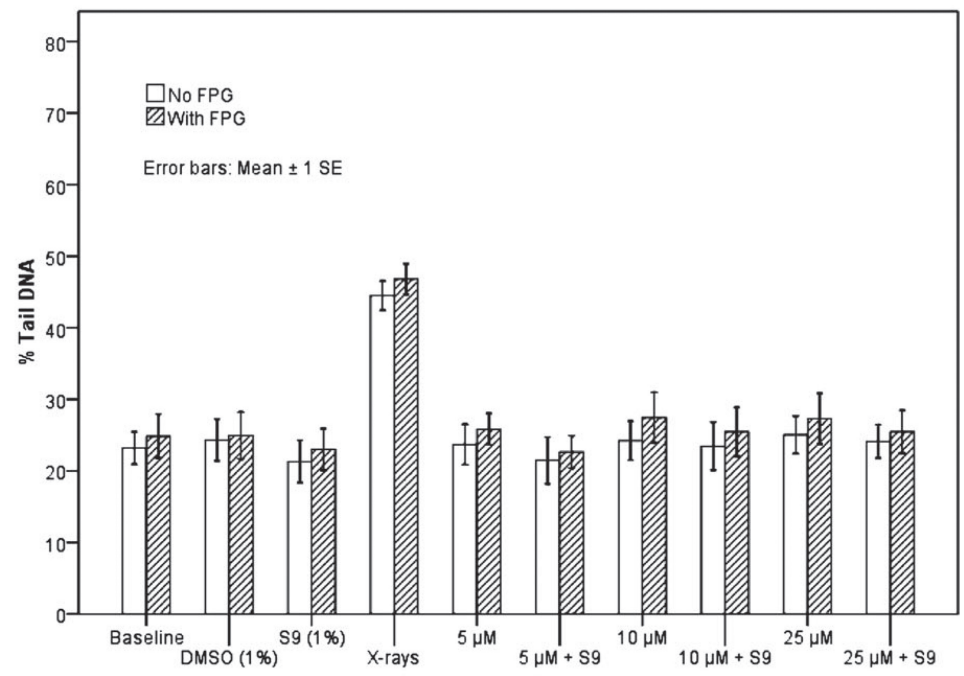

Figure 2a: DNA damage in sperm exposed to 5,10 or $25 \mu \mathrm{M} B[a] P \pm$ human $\mathrm{S} 9$. Comet analysis with or without the FPG enzyme. X-ray irradiation (200 Gy) was used as positive control. Data represent the Mean \% Tail DNA \pm 1 SE, from 3-6 individual experiments, and was assessed by One-way ANOVA with a Tukeys's post-hoc test. Only the $X$-ray irradiated samples were statistically different from the other treatments $(p<0.05)$. Comet assay protocol 2.

a)

Human sperm exposed to benzo[a]pyrene \pm human $\mathrm{S} 9$ and analysed in the comet assay with or without FPG

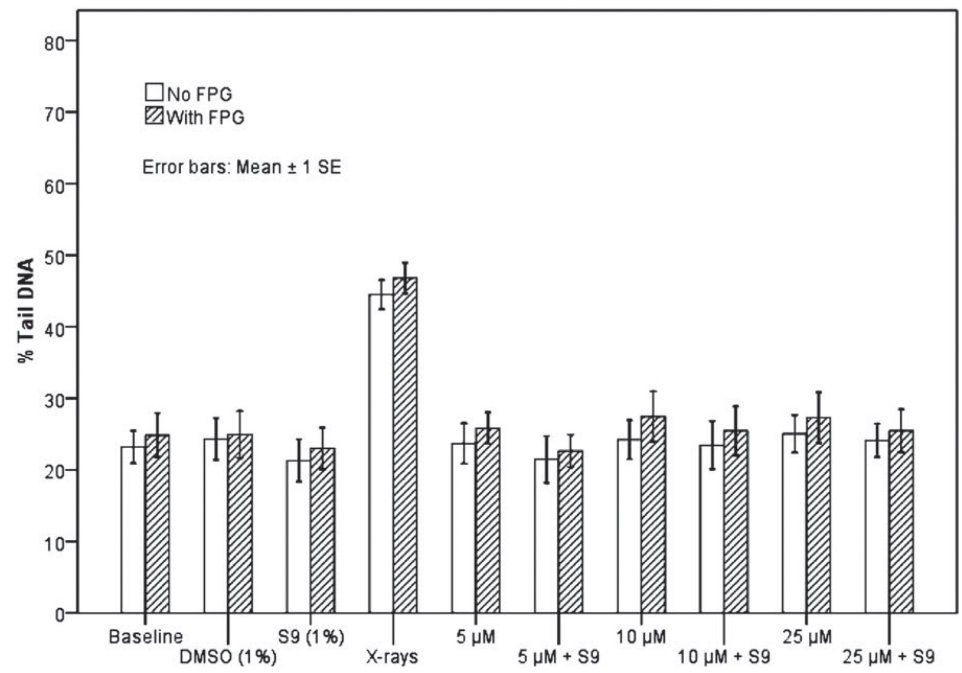

Figure 2b: DNA damage in sperm exposed to 5, 20 or $50 \mu \mathrm{M}$ BPDE. Comet analysis with or without the FPG enzyme. Data are represented as Mean \% Tail DNA from 4-6 individual experiments \pm 1 SE. Assessed by One-way ANOVA with a Tukeys's post-hoc test, only exposure to 20 and $50 \mu \mathrm{M}$ BPDE combined with FPG treatment induced significantly $\left({ }^{*} p<0,05\right)$, higher DNA damage levels than control samples (DMSO, DMSO + FPG). X-ray irradiation (200 Gy), was used as positive control. Comet assay Protocol 2. 


\section{Comet assay analysis comparing sperm from non-smokers and smokers}

On the basis of the differences observed between the responses with the two protocols, Protocol 1 was chosen to study sperm from five smokers and six non-smokers. These groups showed significant differences in their baseline DNA damage levels and also differences in the levels obtained in samples when treated in vitro with DMSO plus S9 or S9 alone; samples from the smokers had higher levels of DNA damage than non-smokers ( $p<0.001 ; p=0.003 ; p=0.023$, respectively) (figure 3$)$. When the samples were treated with $\mathrm{B}[\mathrm{a}] \mathrm{P}$ in vitro, there were dose-dependent increases in DNA damage, in both groups (except non-significant differences of smoker's baseline levels versus treatment of the same samples with $1 \mu \mathrm{M} \mathrm{B}[a] \mathrm{P} \pm \mathrm{S} 9)$. However, a further increase with S9 was only observed in non-smoker samples exposed to either 1 or $25 \mu \mathrm{M} \mathrm{B}[a] \mathrm{P}(p=0.03 ; p=0.04$, respectively).

\section{Human sperm from smokers and non-smokers exposed to benzo[a]pyrene \pm human $\mathrm{S} 9$ and analysed in the comet assay}

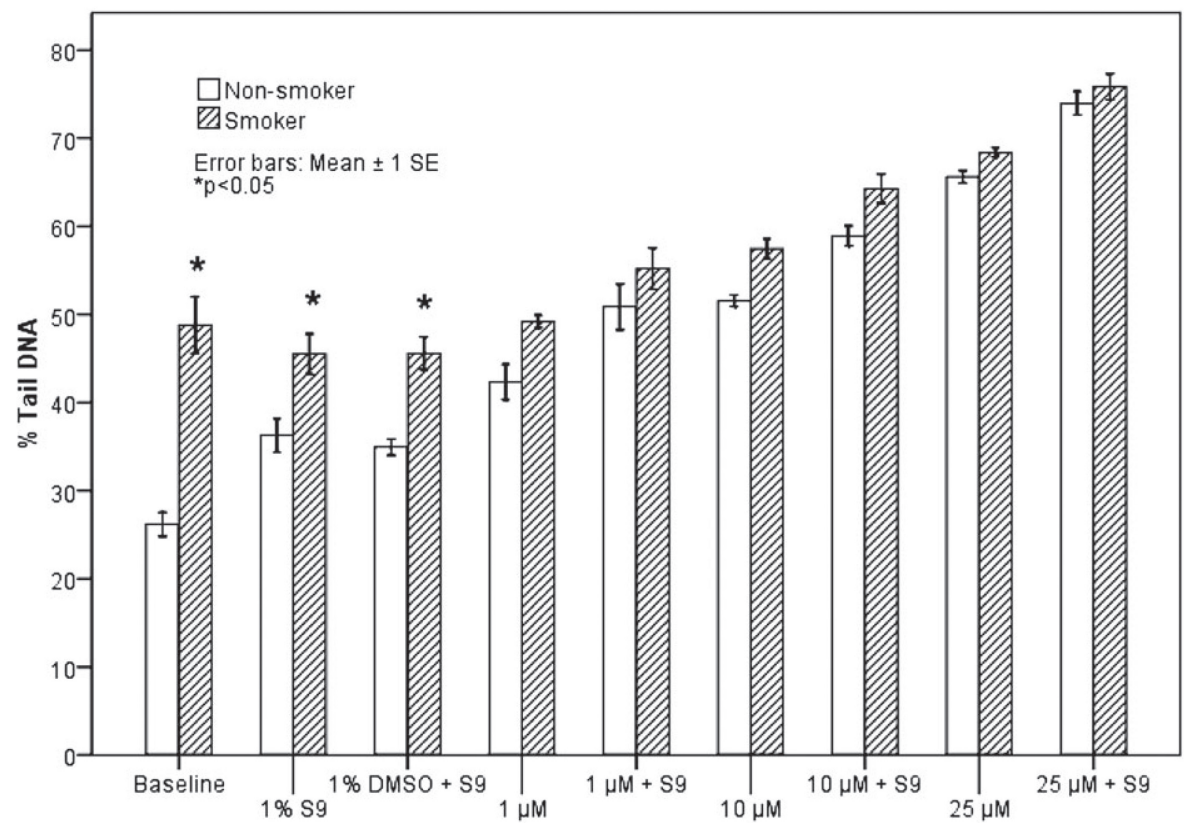

Figure 3: DNA damage in sperm from 5 smokers and 6 non-smokers. Baseline levels, and after in vitro exposure to $0,1,10$ and $25 \mu \mathrm{M}$ of $\mathrm{B}[\mathrm{a}] \mathrm{P} \pm$ human S9. Data represent the Mean \% Tail DNA $\pm 1 \mathrm{SE}$, from three individual experiments repeated for all treatments and samples. Sperm from the smokers had significantly higher levels of DNA damage compared to non-smokers (Baseline, S9, S9 + DMSO). For both groups, B[a]P in vitro exposure led to dose-dependent increases. Comet assay protocol 1. 


\section{In situ immunodetection in sperm cells from smokers and non-smokers using a $\mathrm{B}[\mathrm{a}] \mathrm{P}$ monoclonal antibody}

Table II summarises staining intensity levels using the BPDE-DNA antibody, with samples from three smokers and three non-smokers. The data are derived from typical images shown in figure 4; baseline values are shown as well as responses to $40 \mu \mathrm{M} \mathrm{B}[a]$ $\mathrm{P}$ activated with 1\% S9-mix. The STI score was significantly increased in smokers as compared to non-smokers.

Table II: Mean values for staining intensity levels in sperm cells of non-smokers and smokers. Staining intensity levels (STI \pm SE) and statistical differences ( $p$-values) are shown for sperm samples treated with or without $40 \mu \mathrm{M}$ $\mathrm{B}[\mathrm{a}] \mathrm{P}$ and S9 mix, and analysed with a monoclonal antibody to detect DNA adducts.

\begin{tabular}{|c|c|c|c|c|c|}
\hline & STI Score & STI 0 & STI 1 & STI 2 & STI 3 \\
\hline $\begin{array}{l}\text { Non-Smokers } \\
(n=3, \text { mean } \pm \text { SE })\end{array}$ & $69.0 \pm 2.3$ & $36.0 \pm 3.74$ & $59.0 \pm 4.8$ & $5.0 \pm 1.4$ & $0.0 \pm 0$ \\
\hline $\begin{array}{l}\text { Smokers } \\
(n=3, \text { mean } \pm \text { SE })\end{array}$ & $\begin{array}{l}182.0 \\
\pm 15.2\end{array}$ & $3.0 \pm 1.87$ & $37.0 \pm 5.3$ & $35.0 \pm 3.0$ & $25.0 \pm 10.0$ \\
\hline$P$-value & 0.050 & 0.050 & 0.046 & 0.050 & 0.037 \\
\hline $\begin{array}{l}\text { Non-Smokers, } B[a] P \text { treated } \\
(n=3, \text { mean } \pm S E)\end{array}$ & $186.0 \pm 5.1$ & $0.0 \pm 0$ & $34.0 \pm 3.0$ & $46.0 \pm 3.9$ & $20.0 \pm 4.3$ \\
\hline $\begin{array}{l}\text { Smokers, } B[a] P \text { treated } \\
(n=3, \text { mean } \pm \text { SE })\end{array}$ & $216.0 \pm 9.4$ & $0.0 \pm 0$ & $22.0 \pm 3.2$ & $40.0 \pm 5.0$ & $38.0 \pm 8.3$ \\
\hline$P$-value & 0.050 & 1.000 & 0.050 & 0.275 & 0.127 \\
\hline
\end{tabular}




\section{Smoker}

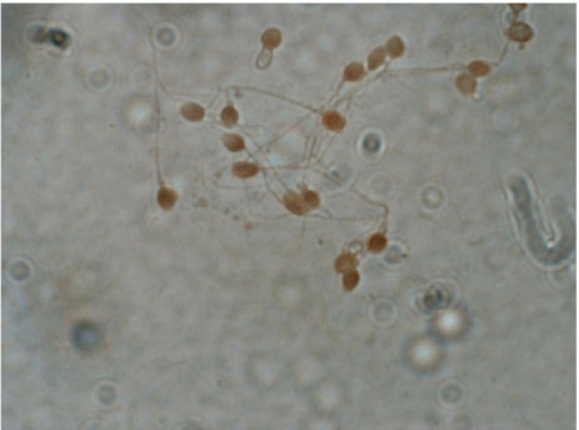

a) Baseline

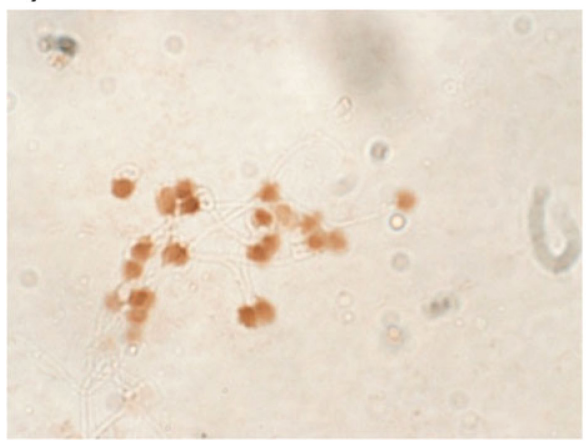

c) $40 \mu \mathrm{M} \mathrm{B}[\mathrm{a}] \mathrm{P}+\mathrm{S} 9 \mathrm{mix}$

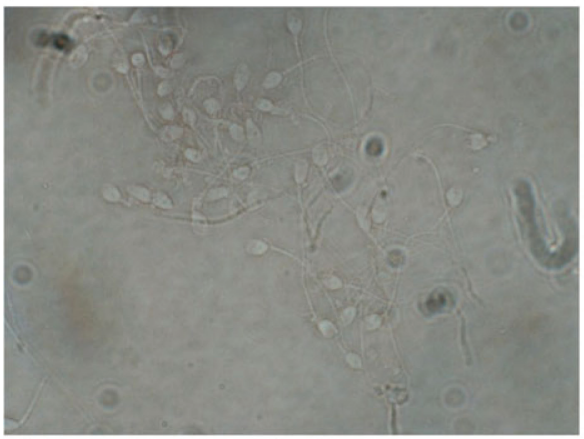

e) Negative control
Non-smoker

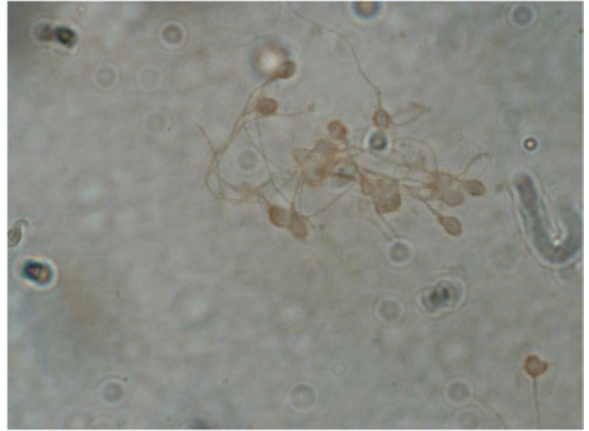

b) Baseline

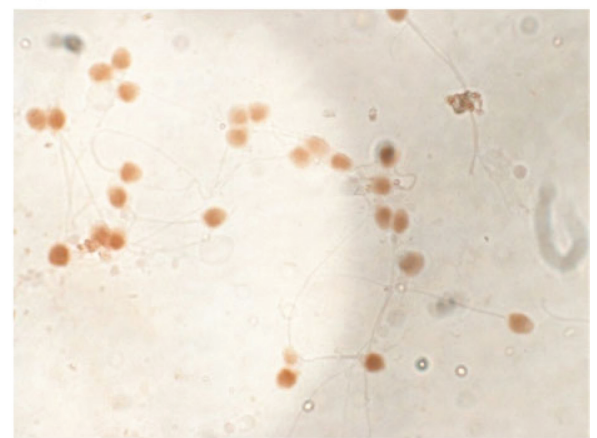

d) $40 \mu \mathrm{M} \mathrm{B}[\mathrm{a}] \mathrm{P}+\mathrm{S} 9 \mathrm{mix}$

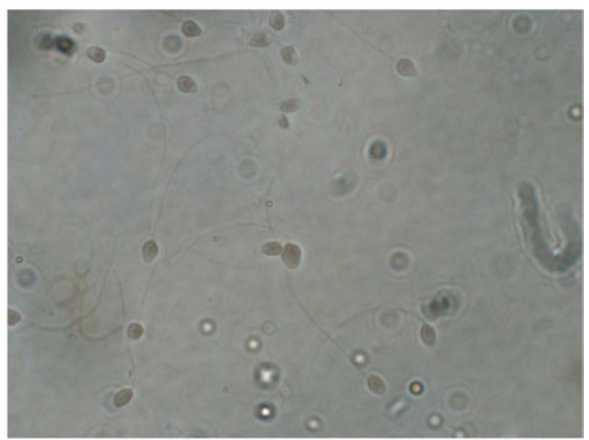

f) Negative control

Figure 4: In situ immunodetection with a monoclonal BPDE-DNA antibody, in sperm from smokers and non-smok-

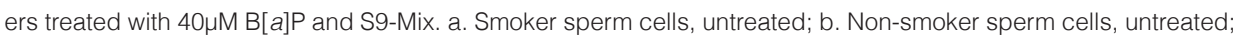

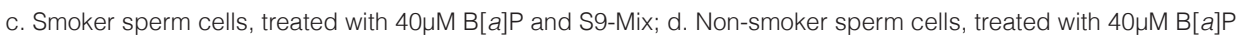
and S9-Mix; e. Control for smoker sperm cells, no primary antibody applied; f. Control for non-smoker sperm cells, no primary antibody applied. 


\section{BPDE adducts analysed with ${ }^{32} \mathrm{P}$ postlabelling in sperm exposed in vitro}

Sperm samples were treated in vitro with 5,10 or $25 \mu \mathrm{M} B[a] P \pm S 9$ mix or 5,20 or $50 \mu \mathrm{M}$ BPDE. DNA was extracted and analysed with the ${ }^{32} \mathrm{P}$ postlabelling technique. No $\mathrm{B}[\mathrm{a}] \mathrm{P}$ induced adducts were detected by ${ }^{32} \mathrm{P}$ postlabelling in samples exposed to either $\mathrm{B}[\mathrm{a}] \mathrm{P}$ or B[a]P plus S9-mix (data not shown). However, BPDE exposure led to a dose-dependent increase in adduct levels; these levels were extremely high and far beyond what is considered to be physiologically relevant (Figure 5).

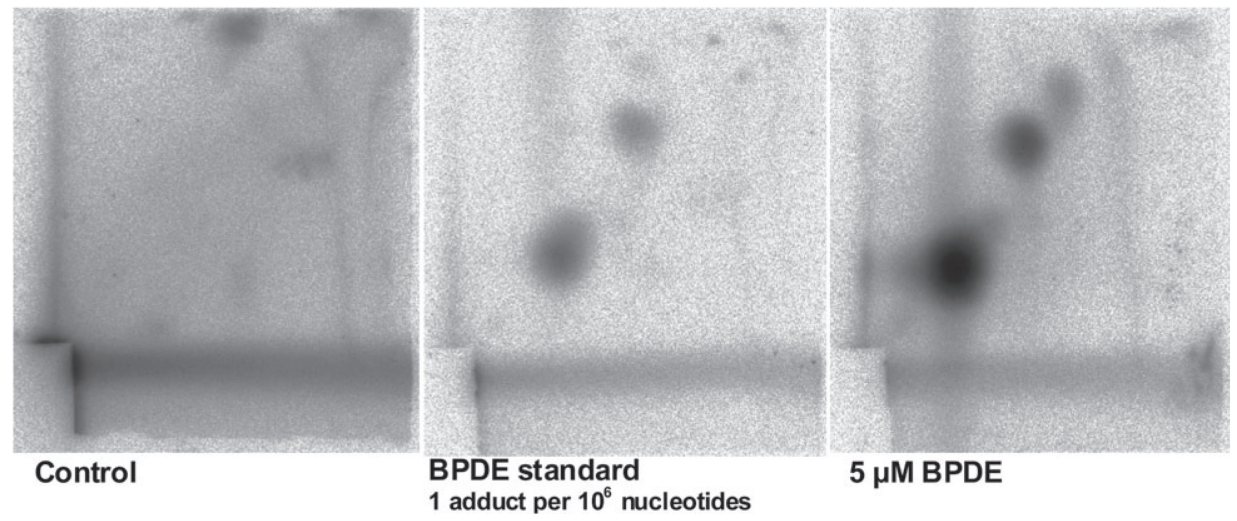

Figure 5: ${ }^{32}$ P-postlabelling analysis of BPDE adducts in sperm cells exposed to 5, 20 or $50 \mu \mathrm{M}$ BPDE. Results for control, BPDE standard, and sperm cells exposed to $5 \mu \mathrm{M}$ BPDE are shown.

\section{HPLC analysis of metabolites after exposure of mature sperm to $\mathrm{B}[\mathrm{a}] \mathrm{P}$}

Mature sperm obtained from an ejaculate is not expected to be able to transform $\mathrm{B}[\mathrm{a}]$ $P$ into reactive metabolites, but the positive results in the comet assay with $B[a] P$ in our study prompted a metabolite analysis by HPLC. Three B[a]P-related metabolites were indeed detectable after $24 \mathrm{~h}$ of incubation of sperm with $10 \mu \mathrm{M} \mathrm{B}[a] \mathrm{P}$ (data not shown). These derivatives could not be chemically identified since they had different retention times as compared to several known metabolites (including 7,8-diol and 9,10-diol B[a]P). The unidentified $\mathrm{B}[\mathrm{a}] \mathrm{P}$ metabolites had retention times very close, but not similar to several known quinones (including 1,6-; 3,6- and 6,12-B[a]P-dione). Although the measured metabolites could not be identified, these results suggest that mature human sperm-or the seminal fluid -is capable of some form of oxidative metabolism of $\mathrm{B}[\mathrm{a}] \mathrm{P}$.

\section{Discussion}

$\mathrm{B}[\mathrm{a}] \mathrm{P}$ has been extensively tested for its adverse effects in a large number of in vitro and in vivo studies and much of its toxicity is well documented. In general, metabolic activation by endogenous enzymes is required for $\mathrm{B}[\mathrm{a}] \mathrm{P}$ to be genotoxic; in particular, the metabolite BPDE is known to interact with biomolecules such as proteins and DNA [34], with new reactive $\mathrm{B}[\mathrm{a}] \mathrm{P}$ metabolites still being discovered [35]. In vivo, some B[a] $P$ activation products probably have sufficient stability to be transported from cells or organs possessing the ability to metabolize $\mathrm{B}[\mathrm{a}] \mathrm{P}$, to cells or tissues lacking such activity [36]. We recently detected adducts in sperm from mice exposed to $\mathrm{B}[\mathrm{a}] \mathrm{P}$ in vivo, strongly 
suggesting that $\mathrm{B}[\mathrm{a}] \mathrm{P}$ activation products had diffused from metabolically competent surrounding tissues [37]. In view of the current understanding of the metabolism of B[a]P, it is expected that there would be little genotoxicity of this compound in various cell types, such as sperm, assumed to be deficient in metabolizing activity when incubated in vitro. However, Anderson et al. have shown genotoxic activities in both lymphocytes as well as sperm, of various compounds generally assumed to require enzymatic activation to be genotoxic [38-43].

DNA damage levels were assessed in $\mathrm{B}[\mathrm{a}] \mathrm{P}$-exposed samples using the alkaline comet assay. Two protocols were employed to validate sperm DNA damage detection in two different laboratories using similar chemical exposure regimens. Contrary to what was expected, we observed a moderate but significantly increased level of DNA damage induced by $\mathrm{B}[\mathrm{a}] \mathrm{P}$. This effect of $\mathrm{B}[\mathrm{a}] \mathrm{P}$ was observed when using Protocol 1 , but not with Protocol 2. Protocol 2 was able to detect DNA damage after treatment with BPDE combined with FPG treatment and also X-ray-induced lesions (at the high doses required when used as a positive control for DNA damage induction in sperm). It is not likely that the different results with the two protocols are related to inter-individual differences, since the response with Protocol 1 was highly uniform for the 11 donors examined. Furthermore, the Protocol 2 experiments included a second donor (data not shown) showing a very similar response to the other donor, to the various treatments (negative to $\mathrm{B}[\mathrm{a}] \mathrm{P} \pm \mathrm{S9}$ ). Russo et al. [44]—using a protocol similar to Protocol 1 to analyse human sperm-reported DNA damage in the absence of S9 (at very high concentrations, 500 $\mu \mathrm{M})$, and increased levels of cellular oxidants were measured. It was suggested that peroxidases present in sperm are important for the oxidative stress induced by B[a]P. A possible factor of importance for the two protocols is the presence of light during in vitro cell exposure. Platt et al. [45]—using the comet Assay—reported that several PAHs (including $\mathrm{B}[\mathrm{a}] \mathrm{P}$ ) were found to induce DNA damage in V79 lung fibroblasts when coexposed to visible light, apparently without a need for metabolic activation. We observed no significant effect of co-exposure of $\mathrm{B}[\mathrm{a}] \mathrm{P}$ and visible light (data not shown).

Using the ${ }^{32} \mathrm{P}$ postlabelling assay, extremely high levels of BPDE-DNA adducts were measured in BPDE-exposed sperm samples (Figure 5). By means of in situ immunodetection using a monoclonal BPDE-DNA antibody, adducts were readily detected also in samples exposed to B[a]P plus S9. This increased staining was not paralleled by ${ }^{32} \mathrm{P}$ postlabelling (data not shown), suggesting the existence of $\mathrm{B}[\mathrm{a}] \mathrm{P}$-related modifications that were recognized by the antibody but could not be detected by ${ }^{32} \mathrm{P}$ postlabelling. The higher immunostaining in smokers versus non-smokers (Figure 4) is in correspondence with the data from Zenzes et al. [10,11,46]. Similarly, the observed higher baseline levels of DNA damage in sperm from smokers compared to non-smokers in the comet assay is in correspondence with the findings of Fraga et al. [47] (Figure 3).

Most bulky DNA adducts induced by B[a]P/BPDE are stable, and they are not detected as DNA breaks in the comet assay in the absence of DNA repair $[48,49]$. In a cell-free system, BPDE reacts with not only DNA forming stable adducts (notably, BPDE-N2-Gua) but also unstable ones including BPDE-N7-guanine, N6-adenine and N3-cytosine $[50,51]$. Unstable lesions caused by chemicals in cells may lead to the formation of ring-opened bases which may in turn be substrates for glycosylases such as FPG [52,53], as has been demonstrated for methyl methanesulfonate [54]. The ultimate level of lesions that are detectable in the comet assay will also be largely affected by the tight packaging of DNA in sperm cells-even after extensive lysis and unwinding, as demonstrated with X-rays.

Taken together, our findings with the different end points seem to mostly correspond with the occurrence and the nature of the various types of lesions induced by BPDE (or $\mathrm{B}[\mathrm{a}] \mathrm{P}$ plus S9). However, the observed effects of $\mathrm{B}[\mathrm{a}] \mathrm{P}$ alone on sperm DNA in vitro using 
Protocol 1 require alternative explanations. The formation of unstable adducts from $\mathrm{B}[\mathrm{a}]$ $P$ is known to occur via a one-electron oxidation; however, both CYP enzymes and aldoketo reductase are needed also for this pathway [34]. An 'untraditional' form of activation of $\mathrm{B}[\mathrm{a}] \mathrm{P}$ therefore seems to be taking place, either via extracellularly or via mitochondria. Some metabolism of $\mathrm{B}[\mathrm{a}] \mathrm{P}$, possibly by mature sperm, was confirmed by the observation of $\mathrm{B}[\mathrm{a}] \mathrm{P}$ related metabolites after an in vitro incubation of sperm with $\mathrm{B}[\mathrm{a}] \mathrm{P}$, and the retention times of these unknown derivatives indicated that they behaved like $B[a] P$ quinones. Quinones are known to generate reactive oxidative species and they have both spermicidal and spermostatic effects [55]. Anderson et al. [56] suggested-based on experiments using the comet assay-that the DNA damage induced by oestrogens in human sperm in vitro may be due to quinone formation. Rivrud [57] described an increased mutagenic activity of $\mathrm{B}[\mathrm{a}] \mathrm{P}$ in the Ames test when seminal fluid was included, suggesting that enzymes in the seminal fluid might be responsible for $\mathrm{B}[\mathrm{a}] \mathrm{P}$ activation. In our comet experiments, the seminal fluid was present during chemical exposures but it was diluted more than 100-fold.

\section{Conclusions}

The presence of DNA adducts in sperm after in vitro B[a]P exposure, as demonstrated with ${ }^{32} \mathrm{P}$ postlabelling or immunostaining, suggests that mature sperm is susceptible to $\mathrm{B}[\mathrm{a}] \mathrm{P}$ adduct induction also when exposed to this compound in vivo. Correspondingly, sperm could possibly be used as a biomarker for exposure to environmental chemicals, both for the individual and at the group level. Differences in biomarker levels may then be attributed to environmental and/or lifestyle factors, which could ultimately be related to fertility and the genetic integrity of sperm.

Despite the very high sensitivity of ${ }^{32} \mathrm{P}$ postlabelling and immunostaining, these techniques are time consuming. The comet assay is quick and low cost and has been made more suitable for cohort studies through the EC FP6 NewGeneris project (http:// www.newgeneris.org/). The differing results obtained using the two separate comet assay protocols emphasize the need for a standardized experimental procedure when applied to sperm [19]. The observation of higher levels of baseline sperm DNA damage in smokers versus non-smokers suggests that lesions induced during spermatogenesis may be specifically measured using the comet assay.

\section{Funding}

Funding to pay the Open Access publication charges for this article was provided by the European Union 6th Framework Programme, Priority 5: 'Food Quality and Safety' [NewGeneris (Newborns and Genotoxic exposure risks; Contract No 016320-2].

\section{Acknowledgements}




\section{References}

1. Pelkonen, O. and Nebert, D. W. (1982) Metabolism of polycyclic aromatic hydrocarbons: etiologic role in carcinogenesis. Pharmacol. Rev., 34, 189-222.

2. Xue, W. and Warshawsky, D. (2005) Metabolic activation of polycyclic and heterocyclic aromatic hydrocarbons and DNA damage: a review. Toxicol. Appl. Pharmacol., 206, 73-93.

3. Jeffrey, A. M., Weinstein, I. B., Jennette, K. W. et al. (1977) Structures of benzo(a)pyrene-nucleic acid adducts formed in human and bovine bronchial explants. Nature, 269, 348-350.

4. Gao, D., Luo, Y., Guevara, D. et al. (2005) Benzo[a]pyrene and its metabolites combined with ultraviolet $A$ synergistically induce 8-hydroxy-2'-deoxyguanosine via reactive oxygen species. Free Radic. Biol. Med., 39, 1177-1183.

5. Denissenko, M. F., Pao, A., Tang, M. et al. (1996) Preferential formation of benzo[a]pyrene adducts at lung cancer mutational hotspots in P53. Science, 274, 430-432.

6. Eastman, A. and Barry, M. A. (1992) The origins of DNA breaks: a consequence of DNA damage, DNA repair, or apoptosis? Cancer Invest., 10, 229-240.

7. Li, D., Wang, M., Dhingra, K. et al. (1996) Aromatic DNA adducts in adjacent tissues of breast cancer patients: clues to breast cancer etiology. Cancer Res., 56, 287-293.

8. Penning, T. M. (2004) Aldo-keto reductases and formation of polycyclic aromatic hydrocarbon o-quinones. Methods Enzymol., 378, 31-67.

9. Xia, Y., Zhu, P., Han, Y. et al. (2009) Urinary metabolites of polycyclic aromatic hydrocarbons in relation to idiopathic male infertility. Hum. Reprod., 24, 1067-1074.

10. Zenzes, M. T., Puy, L. A., Bielecki, R. et al. (1999) Detection of benzo[a]pyrene diol epoxide-DNA adducts in embryos from smoking couples: evidence for transmission by spermatozoa. Mol. Hum. Reprod., 5, 125-131.

11. Zenzes, M. T., Bielecki, R. and Reed, T. E. (1999) Detection of benzo(a)pyrene diol epoxide-DNA adducts in sperm of men exposed to cigarette smoke. Fertil. Steril., 72, 330-335.

12. Tice, R. R., Agurell, E., Anderson, D. et al. (2000) Single cell gel/comet assay: guidelines for in vitro and in vivo genetic toxicology testing. Environ. Mol. Mutagen., 35, 206-221.

13. Dusinska, M. and Collins, A. R. (2008) The comet assay in human biomonitoring: gene-environment interactions. Mutagenesis, 23, 191-205.

14. Cordelli, E., Fresegna, A. M., D'Alessio, A. et al. (2007) ReProComet: a new in vitro method to assess DNA damage in mammalian sperm. Toxicol. Sci., 99, 545-552.

15. Thorne, D., Wilson, J., Kumaravel, T. S. et al. (2009) Measurement of oxidative DNA damage induced by mainstream cigarette smoke in cultured NCl-H292 human pulmonary carcinoma cells. Mutat. Res., 673, 3-8.

16. Collins, A. R., Duthie, S. J. and Dobson, V. L. (1993) Direct enzymic detection of endogenous oxidative base damage in human lymphocyte DNA. Carcinogenesis, 14, 1733-1735.

17. Collins, A. R., Dusinska, M., Gedik, C. M. et al. (1996) Oxidative damage to DNA: do we have a reliable biomarker? Environ. Health Perspect., 104 (Suppl. 3), 465-469.

18. Collins, A., Dusinska, M., Franklin, M. et al. (1997) Comet assay in human biomonitoring studies: reliability, validation, and applications. Environ. Mol. Mutagen., 30, 139-146.

19. Baumgartner, A., Cemeli, E. and Anderson, D. (2009) The comet assay in male reproductive toxicology. Cell Biol. Toxicol., 25, 81-98.

20. Lewis, S. E. and Agbaje, I. M. (2008) Using the alkaline comet assay in prognostic tests for male infertility and assisted reproductive technology outcomes. Mutagenesis, 23, 163-170.

21. Chandley, A. C. (1991) On the parental origin of Denovo mutation in man. Journal of Medical Genetics, 28, 217-223.

22. Olsen, A. K., Bjortuft, H., Wiger, R. et al. (2001) Highly efficient base excision repair (BER) in human and rat male germ cells. Nucleic Acids Res., 29, 1781-1790.

23. Olsen, A. K., Duale, N., Bjoras, M. et al. (2003) Limited repair of 8-hydroxy-7,8-dihydroguanine residues in human testicular cells. Nucleic Acids Res., 31, 1351-1363.

24. Olsen, A. K., Lindeman, B., Wiger, R. et al. (2005) How do male germ cells handle DNA damage? Toxicol. Appl. Pharmacol., 207, 521-531. 
25. Holstein, A. F., Schulze, W. and Davidoff, M. (2003) Understanding spermatogenesis is a prerequisite for treatment. Reprod. Biol. Endocrinol., 1, 107.

26. Jansen, J., Olsen, A. K., Wiger, R. et al. (2001) Nucleotide excision repair in rat male germ cells: low level of repair in intact cells contrasts with high dual incision activity in vitro. Nucleic Acids Res., 29, 1791-1800.

27. Marchetti, F. and Wyrobek, A. J. (2005) Mechanisms and consequences of paternally-transmitted chromosomal abnormalities. Birth Defects Res. C Embryo Today, 75, 112-129.

28. Ward, W. S. and Coffey, D. S. (1991) DNA packaging and organization in mammalian spermatozoa: comparison with somatic cells. Biol. Reprod., 44, 569-574.

29. van Leeuwen, D. M., Gottschalk, R. W., van Herwijnen, M. H. et al. (2005) Differential gene expression in human peripheral blood mononuclear cells induced by cigarette smoke and its constituents. Toxicol. Sci., 86, 200-210.

30. Singh, N. P., McCoy, M. T., Tice, R. R. et al. (1988) A simple technique for quantitation of low levels of DNA damage in individual cells. Exp. Cell Res., 175, 184-191.

31. Agbaje, I. M., Rogers, D. A., McVicar, C. M. et al. (2007) Insulin dependant diabetes mellitus: implications for male reproductive function. Hum. Reprod., 22, 1871-1877.

32. Santella, R. M., Lin, C. D., Cleveland, W. L. et al. (1984) Monoclonal antibodies to DNA modified by a benzo[a] pyrene diol epoxide. Carcinogenesis, 5, 373-377.

33. Godschalk, R. W., Ostertag, J. U., Moonen, E. J. et al. (1998) Aromatic DNA adducts in human white blood cells and skin after dermal application of coal tar. Cancer Epidemiol. Biomarkers Prev., 7, 767-773.

34. Godschalk, R. W., van Schooten, F. J. and Bartsch, H. (2003) A critical evaluation of DNA adducts as biological markers for human exposure to polycyclic aromatic compounds. J Biochem. Mol. Biol., 36, 1-11.

35. Sagredo, C., Olsen, R., Greibrokk, T. et al. (2006) Epimerization and stability of two new cis-benzo[a]pyrene tetrols by the use of liquid chromatography-fluorescence and mass spectrometry. Chem. Res. Toxicol., 19, 392-398.

36. Ginsberg, G. L. and Atherholt, T. B. (1989) Transport of DNA-adducting metabolites in mouse serum following benzo[a]pyrene administration. Carcinogenesis, 10, 673-679.

37. Verhofstad,N., van Oostrom, C. T., van, B. J. et al. (2010)DNAadduct kinetics in reproductive tissues of DNA repair proficient and deficient male mice after oral exposure to benzo(a)pyrene. Environ. Mol. Mutagen., 51, 123-129.

38. Anderson, D., Dobrzynska, M. M., Yu, T. W. et al. (1997) DNA integrity in human sperm. Teratog. Carcinog. Mutagen., 17, 97-102.

39. Anderson, D., Basaran, N., Dobrzynska, M. M. et al. (1997) Modulating effects of flavonoids on food mutagens in human blood and sperm samples in the comet assay. Teratog. Carcinog. Mutagen., 17, 45-58.

40. Anderson, D., Dobrzynska, M. M. and Basaran, N. (1997) Effect of various genotoxins and reproductive toxins in human lymphocytes and sperm in the Comet assay. Teratog. Carcinog. Mutagen., 17, 29-43.

41. Najafzadeh, M., Reynolds, P. D., Baumgartner, A. et al. (2009) Flavonoids inhibit the genotoxicity of hydrogen peroxide $(\mathrm{H}(2) \mathrm{O}(2))$ and of the food mutagen 2-amino-3-methylimadazo[4,5-f]-quinoline $(\mathrm{IQ})$ in lymphocytes from patients with inflammatory bowel disease (IBD). Mutagenesis, 24, 405-411.

42. Ruf, A. A., Webb, J. and Anderson, D. (2003) Modulation by flavonoids of the effects of a food mutagen in different thalassaemia genotypes in the Comet assay. Teratog. Carcinog. Mutagen., (Suppl. 2), 93-102.

43. Ruf, A. A., Jerwood, D., Webb, J. et al. (2003) Sensitivity of different thalassaemia genotypes to food mutagens in the Comet assay. Teratog. Carcinog. Mutagen., (Suppl. 2), 83-91.

44. Russo, A., Troncoso, N., Sanchez, F. et al. (2006) Propolis protects human spermatozoa from DNA damage caused by benzo[a]pyrene and exogenous reactive oxygen species. Life Sci., 78, 1401-1406.

45. Platt, K. L., Aderhold, S., Kulpe, K. et al. (2008) Unexpected DNA damage caused by polycyclic aromatic hydrocarbons under standard laboratory conditions. Mutat. Res., 650, 96-103.

46. Zenzes, M. T. (2000) Smoking and reproduction: gene damage to human gametes and embryos. Hum. Reprod. Update., 6, 122-131.

47. Fraga, C. G., Motchnik, P. A., Wyrobek, A. J. et al. (1996) Smoking and low antioxidant levels increase oxidative damage to sperm DNA. Mutat. Res., 351, 199-203.

48. Speit, G., Schutz, P. and Hoffmann, H. (2004) Enhancement of genotoxic effects in the comet assay with human blood samples by aphidicolin. Toxicol. Lett., 153, 303-310. 
49. Speit, G. and Hartmann, A. (1995) The contribution of excision repair to the DNA effects seen in the alkaline single cell gel test (comet assay). Mutagenesis, 10, 555-559.

50. Osborne, M. R., Harvey, R. G. and Brookes, P. (1978) The reaction of trans-7,8-dihydroxy-anti-9,10-epoxy7,8,9,10-tetrahydrobenzo(a)pyrene with DNA involves attack at the N7-position of guanine moieties. Chem. Biol. Interact., 20, 123-130.

51. Osborne, M. R., Jacobs, S., Harvey, R. G. et al. (1981) Minor products from the reaction of ( $p$ ) and (-) benzo[a]pyrene-anti-diolepoxide with DNA. Carcinogenesis, 2, 553-558.

52. Chetsanga, C. J. and Frenette, G. P. (1983) Excision of aflatoxin B1-imidazole ring opened guanine adducts from DNA by formamidopyrimidine-DNA glycosylase. Carcinogenesis, 4, 997-1000.

53. Tudek, B. (2003) Imidazole ring-opened DNA purines and their biological significance. J. Biochem. Mol. Biol., 36, 12-19.

54. Speit, G., Schutz, P., Bonzheim, I. et al. (2004) Sensitivity of the FPG protein towards alkylation damage in the comet assay. Toxicol. Lett., 146, 151-158.

55. Hughes, L. M., Griffith, R., Carey, A. et al. (2009) The spermostatic and microbicidal actions of quinones and maleimides: toward a dual-purpose contraceptive agent. Mol. Pharmacol., 76, 113-124.

56. Anderson, D., Schmid, T. E., Baumgartner, A. et al. (2003) Oestrogenic compounds and oxidative stress (in human sperm and lymphocytes in the Comet assay). Mutat. Res., 544, 173-178.

57. Rivrud, G. N. (1988) Mutagenicity testing of seminal fluid: seminal fluid increases the mutagenicity of the precursor mutagen benzo[a]pyrene in the presence of S9 mix. Mutat. Res., 208, 195-200. 

Reproductive Toxicology (2011) Jul;32(1):106 - 11

Joost O. Linschooten

Julian Laubenthal

Eduardo Cemeli

Adolf Baumgartner

Diana Anderson Ville E. Sipinen

Gunnar Brunborg

Guido R.M.M. Haenen

Eleni Fthenou

Jacob J. Briedé

Frederik J. van Schooten

Roger W.L. Godschalk 


\section{Abstract}

Although DNA damage in human spermatozoa is associated with adverse health effects, its origin is not fully understood. Therefore, we assessed biomarkers in ejaculates that retrospectively reflect processes that occurred in the epididymis or testis. Smoking increased the amount of DNA strand breaks $(p<0.01)$, and enhanced the presence of vitamin $C$ radicals in seminal plasma. In vitro, vitamin $C$ protected mature spermatozoa against DNA damage, but this protection appeared to be insufficient in vivo. CAT and DDIT4 expression in spermatozoa were higher in smokers than in non-smokers, but were not related to DNA damage. CAT and DDIT4 expression were inversely related with sperm count ( $p=0.039$ and 0.024 resp.), but no effect was observed for SOD2 expression. These data indicate that spermatozoa of smokers encounter higher levels of oxidative stress. Expression of antioxidant enzymes and seminal vitamin $\mathrm{C}$ were insufficient to provide full protection of spermatozoa against DNA damage. 


\section{Introduction}

Exposure to genotoxic agents causes DNA damage in somatic cells and in germ cells. DNA damage in somatic cells can be repaired by a number of DNA repair mechanisms, whereas in mature male germ cells these systems are thought to be largely inactive. Exposure to genotoxicants may thus have an influence on DNA integrity in male reproductive cells, putting future progeny at risk for developmental defects and diseases later in life. One major source of exposure to genotoxicants is cigarette smoking, which is known to induce DNA strand breaks in sperm [1]. An increased number of sperm cells with high levels of DNA damage in the ejaculate of smokers may result from the formation of reactive oxygen species (ROS) [2], but could also arise via inhibition of apoptosis during spermatogenesis leading to the accumulation of damaged cells in the ejaculate [3]. Although oxidative stress can result in several types of DNA damage [4], it cannot be considered only as adverse effects for spermatogenesis; oxidative stress is also needed for several sperm specific physiological processes such as capacitation, the acrosome reaction and sperm-oocyte fusion [5]. However, during an overwhelming production of ROS, the antioxidant defence system of spermatozoa and seminal plasma might be overrun, which will subsequently lead to accumulation of DNA damage.

It was reported that high levels of seminal ROS are detected in $25 \%$ to $40 \%$ of infertile men [6]. Several studies have investigated how ROS can induce damage to spermatozoa, and why excessive levels of ROS are dangerous to the sperm; the sperm plasma membrane contains high concentrations of polyunsaturated fatty acids, which are vulnerable to attack by ROS to elicit lipid peroxidation [7]. Furthermore, ROS are able to directly interact with DNA [8,9], leading to oxidative DNA damage and DNA fragmentation, which is commonly observed in spermatozoa of infertile men [6].

Smoking has been shown to increase ROS formation in male germ cells; it is therefore likely that the risk of an imbalance between oxidants and anti-oxidants leading to oxidative stress in smokers is higher compared to non-smokers. Fraga et al. showed that smoking in combination with low antioxidant levels causes an increase in oxidative damage to sperm DNA [10]. However, high levels of ROS will not necessarily lead to increased levels of DNA damage. In mature spermatozoa, DNA is very tightly packed due to the replacement of histones with protamines during maturation and is therefore less accessible for DNA damaging agents [11]. There is also an anti-oxidative protective role of seminal plasma, which contains anti-oxidant enzymes and high concentrations of vitamin C (ca. $0.5 \mathrm{mM}$ ), which could protect sperm against excessive levels of ROS. Additionally, during spermatogenesis anti-oxidant enzymes are expressed, of which catalase (CAT), superoxide dismutase 2 (SOD2) and DNA damage inducible transcript 4 (DDIT4, also known as REDD1, RTP801 or DIG1) may be of particular interest, because they regulate the cells own production of ROS in mitochondria, which plays a central role in cellular energy production and redox status [12].

Spermatozoa containing abnormal levels of DNA damage may become apoptotic to prevent these cells from entering the ejaculate. Since DNA repair activity is largely absent in spermatozoa, apoptosis seems the only mechanism with which abnormal cells can be removed. However, our group has previously shown using gene expression profiles obtained from spermatozoal mRNA that it is in fact anti-apoptosis which is promoted in smoking subjects [3]. As a result, a higher number of cells containing high levels of DNA damage will be present in the ejaculate. In that particular study, a sperm specific transcription factor was identified to be significantly up-regulated in sperm from cigarette smokers; STON1-GTF2A1L (also known as SALF). SALFmRNA is a read-through product of the neighboring STON1 and GTF2A1L genes and its expression is specific for sperm. Although the significance of its protein product has yet to be determined, it is thought 
to stabilize the binding of TATA box binding proteins (TBP) to DNA. Since SALF is upregulated in smokers, it may represent an important transcription factor to regulate the stress response during spermatogenesis.

Thus, it can be concluded that ROS-induced DNA damage detectable in sperm will represent the net effect of radical formation and scavenging, DNA damage formation and removal by DNA repair (at cell stages at which DNA repair is still effective) and/or apoptosis. We have therefore studied DNA damage, vitamin C concentrations and its radical in seminal plasma and the expression of several relevant enzymes (CAT, SOD2, DDIT4 and SALF) in 21 sperm samples from healthy fertile smoking $(\mathrm{N}=12)$ and nonsmoking $(\mathrm{N}=9)$ men, to better understand the interaction between these parameters in determining the amount of DNA damage in mature spermatozoa.

\section{Materials \& Methods}

\section{Sample collection}

Twenty-one sperm samples were available after collection and analysis of semen quality according to WHO guidelines (1999), performed at The Crete University, Greece. After giving their informed consent, all subjects provided an ejaculate by masturbation. Each semen sample was processed within $2 \mathrm{~h}$ and analyzed for sperm quality parameters. Semen samples were aliquoted, snap-frozen in liquid nitrogen and subsequently stored at $-80{ }^{\circ} \mathrm{C}$ until analysis. Fertility of all fathers was furthermore proven by the recent birth of a child. All participants filled in a questionnaire on daily average diet, occupation and smoking habits at the same day the sample was provided. Ethical approval has been granted by the University of Bradford's Sub-Committee for Ethics in Research involving Human Subjects (Reference no: 0405/8).

\section{In vitro exposure of sperm to $\mathrm{H}_{2} \mathrm{O}_{2}$ with or without vitamin $\mathrm{C}$}

Sperm samples of 2 additional healthy, non-smoking volunteers were collected and in vitro exposed to $80 \mu \mathrm{M} \mathrm{H}_{2} \mathrm{O}_{2}$, with or without 0.5 or $1.0 \mathrm{mM}$ vitamin C. After exposure sperm samples were centrifuged for 10 minutes at 450xg at room temperature. From the resuspended pellet $100 \mu \mathrm{l}$ was mixed immediately $1: 1$ with $2 \%$ LMP agarose for comet assay. From every sample, two slides were prepared. DNA damage induced by $\mathrm{H}_{2} \mathrm{O}_{2}$ and the protective effects of vitamin $\mathrm{C}$ were then assessed with the comet assay.

\section{Comet assay}

The comet protocol is based on Singh and colleagues [13], with modifications as provided by Sipinen et al. [1]. Sperm samples were centrifuged for 10 minutes at 450xg at room temperature, resuspended in cold PBS and kept on ice until mixed 1:1 with $2 \%$ low melting point agarose. The samples were subsequently casted onto standard glass slides pre-coated with $1 \%$ normal melting-point agarose. Cell lysis was achieved through submerging the slides in two consecutive lysis solutions: a) Lysis buffer (2.5 M NaCl, $100 \mathrm{mM} \mathrm{Na}{ }_{2}$ EDTA, $10 \mathrm{mM}$ Trizma ${ }^{\circledR}$ base, 1\% Triton X-100, pH 10) containing $10 \mathrm{mM}$ dithiothreitol (DTT) for $60 \mathrm{~min}$ at $4{ }^{\circ} \mathrm{C}$; b) Lysis buffer containing $0.05 \mathrm{mg} / \mathrm{ml}$ proteinase $\mathrm{K}$ for 60 minutes at $4{ }^{\circ} \mathrm{C}$. After lysis, the slides were incubated in electrophoresis buffer (300 mM NaOH, $1 \mathrm{mM} \mathrm{Na} 2$ EDTA, pH 13.2) at $4{ }^{\circ} \mathrm{C}$ for 20 min to unwind DNA and then 
subjected to electrophoresis at $25 \mathrm{~V}(0.8 \mathrm{~V} / \mathrm{cm}$ on platform, $300 \mathrm{~mA})$ for $20 \mathrm{~min}$ at $4{ }^{\circ} \mathrm{C}$. Prior to staining with ethidium bromide $(20 \mu \mathrm{g} / \mathrm{ml})$ for $10 \mathrm{~min}$, the slides were neutralised (0.4 M Trizma $\AA$ base, $\mathrm{pH}$ 7.5) three times for 5 minutes each. Comet visualisation and scoring was performed with a Leica fluorescence microscope equipped with a CCDcamera using the image analysis software "Komet 4" from Kinetic Imaging Ltd.

\section{Vitamin C concentration in seminal plasma}

Total vitamin $\mathrm{C}$ concentration in seminal plasma was determined as described by Boots et al. [14]. A volume of $250 \mu \mathrm{l}$ cell-free seminal plasma was deproteinized using $10 \%$ trichloroacetic acid (TCA) (1:4) followed by centrifugation $\left(14,000 \times \mathrm{g}, 5\right.$ min at $4{ }^{\circ} \mathrm{C}$ ). All samples were stored at $-20^{\circ} \mathrm{C}$ prior to analysis. Standards were prepared freshly, containing the same amount of TCA as the samples. Samples were thawed and centrifuged $\left(14,000 \times \mathrm{g}, 10 \mathrm{~min}\right.$ at $\left.4{ }^{\circ} \mathrm{C}\right)$ after which the supernatant was added to a $4.5 \mathrm{M}$ sodium acetate buffer ( $\mathrm{pH}$ 6.2), containing an ascorbate oxidase spatula, and incubated for $5 \mathrm{~min}$ at $37^{\circ} \mathrm{C}$. Subsequently, the spatula was removed and $0.1 \%$ (w:v) o-phenylene diamine (OPDA) was added. After mixing, the samples were incubated for 30 min at 37 ${ }^{\circ} \mathrm{C}$. Afterwards, the samples were injected into an HPLC system. HPLC analysis of the samples was performed using a Hypersil BDS column (125 mm $\times 2 \mathrm{~mm}$ ). The column was eluted isocratically with eluens containing $20 \%$ methanol and $80 \%$ potassium phosphate buffer using a fluorescence detector with $355 \mathrm{~nm}$ as excitation and $425 \mathrm{~nm}$ as emission wavelengths [15].

\section{Electron spin resonance spectroscopy measurements}

After centrifugation of the semen samples (5 min at $8,000 \times \mathrm{g}$ ) the seminal plasma was separated from the sperm cell pellet. Cell pellets were used for RNA isolation. Seminal plasma was transferred to new tubes and stored at $-20^{\circ} \mathrm{C}$ until analysis. ESR spectra were recorded at room temperature in a Bruker EMX 1273 spectrometer equipped with an ER $4119 \mathrm{HS}$ high sensitivity resonator and $12 \mathrm{~kW}$ power supply operating at X-band frequencies. The modulation frequency of the spectrometer was $100 \mathrm{kHz}$. Instrumental conditions for the recorded spectra were as follows: magnetic field, $3490 \mathrm{G}$; scan range, $100 \mathrm{G}$; modulation amplitude, $1 \mathrm{G}$; receiver gain, $1 \times 10^{4}$; microwave frequency, 9.85 $\mathrm{GHz}$; power, 50 mW; time constant, $40.96 \mathrm{~ms}$; scan time, $20.97 \mathrm{~s}$; number of scans, 35. Quantification of the spectra was performed by peak surface measurements through double integration of the ESR spectrum using the WIN-EPR spectrum manipulation program (Bruker BioSpin, Wormer, The Netherlands). Control experiments indicated that the ESR signal of the vitamin $\mathrm{C}$ radical was reduced by freeze-thaw cycles. Therefore, care was taken to assure that all samples had the same number of freeze-thaw cycles. After thawing, samples were stored on ice and the ESR-signals were stable for the whole experiment as assessed by repeated measurement of the same sample.

\section{RNA isolation and cDNA synthesis}

Prior to RNA isolation from spermatozoa, somatic cells in the ejaculate were lysed using $0.1 \%$ SDS and $0.5 \%$ Triton-X, as described by Goodrich et al. [16] with minor modifications. From previous studies it is known that this lysis is sufficient to remove all somatic cells and continue with the spermatozoal cells only [3]. Lysis was followed with an additional washing step in lysis buffer, and the cells were subsequently resuspended in Qiazol solution (Qiagen Westburg bv., Leusden, the Netherlands), according to the 
producers' manuals. From these solutions RNA was isolated using a RNeasy Minelute kit (Qiagen Westburg bv., Leusden, the Netherlands). RNA concentrations were measured spectrophotometrically using a Nanodrop spectrophotometer (Nanodrop technologies, Wilmington, USA). From each sample, $200 \mathrm{ng}$ of RNA was used for cDNA synthesis in combination with the iScript cDNA Synthesis kit (Bio-Rad Laboratories, Hercules, CA). cDNA was stored at $-20{ }^{\circ} \mathrm{C}$ until use. RNA integrity could not be checked by standard procedures, since it is known that spermatozoal RNA is fragmented and does not contain the $18 \mathrm{~S}$ and $28 \mathrm{~S}$ ribosomal subunits. Nevertheless, it has been shown that short sequences could still be amplified [3]; the expression of the sperm specific gene protamine 2 ( $P R M 2$ ) was therefore used as a control for RNA integrity.

\section{Real-time PCR}

RT-PCR reactions were carried out using iQ SYBR Green Supermix, which contains iTaq DNA Polymerase, deoxynucleoside triphosphates, $\mathrm{MgCl}_{2}$ and SYBR Green I (Bio-Rad laboratories). The cDNA was 10 times diluted before analysis and an amount of $5 \mu l$ sample was added to each reaction well, and all samples were measured in duplicate. Samples were analysed on a MyiQ Single-Colour Real-Time PCR detection System (BioRad laboratories), using the following parameters: 3 min at $95^{\circ} \mathrm{C}, 40$ cycles at $95^{\circ} \mathrm{C}$ for $15 \mathrm{~s}$ and at $60{ }^{\circ} \mathrm{C}$ for $45 \mathrm{~s}$. Protamine 2, a sperm specific protein, was selected as reference gene. The PRM2 normalized values were used to calculate differences in gene expression levels in all samples. Samples were analyzed for the expression of CAT, SOD2, DDIT4 and SALF and data were analyzed using the MyiQ software system (BioRad laboratories). Expression of these genes in smokers was calculated using the $2^{-\Delta \Delta C t}$ method. After calculation of average Ct values of each samples' duplicates, $\Delta$ Ct values were calculated using PRM2 as reference gene. Subsequently, the geometric mean of this $\Delta \mathrm{Ct}$ was calculated for non-smokers and this value was subtracted from all $\Delta \mathrm{Ct}$ values (as a result, average $\Delta \Delta \mathrm{Ct}$ in non-smokers will be 0 ). Finally, this $\Delta \Delta \mathrm{Ct}$ was used to calculate the fold change by using the formula $2^{-\Delta \Delta c t}$ (in non-smokers $2^{0}=1=$ reference).

\section{Statistical analysis}

Data are presented as mean \pm standard error. All spermatozoal parameters were analysed using SPSS $15.0^{\circ}$ and tested for significance using independent samples $t$-tests. The level of significance is $p<0.05$.

\section{Results}

\section{Characteristics of study population}

A total number of 21 fertile subjects living in Crete gave their informed consent and all samples were analyzed according to WHO guidelines for semen analyses (results shown in table I). Among these 21 samples a total number of 12 were smokers or stopped smoking very recently and 9 non-smokers or long-term ex-smokers (stopped smoking for $>5$ years). None of the variables on sperm quality differed significantly between smokers and non-smokers. Vitamin C concentrations in the seminal plasma were comparable to normal physiological levels [17] and no differences were found between smokers and non-smokers. Regarding the amount of DNA damage in sperm, smokers' sperm 
contained more damage as determined by the comet assay (\% DNA in tail), than nonsmokers' sperm $(p<0.01)$, as shown in table I.

Table I: Characteristics of study population

\begin{tabular}{llll}
\hline Variable & All $(n=21)$ & Non-smokers $(n=9)$ & Smokers $(n=12)$ \\
\hline Age (years) & $32.9 \pm 1.0$ & $34.4 \pm 1.4$ & $31.8 \pm 1.3$ \\
Cigarettes per day & $3.7 \pm 0.5$ & $0 \pm 0$ & $3.7 \pm 0.5^{*}$ \\
Abstinence (days) & $4.2 \pm 0.3$ & $4.7 \pm 0.5$ & $3.8 \pm 0.4$ \\
\hline Sperm quality data & & & \\
\hline Sperm concentration $\left(\times 10^{6} \mathrm{cells} / \mathrm{ml}\right)$ & $31.2 \pm 6.5$ & $35.7 \pm 12.2$ & $27.9 \pm 7.2$ \\
pH & $8.8 \pm 0.1$ & $8.8 \pm 0.1$ & $8.8 \pm 0.1$ \\
Motility & $48 / 10 / 7 / 35$ & $51 / 10 / 7 / 33$ & $44 / 10 / 8 / 39$ \\
Morphology (\% normal) & $80.3 \pm 1.9$ & $79.8 \pm 3.2$ & $81.0 \pm 2.4$ \\
\hline Other parameters & & & $478 \pm 55$ \\
\hline Seminal vitamin C levels $(\mu M)$ & $448 \pm 54$ & $408 \pm 105$ & $30.8 \pm 1.4^{\star *}$ \\
DNA fragmentation $(\%$ DNA in tail) & $27.9 \pm 1.2$ & $24.1 \pm 1.3$ & \\
\hline
\end{tabular}

Average values \pm SE of the mean are shown. Comet experiments were repeated three times for each donor. Spermiograms were scored manually.

a Motility format: 3/2/1/0 in average percentages, with $3=$ fast-progressive; 2 = slow-progressive; $1=$ nonprogressive, but tail movement; 0 = immobile, no tail movement.

*: P-value $<0.05$ as compared to non-smokers

**: P-value $<0.01$ as compared to non-smokers

\section{In vitro data comet exposure to $\mathrm{H}_{2} \mathrm{O}_{2}$ with or without the addition of vitamin C}

The baseline levels of DNA damage in mature spermatozoa obtained from ejaculates from 2 individuals were approximately $20 \%$ tail DNA, as measured by the comet assay (figure 1). Addition of $0.5 \mathrm{mM}$ or $1.0 \mathrm{mM}$ vitamin $\mathrm{C}$ did not significantly change these DNA damage levels. After treatment of the spermatozoa with $80 \mu \mathrm{M} \mathrm{H}_{2} \mathrm{O}_{2}$, there was a significant increase in \% tail DNA indicating increased DNA damage. However, when the cells were exposed to hydrogen peroxide in the presence of $0.5 \mathrm{mM}$ vitamin $\mathrm{C}$ the DNA damage levels were significantly reduced. Enhancing the concentration of vitamin $\mathrm{C}$ to $1 \mathrm{mM}$ did not further reduce the amount of DNA damage. These results suggest that vitamin $\mathrm{C}$ is able to scavenge ROS thereby protecting the germ cells against oxidative stress. 


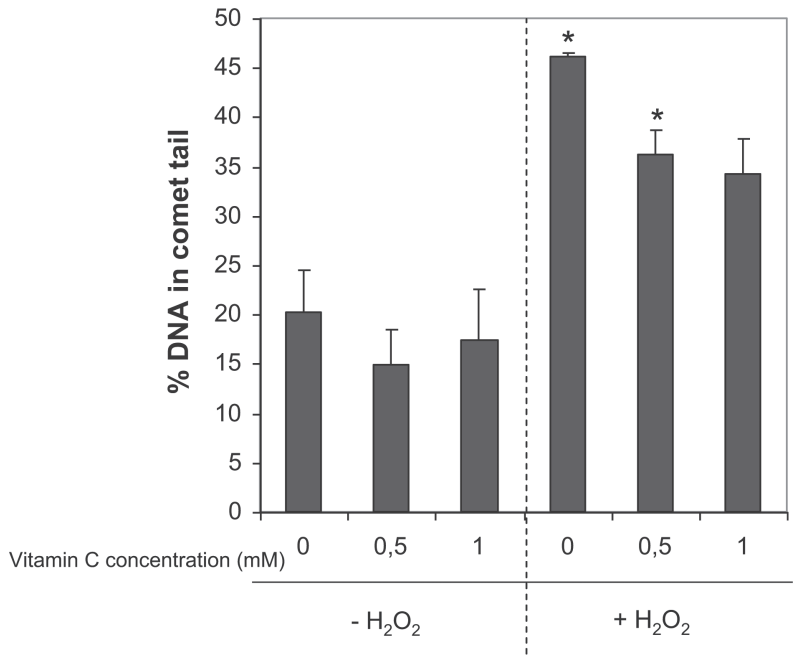

Figure 1: DNA damage determined by the comet assay in sperm exposed to $80 \mu \mathrm{M} \mathrm{H}_{2} \mathrm{O}_{2}$, with or without the addition of 0.5 or $1.0 \mathrm{mM}$ vitamin $\mathrm{C}$. Values are presented as mean \% tail DNA $\pm 1 \mathrm{SD}$. ${ }^{*} p<0.05$ as compared to incubation without vitamin C. Experiments were repeated twice for each donor and each exposure dose.

After in vitro exposure of the samples obtained from our study population from Crete to $40 \mu \mathrm{M} \mathrm{H}_{2} \mathrm{O}_{2}$, there was a statistically significant increase of $6.40 \pm 2.07 \%$ tail DNA $(p<$ 0.05). Although initial DNA damage levels in smokers were significantly higher than in non-smoking subjects, the increase in DNA damage by $\mathrm{H}_{2} \mathrm{O}_{2}$ exposure was not significantly different between these two groups (6.04 \pm 2.30 in non-smokers vs. $6.68 \pm 2.09$ in smokers respectively). This suggests that all samples are equally prone to DNA damaging agents, independent from the initial damage in the cells caused by smoking.

\section{In vivo scavenging of $\mathrm{ROS}$ by vitamin $\mathrm{C}$ in seminal plasma}

The in vitro experiments indicate that vitamin $\mathrm{C}$ can scavenge ROS, which will result in the formation of vitamin $\mathrm{C}$ radicals that can be measured by ESR/EPR (figure 2). This vitamin $\mathrm{C}$ radical was detected in all samples of human volunteers and it mainly originated from the seminal plasma; no ESR-signal was detected in samples containing sperm cells only, i.e. washed in phosphate buffer, and the presence of spermatozoa in the ejaculate did not further increase the signal when using whole ejaculate. This ESR-signal can be considered as a biomarker of oxidative stress in the ejaculate. Indeed, higher levels of vitamin C radical were detected in smokers than in non-smokers $\left(2.02 \times 10^{6} \pm 0.95 \times 10^{6} \mathrm{vs} .1 .30 \times 10^{6}\right.$ $\pm 0.10 \times 10^{6}$ in smokers and non-smokers respectively, $\left.p=0.028\right)$, which indicates that smoking increases exposure of sperm to oxidative stress. However, this scavenging of ROS by increased levels of vitamin $\mathrm{C}$ in smokers does not seem to be sufficient to provide full protection of the sperm, because DNA damage was higher in smokers as compared to non-smokers. 


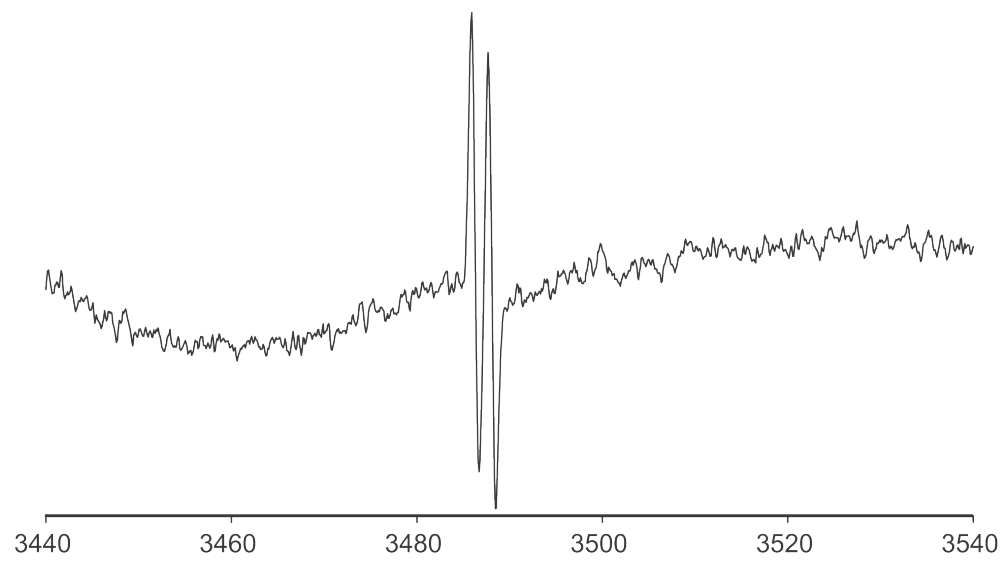

[G]

Figure 2: Representative spectrum from vitamin C radical in seminal plasma of a healthy volunteer. Sperm samples were screened for reactive oxygen species formation by ESR. Data show that in seminal plasma a signal was detected which was identified originating from Vitamin $\mathrm{C}$ radical (splitting constant $(\mathrm{aH})$ is $1,8 \mathrm{G}$ ).

\section{Gene expression in spermatozoal mRNA and relation to seminal parameters}

Previous results showed that the sperm specific gene protamine 2 (PRM2) can be used as a reference gene, since it is sperm cell specific and its expression was not influenced by smoking behaviour. All sampvles provided reproducible duplicates and from these duplicates, average Ct values were calculated for each sample. Ct values for all individuals of each gene are presented in table II. In order to calculate differences between smoking and non-smoking subjects, the latter group were used as controls. We have previously reported SALF was a potential biomarker of exposure to cigarette smoke [3] and in this subset of samples this germline specific transcription factor is again upregulated in smoking subjects, although the increase was not statistically significant ( $p$ $=0.19$ ). The expression of the anti-oxidant enzymes catalase and DDIT4 was increased in smokers, but again the difference did not reach statistical significance ( $p=0.22$ and 0.45 , respectively). Gene expression of DDIT4 and CAT were significantly correlated, which suggests that these genes are possibly co-regulated. Both genes also showed a strong relationship with the expression of SALF (correlation coefficients were $>0.85$ and highly significant, Table II). The correlations between SOD2 and SALF was less pronounced $(r=0.47)$. 
Table II: Gene expression data measured by real-time PCR; average and median values (range between brackets) of $\mathrm{Ct}$ values per gene of all samples are shown. To calculate differences in gene expression between smokers and non-smokers, $\Delta \Delta \mathrm{Ct}$ values in all samples were calculated using average $\Delta \mathrm{Ct}$ values in non-smokers. In this way fold changes in the group of smokers could be related to non-smokers (average fold change in non-smokers as reference $=1.00$ ). Finally, correlation coefficients between gene-expression levels are given.

\begin{tabular}{|c|c|c|c|c|c|c|}
\hline \multirow{2}{*}{$\begin{array}{l}\text { Gene } \\
\text { name }\end{array}$} & \multicolumn{2}{|l|}{ Ct values } & \multirow{2}{*}{$\begin{array}{l}\text { Fold } \\
\text { change }^{\star *}\end{array}$} & \multicolumn{3}{|c|}{ Correlations } \\
\hline & Average* $^{*}$ & Median & & $S A L F$ & CAT & DDIT4 \\
\hline PRM2 & 20.86 & $\begin{array}{l}21.17 \\
(18.06-22.93)\end{array}$ & & & & \\
\hline SALF & 28.31 & $\begin{array}{l}28.22 \\
(27.27-29.69)\end{array}$ & $1.64 \pm 0.41$ & & & \\
\hline Catalase & 26.47 & $\begin{array}{l}26.40 \\
(25.01-27.98)\end{array}$ & $1.62 \pm 0.41$ & $\begin{array}{l}0.94 \\
(p<0.001)\end{array}$ & & \\
\hline DDIT4 & 33.90 & $\begin{array}{l}33.72 \\
(32.16-36.24)\end{array}$ & $1.46 \pm 0.44$ & $\begin{array}{l}0.86 \\
(p<0.001)\end{array}$ & $\begin{array}{l}0.78 \\
(p<0.001)\end{array}$ & \\
\hline SOD2 & 32.66 & $\begin{array}{l}31.80 \\
(30.11-37.01)\end{array}$ & $0.70 \pm 0.30$ & $\begin{array}{l}0.47 \\
(p=0.030)\end{array}$ & $\begin{array}{l}0.43 \\
(p=0.054)\end{array}$ & $\begin{array}{l}0.58 \\
(p=0.005)\end{array}$ \\
\hline
\end{tabular}

Average values of all 21 samples are given. Fold changes were calculated by the $2^{-\Delta \Delta C t}$ method in which the $\mathrm{Ct}$ value of each gene was subtracted by the $\mathrm{Ct}$ value of the housekeeping gene (PRM2). Subsequently, the geometric mean of this dCt in non-smokers was calculated and this was subtracted from all $\triangle \mathrm{Ct}$ values (as a result, average $\Delta \Delta \mathrm{Ct}$ in non-smokers will be 0 ). Finally, this $\Delta \Delta \mathrm{Ct}$ was used to calculate the fold change by using the formula $2^{-\Delta \Delta C t}$ (in non-smokers $2^{0}=1=$ reference).
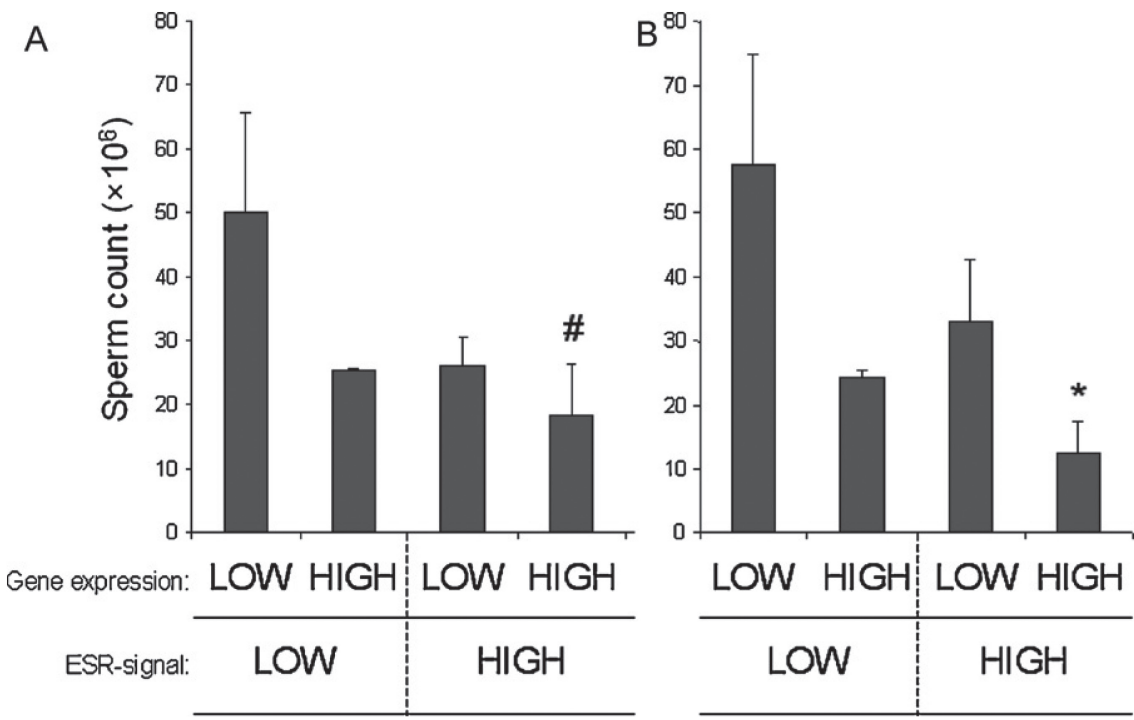

Figure 3: Expression of catalase (A) and DDIT4 (B) related to sperm count in ejaculates of subjects with a high or low ESR signal. In this analysis, high or low expression of CAT and DDIT4 or ESR signal was based on above or below the median value of the whole study population. Figures $A$ and $B$ look very similar because CAT and DDIT4 were highly correlated. \#: $p=0.07,{ }^{*}: p=0.01$ as compared to subjects with low levels of expression and low levels of oxidative stress. 
When smokers and never-smokers were analysed together, a high expression of CAT and/or DDIT4 was found to be related to a lower sperm count in the ejaculate $(p=0.039$ and 0.024 respectively). This finding was independent from smoking behaviour. The lowest sperm counts were observed in subjects with a combined high expression of CAT or DDIT4 and a high ESR signal (i.e. high oxidative stress, Figure 3). This might indicate that sperm cells experiencing high levels of oxidative stress during development survive due to increased expression of putatively protective CAT or DDIT4 and eventually reach the ejaculate.

\section{Discussion}

Although the genetic material in mature spermatozoa is protected against oxidative stress via tight packaging of the DNA, expression of anti-oxidants and the presence of (non)enzymatic anti-oxidants in seminal plasma, increased levels of DNA damage were observed in smokers compared to non-smokers. This damaged genetic material in sperm may be transmitted to the oocyte, where the quality of the DNA is an important determinant for successful fertilisation, preimplantation and embryonic development. DNA damage in sperm may lead to increased rates of miscarriage and an enhanced risk of disease in the progeny [18].

Oxidative stress is one of the major sources of DNA damage in mature spermatozoa [19] and can be caused by many environmental factors, of which smoking is a wellstudied example. Studies have shown that smoking affects fertility of the offspring, as reviewed in Soares et al. [20] and animal studies have shown that newborns from parent mice exposed to mainstream tobacco smoke contain a higher mutation rate in their DNA, with de novo mutations mainly originating from the paternal side [21]. Therefore, a better understanding of the origins of this heritable damage is needed in order to increase DNA integrity and prevent such effects.

One major anti-oxidant in seminal plasma is vitamin $\mathrm{C}$, which reaches concentrations up to $0.5 \mathrm{mM}$. To determine whether vitamin $\mathrm{C}$ can indeed act as an antioxidant to protect DNA integrity of sperm cells, mature spermatozoa were in vitro exposed to hydrogen peroxide in the presence of varying concentrations of vitamin C. DNA damage decreased significantly after the addition of vitamin $C$ at physiological concentrations to the cells. It has previously been indicated that antioxidant supplementation might not only reduce sperm DNA fragmentation, but also lower pregnancy loss rates [22]. In this study we confirm that smoking is able to induce damage to mature spermatozoal DNA [1]. Sperm DNA from smokers appeared not more prone to damage induced by $\mathrm{H}_{2} \mathrm{O}_{2}$ than DNA from non-smokers, which indicates that the differences seen in vivo are predominantly induced by differences in exposure. Additionally, the increased concentrations of vitamin $\mathrm{C}$ radicals in seminal plasma may be produced through mediation of oxidative stress. Since the major part of vitamin $\mathrm{C}$ in semen is originating from the epididymal fluid [17] and there appeared to be no further formation of vitamin $\mathrm{C}$ radicals after ejaculation and processing of the samples, it can be speculated that the vitamin $\mathrm{C}$ radicals originated from the epididymis and / or testis. Thus, the vitamin $\mathrm{C}$ radicals reflect the oxidative stress environment during storage of spermatozoa and / or spermatogenesis respectively. Supplementation with anti-oxidants via the diet is known to protect against oxidative stress, not only in somatic cells but also in mature sperm [23]. Other studies have indeed shown that semen quality increased after vitamin C supplementation [24]. Therefore, we determined the concentration of vitamin $\mathrm{C}$ in the seminal plasma in our study population. However, there was no significant difference in vitamin $\mathrm{C}$ concentrations in the seminal plasma from smokers compared to non-smokers and no relationship was found with dietary intake 
(data not shown). This could be due to the fact that seminal vitamin $\mathrm{C}$ levels are possibly independently regulated from dietary vitamin $\mathrm{C}$ intake (as reviewed by Agarwal et al. [25]). Vitamin $\mathrm{C}$ levels are thought to be regulated because the $\mathrm{pH}$ is relevant for sperm survival [17].

Using the ESR method the vitamin $\mathrm{C}$ radical could be detected in all seminal samples, which in this study appeared to provide a stable signal and it was shown to be a reliable marker for the oxidative stress status [26]. We found that smoking increases the intensity of the vitamin $\mathrm{C}$ radical in seminal plasma. The increase of the intensity of the vitamin $\mathrm{C}$ radical could possibly be related to the concentration of vitamin $\mathrm{C}$ in the seminal plasma. However, there was no correlation between vitamin $\mathrm{C}$ levels in the plasma and the intensity of the radical signal.

Not only oxidative stress can increase DNA damage levels in mature spermatozoa, also the abortion of the apoptotic pathway can be responsible for a loss of DNA integrity, as reviewed by Cocuzza et al. [27]. When a cell is suffering from DNA damage and DNA repair is insufficient, the cell will usually go into apoptosis [28], however, we previously described that anti-apoptosis was promoted in sperm of smokers at the gene-expression level [3]. In that study, we observed that SALF in spermatozoal mRNA was a reliable biomarker of exposure to cigarette smoke. In the current study the increase of SALF expression in smokers' sperm was not statistically significant, but this may be explained by the lower number of cigarettes smoked per day as reported by the participants compared to the participants in our previous study.

An additional selection of genes was made to study their expression in this dataset, based on their role in protection against oxidative stress. It should be noted that mRNA remnants in sperm probably reflect processes that have taken place earlier during spermatogenesis (probably already in the testis, where transcription is still effective) and thus originates from cells that survived genotoxic exposures. Cells with very high levels of DNA damage may go into apoptosis, but if these cells are inhibited from this they remain present in the ejaculate. This is in line with the results from the comet assay, where the DNA damage in smokers' sperm is significantly higher compared to the damage seen in non-smokers' sperm. Furthermore, mRNA from smoking subjects showed an increased expression of catalase and DDIT4, probably as a response to elevated oxidative stress. A very strong correlation was found between the expression of these genes and the expression of SALF. Although the biological role of its protein product has yet to be determined, these correlations suggest that $S A L F$ is involved in the stress response during spermatogenesis.

A high expression of CAT and/ or DDIT4 was related to a lower sperm count in the ejaculate, especially in those volunteers that also had a high ESR-signal. The protein products of these two genes are both involved in reducing oxidative stress; catalase decomposes hydrogen peroxide, whereas DDIT4 likely functions as a direct regulator of mitochondrial metabolism. DDIT4 localizes to the mitochondria, and is important for reducing ROS production and release by mitochondria [29]. Interestingly, excessive ROS production by mitochondria is indeed related to lower sperm quality [30]. These data suggest that expression of CAT and/ or DDIT4 is of importance for cell survival during germ cell development, because only cells with a high expression of these genes seem to be sufficiently protected against oxidative stress and reach the ejaculate. Cells that do not sufficiently express these genes will probably die before they reach the mature state, and as a result, sperm count is significantly decreased. The lowest sperm count was observed in the group of high expression, combined with a high ESR signal. The high ESR signal could be interpreted as high levels of oxidative stress, but also as a measure of protection against oxidative stress by effective scavenging of ROS. However, in the current study it is not possible to disentangle these phenomena, and therefore 
the meaning of the presence of vitamin $C$ radicals for sperm quality and DNA integrity deserves further attention. Therefore it is recommended to further increase the number of both smoking and non-smoking subjects in future studies, and thus add more power to the validation of this biomarker.

Altogether the data suggest that DNA damage in mature sperm cells of smokers originates from exposure to oxidative stress. Mechanisms to protect the sperm DNA integrity, such as upregulation of enzymatic anti-oxidants and anti-oxidants in seminal plasma are insufficient to avoid this DNA damage, but seem to be important for cell survival. Thus, there seems to be a conflict in smokers between simultaneously preserving fertility on the one hand and DNA integrity on the other; our data indicate that sperm count is favoured above germline DNA integrity. Whether this has consequences for the offspring needs further evaluation.

\section{Acknowledgements}

The authors would like to thank Marie-José Drittij for technical assistance. This work was supported by the EU Integrated Project NewGeneris, 6th Framework Programme, Priority 5: Food Quality and Safety (Contract no. FOOD-CT-2005-016320). NewGeneris is the acronym of the project 'Newborns and Genotoxic exposure risks' http://www.newgeneris.org. 


\section{References}

1. Sipinen, V., J. Laubenthal, A. Baumgartner, E. Cemeli, J.O. Linschooten, R.W. Godschalk, et al., In vitro evaluation of baseline and induced DNA damage in human sperm exposed to benzo[a]pyrene or its metabolite benzo[a]pyrene-7,8-diol-9,10-epoxide, using the comet assay. Mutagenesis, 2010. 25(4): p. 417-25.

2. Saleh, R.A., A. Agarwal, R.K. Sharma, D.R. Nelson, and A.J. Thomas, Jr., Effect of cigarette smoking on levels of seminal oxidative stress in infertile men: a prospective study. Fertil Steril, 2002. 78(3): p. 491-9.

3. Linschooten, J.O., F.J. Van Schooten, A. Baumgartner, E. Cemeli, J. Van Delft, D. Anderson, et al., Use of spermatozoal mRNA profiles to study gene-environment interactions in human germ cells. Mutat Res, 2009. 667(1-2): p. 70-6.

4. Sharma, R.K. and A. Agarwal, Role of reactive oxygen species in male infertility. Urology, 1996. 48(6): p. 83550.

5. Griveau, J.F. and D. Le Lannou, Reactive oxygen species and human spermatozoa: physiology and pathology. Int J Androl, 1997. 20(2): p. 61-9.

6. Agarwal, A. and R.A. Saleh, Role of oxidants in male infertility: rationale, significance, and treatment. Urol Clin North Am, 2002. 29(4): p. 817-27.

7. Aitken, R.J., The Amoroso Lecture. The human spermatozoon--a cell in crisis? J Reprod Fertil, 1999. 115(1): p. $1-7$.

8. Sakkas, D., E. Mariethoz, G. Manicardi, D. Bizzaro, P.G. Bianchi, and U. Bianchi, Origin of DNA damage in ejaculated human spermatozoa. Rev Reprod, 1999. 4(1): p. 31-7.

9. Said, T.M., A. Agarwal, R.K. Sharma, A.J. Thomas, Jr., and S.C. Sikka, Impact of sperm morphology on DNA damage caused by oxidative stress induced by beta-nicotinamide adenine dinucleotide phosphate. Fertil Steril, 2005. 83(1): p. 95-103.

10. Fraga, C.G., P.A. Motchnik, A.J. Wyrobek, D.M. Rempel, and B.N. Ames, Smoking and low antioxidant levels increase oxidative damage to sperm DNA. Mutat Res, 1996. 351(2): p. 199-203.

11. Carrell, D.T., B.R. Emery, and S. Hammoud, Altered protamine expression and diminished spermatogenesis: what is the link? Hum Reprod Update, 2007. 13(3): p. 313-27.

12. Lucena, M.I., E. Garcia-Martin, R.J. Andrade, C. Martinez, C. Stephens, J.D. Ruiz, et al., Mitochondrial superoxide dismutase and glutathione peroxidase in idiosyncratic drug-induced liver injury. Hepatology, 2010. 52(1): p. 303-12.

13. Singh, N.P., M.T. McCoy, R.R. Tice, and E.L. Schneider, A simple technique for quantitation of low levels of DNA damage in individual cells. Exp Cell Res, 1988. 175(1): p. 184-91.

14. Boots, A.W., M. Drent, E.L. Swennen, H.J. Moonen, A. Bast, and G.R. Haenen, Antioxidant status associated with inflammation in sarcoidosis: a potential role for antioxidants. Respir Med, 2009. 103(3): p. 364-72.

15. Speek, A.J., J. Schrijver, and W.H. Schreurs, Fluorometric determination of total vitamin C in whole blood by high-performance liquid chromatography with pre-column derivatization. J Chromatogr, 1984. 305(1): p. 5360.

16. Goodrich, R., G. Johnson, and S.A. Krawetz, The preparation of human spermatozoal RNA for clinical analysis. Arch Androl, 2007. 53(3): p. 161-7.

17. Colagar, A.H. and E.T. Marzony, Ascorbic Acid in human seminal plasma: determination and its relationship to sperm quality. J Clin Biochem Nutr, 2009. 45(2): p. 144-9.

18. Aitken, R.J. and A.J. Koppers, Apoptosis and DNA damage in human spermatozoa. Asian J Androl, 2010. in press.

19. Aitken, R.J. and G.N. De luliis, On the possible origins of DNA damage in human spermatozoa. Mol Hum Reprod, 2010. 16(1): p. 3-13.

20. Soares, S.R. and M.A. Melo, Cigarette smoking and reproductive function. Curr Opin Obstet Gynecol, 2008. 20(3): p. 281-91.

21. Yauk, C.L., M.L. Berndt, A. Williams, A. Rowan-Carroll, G.R. Douglas, and M.R. Stampfli, Mainstream tobacco smoke causes paternal germ-line DNA mutation. Cancer Res, 2007. 67(11): p. 5103-6.

22. Gil-Villa, A.M., W. Cardona-Maya, A. Agarwal, R. Sharma, and A. Cadavid, Role of male factor in early recurrent embryo loss: do antioxidants have any effect? Fertil Steril, 2009. 92(2): p. 565-71. 
23. Fraga, C.G., P.A. Motchnik, M.K. Shigenaga, H.J. Helbock, R.A. Jacob, and B.N. Ames, Ascorbic acid protects against endogenous oxidative DNA damage in human sperm. Proc Natl Acad Sci U S A, 1991. 88(24): p. 11003-6.

24. Eskenazi, B., S.A. Kidd, A.R. Marks, E. Sloter, G. Block, and A.J. Wyrobek, Antioxidant intake is associated with semen quality in healthy men. Hum Reprod, 2005. 20(4): p. 1006-12.

25. Agarwal, A., S.A. Prabakaran, and T.M. Said, Prevention of oxidative stress injury to sperm. J Androl, 2005. 26(6): p. 654-60.

26. Buettner, G.R. and B.A. Jurkiewicz, Ascorbate free radical as a marker of oxidative stress: an EPR study. Free Radic Biol Med, 1993. 14(1): p. 49-55.

27. Cocuzza, M., S.C. Sikka, K.S. Athayde, and A. Agarwal, Clinical relevance of oxidative stress and sperm chromatin damage in male infertility: an evidence based analysis. Int Braz J Urol, 2007. 33(5): p. 603-21.

28. Wang, X., R.K. Sharma, S.C. Sikka, A.J. Thomas, Jr., T. Falcone, and A. Agarwal, Oxidative stress is associated with increased apoptosis leading to spermatozoa DNA damage in patients with male factor infertility. Fertil Steril, 2003. 80(3): p. 531-5.

29. Horak, P., A.R. Crawford, D.D. Vadysirisack, Z.M. Nash, M.P. DeYoung, D. Sgroi, et al., Negative feedback control of HIF-1 through REDD1-regulated ROS suppresses tumorigenesis. Proc Natl Acad Sci U S A, 2010. 107(10): p. 4675-80.

30. Koppers, A.J., G.N. De Iuliis, J.M. Finnie, E.A. McLaughlin, and R.J. Aitken, Significance of mitochondrial reactive oxygen species in the generation of oxidative stress in spermatozoa. J Clin Endocrinol Metab, 2008. 93(8): p. 3199-207. 



\section{CHAPTER 5 \\ NEW METHODS FOR ASSESSING MALE GERMLINE MUTATIONS IN HUMANS AND GENETIC RISKS IN THEIR OFFSPRING}

75

Mutagenesis (2008) Jul;23(4):241 - 247

Nicole Verhofstad Joost O. Linschooten Jan van Benthem Yuri E. Dubrova Harry van Steeg Frederik J. van Schooten Roger W.L. Godschalk 


\section{Abstract}

Germline mutations resulting from chemical or radiation exposure are a particular problem in toxicology as they affect not only the exposed generation but also an infinite number of generations thereafter. Established methods to show that these mutations occur in an F1 or subsequent population require the use of a large number of progeny for statistical significance. Consequently, many thousands of animals have been used in the past. Such a use is no longer considered desirable and is also very expensive. Several new molecular techniques (including analysis of tandem repeats and randomly amplified polymorphic DNA) now provide alternative methods of assessment, which also allow the quantification of individual mutations in individual sperm cells. These can also be applied to human offspring, making extrapolation obsolete. The downside of these methods is that they effectively determine the mutation rate in certain regions of DNA and the relevance of these to diseases, particularly cancer, is not always apparent. Therefore, it must be assumed that an increase in mutation rates in these selected regions correlates with altered phenotype. However, disease types linked to changes in tandem repeat length indicate that these may act as relevant markers for the development of phenotypes. Further research and evaluation are required to more closely link changes in DNA with altered phenotype and validate the use of tandem repeats and randomly amplified polymorphic DNA in transgenerational genotoxicity testing. This paper introduces and compares recently developed methods to assess mutations in sperm due to stem cell damage. 


\section{Introduction}

New methods are needed to detect germline mutations induced by exposures to genotoxins in humans. Too little is known about how genotoxic compounds induce mutations in human germ cells and the subsequent transmission of these to offspring. Transmittable genetic damage in humans has been studied in populations exposed to radiation [1], whereas germline mutations induced by environmental pollutants have only been studied in animals. Most of the mutations transmitted to offspring had a paternal origin [2-5]. A similar result might be expected in humans although a direct relationship between mutations in human sperm and a genetic disease induced in the progeny has not been reported yet [6].

A parallelogram approach developed by Sobels [7] and extended by Adler [8] has been used until now to extrapolate measurable effects in rodent germ cells, their progeny and human germ cells in vitro to estimate the genetic risks in humans in vivo (Figure 1). This approach uses classical methods, such as the morphological specific locus (MSL) test and the dominant lethal test. These tests have low sensitivity, use large numbers of progeny to obtain the recommended sample size and are very time consuming and expensive. Recently developed germ cell mutagenicity tests seem to have rendered this parallelogram approach obsolete since these new tests can detect mutations in human germ cells and offspring and are suitable for studying genetic risks in human populations. A recent review by Singer et al. [9] compared classical approaches (e.g. MSL and heritable translocation assay) with new methodologies [e.g. expanded simple tandem repeat (ESTR) mutation assay and the gene mutation test in transgenic rodents] but too little data were available to compare the performances of these tests in detail.

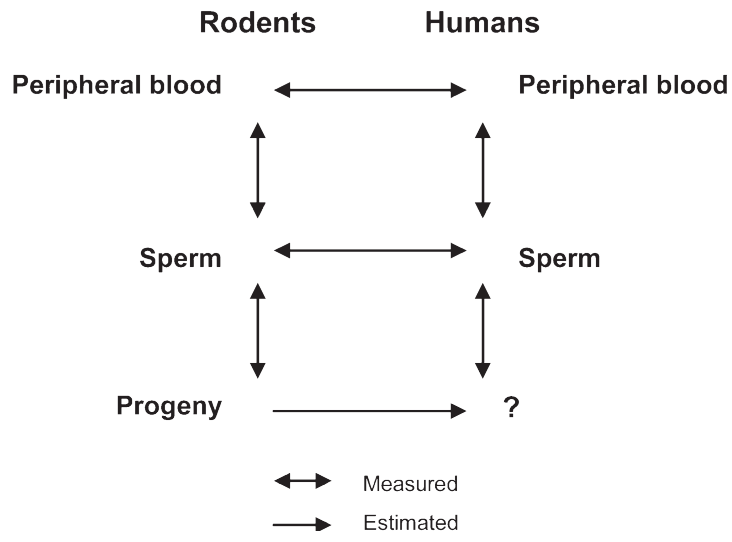

Figure 1: A parallelogram approach to estimate the genetic risk in humans. Adapted from ref. [8].

Of these new techniques, only the analysis of tandem repeat sequences seems suitable for testing in humans. We will therefore discuss this assay in greater detail together with randomly amplified polymorphic DNA PCR (RAPD-PCR), an assay that could be used to quickly screen exposed humans for the transmission of mutations to their offspring. Although these new methods seem to have a high sensitivity, they have yet to be validated and only a few laboratories are equipped to perform the analysis of tandem repeat sequences.

Germ cell tests play a decisive role in classifying and labelling chemicals for genotoxicity. To minimize animal use, tests that detect effects in germ cells should be performed first. However, if quantification of these effects is required, assays for mutations in the offspring are essential. In the guidance document for genotoxicity under Registration 
Evaluation and Authorisation of Chemical Substances, the new European Community (EC) policy for authorization of new and existing chemicals, a test that determines changes in hypervariable tandem repetitive regions is stated as an alternative to classical tests. As this test also allows the measurement of heritable damage in humans, it is a recommended alternative.

\section{Germline mutagenicity tests}

\section{RAPD-PCR}

RAPD-PCR was first described by Williams et al. [10] and is based on the amplification of random unknown DNA segments with a single primer of arbitrary nucleotide sequence. RAPD-PCR can be used to detect genomic alterations without prior information about the loci. Multiple fragments are generated in a single reaction that can be visualized after gel electrophoresis (Figure 2A). Any genomic alteration (point mutations, structural rearrangements, deletions, insertions, etc.) may change the place where the primer anneals resulting in different profiles (Figure 2B and $\mathrm{C}$ ). For germ cell mutagenicity testing, the patterns obtained from the mother and father can be compared with those from the offspring. Differences between the patterns may indicate a genomic alteration if (i) the DNA fragment is only visible in the pattern of the child, (ii) the DNA fragment is present in the pattern of the father and/or the mother, but absent in the pattern of the child or (iii) bands are increased or decreased in intensity. However, PCR products that disappear or change in intensity should be interpreted with care because of the possibility of heterozygosity in the parents. Other PCR-based techniques have also been developed, like DNA amplification fingerprinting and arbitrarily primed PCR $[11,12]$. However, these have yet to be used for germline mutation detection.

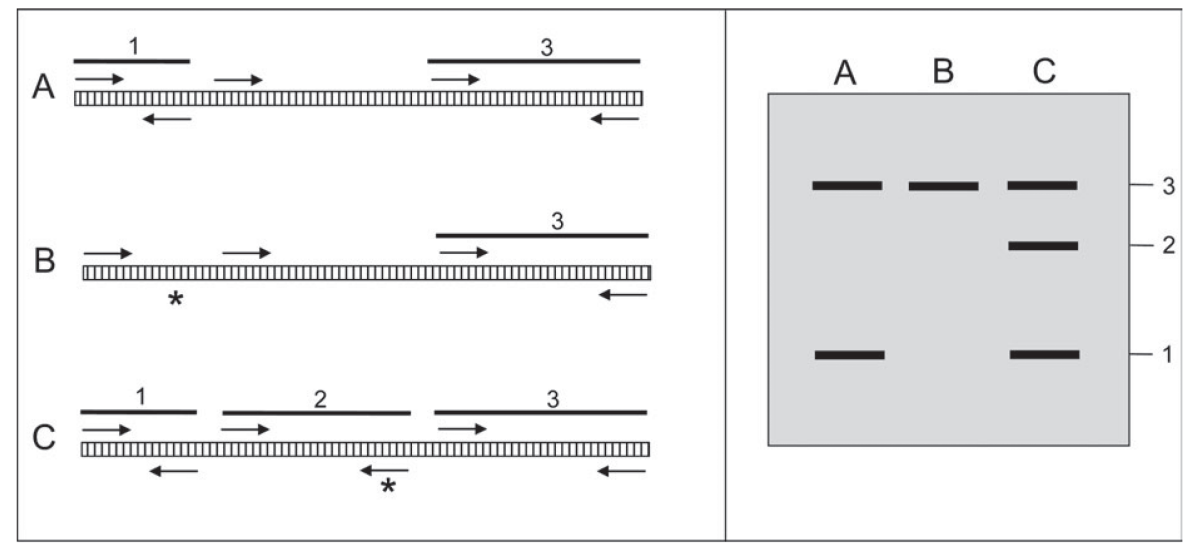

Figure 2: Simplified overview of the RAPD-PCR principle: A. a single random primer is able to bind at several sites in the DNA (indicated by arrows) and produces fragments of different lengths upon PCR (products 1 and 3), which can subsequently be detected after gel electrophoresis (panel on the right). B. if a mutation is introduced at a site at which a primer binds, this binding site is lost (indicated by *) under stringent conditions, and so the PCR product (product 1) cannot be formed. C. mutations can also lead to the introduction of new binding sites for the primer (indicated by *), leading to the formation of a new PCR product (product 2). Situations B and C can involve a range of genomic alterations such as deletions, insertions and chromosomal rearrangements. If the distance between two primers due to a genomic alteration is too large for effective amplification during PCR, the PCR product will also be lost. However, a deletion may result in primers that are close enough to allow amplification. 
RAPD-PCR might detect single-base changes in genomic DNA [10], although genomic rearrangements are probably detected the most [13]. As RAPD-PCR only detects genomic alterations in or close to a priming site, the use of multiple primers may increase the sensitivity of this method. Moreover, the sensitivity of the test could be improved by using a more accurate method described by Valentini et al. [14] for the separation and detection of multiple amplified fragments. In toxicological exposure experiments to assess population genetic effects, this method successfully detected genomic alterations induced by benzo[a]pyrene $(\mathrm{B}[\mathrm{a}] \mathrm{P})$, copper, mitomycin $\mathrm{C}$, UV radiation and X-rays [15-18]. Theoretically, all routes of exposure in which toxicants may affect the genetic structure can be analysed. Experimental studies usually require several hundred offspring for the powerful detection of germline alterations using approximately 5-10 RAPD primers.

RAPD-PCR has several advantages: (i) it is relatively inexpensive and rapid, (ii) it yields information on a large number of loci, (iii) the same primers can be used for genomic analysis in all species, including humans, and (iv) it can be performed with relatively small sample sizes. However, there are also several drawbacks: (i) the results are considered to be qualitative and indicative and should be further corroborated by cloning, sequencing and probing techniques, (ii) the nature of the genomic change observed cannot be assessed from the sequence of the RAPD-PCR product, (iii) the technique may not screen the genome as randomly as expected and (iv) both nuclear and mitochondrial DNA may be amplified during PCR. Amplification of mitochondrial DNA may complicate the interpretation of RAPD fingerprints as it is not a Mendelian marker, but only inheritable from the mother [19]. Reproducibility of RAPD profiles is another potential pitfall [20]. However, this can be overcome by using appropriate PCR conditions and by cleaving DNA with restriction enzymes prior to the amplification [21].

So far, RAPD-PCR has mainly been used in ecotoxicological studies, for example, to detect genomic alterations in Daphnia magna exposed to B[a]P $[13,22]$. Weinberg et al. [23] have used the method in humans and they detected a 7-fold increase in mutation frequencies in blood from children of families conceived after parental exposure to radiation from the Chernobyl accident compared to children conceived before parental exposure. They concluded that exposure to low-dose radiation induces genetic changes in the germline. Although the finding of a 7 -fold increase in mutation rate has been questioned by Jeffreys and Dubrova [24] and mutants have not been validated, the study nevertheless raises major concerns regarding radiation-induced heritable genetic effects.

In conclusion, RAPD-PCR seems to be a promising method for the analysis of germline mutations in offspring. For human studies, however, PCR conditions and RAPDPCR methods should be optimized to yield reproducible DNA fingerprints, and several verification methods should be used to validate and confirm results [13]. Although the findings obtained by RAPD-PCR can only be regarded as indicative at present, the method can still be used as an effective screening tool in studying germline mutagenesis.

\section{DNA fingerprinting of tandem repetitive DNA sequences}

Part of the genome consists of tandem repetitive sequences, which are known to be unstable and predominantly non-coding DNA. These sequences can be divided into microsatellites, minisatellites and ESTRs based on sequence size and number of repeats (Table I). Yauk [25] provides further information on the differences between minisatellites and ESTRs with respect to their structure and mutational mechanisms. 
Table I: Structural differences of tandem repetitive sequences

\begin{tabular}{l|l|l|l}
\hline $\begin{array}{l}\text { Tandem repetitive } \\
\text { sequences }\end{array}$ & Sequence size $(\mathrm{nt})$ & Number of repeats & Total size \\
\hline Microsatellites & $2-5$ & $10-100$ & - \\
Minisatellites & $5-100$ & Up to 6000 & Up to $30 \mathrm{~kb}$ \\
ESTRs & $4-6$ & Up to 4000 & Up to $16 \mathrm{~kb}$ \\
\hline
\end{tabular}

The structure of tandem repetitive sequences can be classified according to sequence size and number of repeats; nt, nucleotides.

Minisatellites and ESTRs can be sensitive tools for monitoring germline mutations after mutagenic exposure since both exhibit high mutation rates. This facilitates the assessment of induced mutations in a relatively small number of samples following environmentally relevant exposure [26]. The DNA is digested with restriction enzymes and subsequently electrophoresed, before being hybridized with probes that are complementary to hypervariable loci. This gives a unique pattern of fragments (DNA fingerprint) (Figure 3). The use of multiple probes can increase the probability of detecting mutations, when comparing the patterns between parents and their offspring (each band should also be present in one of the parents). Therefore this is a statistically powerful technique that reduces the time needed and costs involved to quantify the number of germline mutations

A

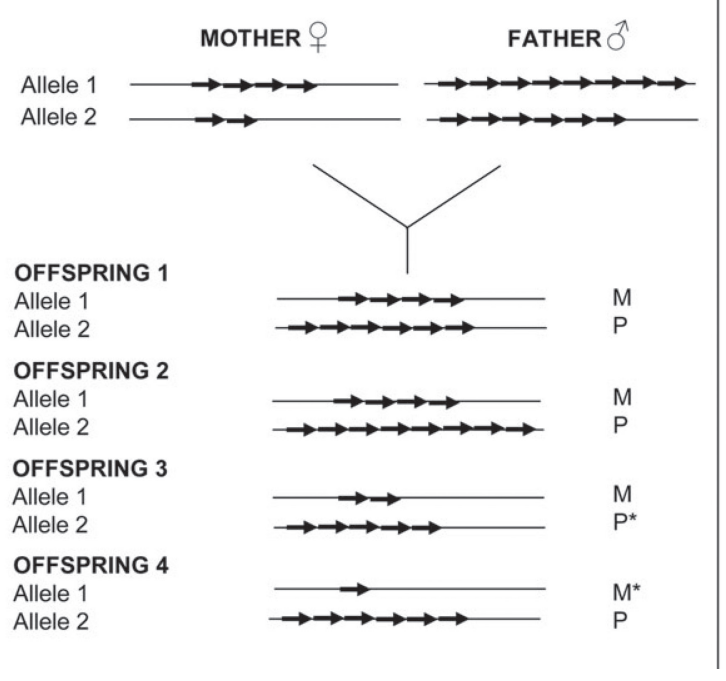

B

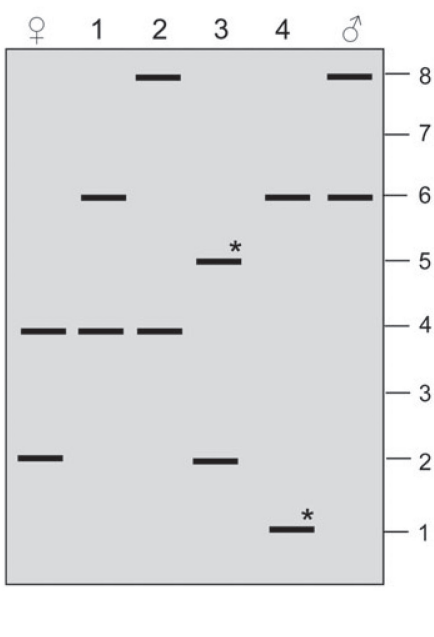

Figure 3: Simplified overview of tandem repeat mutation analysis. Children always inherit one tandem repeat allele from their mother and one from their father. Changes in allele size indicate a deletion or insertion of one or more repeat units. A. Offspring 1 has inherited allele 1 from the mother and allele 2 from the father and no changes in allele size are detectable. There are also no changes detectable in offspring 2, who inherited another allele from the father. Offspring 3 has inherited allele 1 from the mother and allele 2 from the father. However, a change in repeat size of the allele inherited from the father (allele 2) has occurred, which indicates a deletion of one repeat unit. In offspring 4, a change in repeat size of allele 1 has occurred. A deletion of one repeat unit is visible in the allele inherited from the mother. B. Changes in allele size are visible after hybridisation of digested and electrophoresed DNA, which gives a pattern of tandem repeat fragments unique for a person. 
Recent experiments have shown that minisatellites and ESTRs are able to detect an increase in germline mutations in humans and animals exposed to radioactive or chemical pollutants in their natural environment [2-5]. Multilocus DNA fingerprinting has also demonstrated significantly elevated mutation rates in the offspring of humans inhabiting the radioactive polluted areas of Belarus near Chernobyl, when compared to control families from the UK. Moreover, a significant radiation-dose effect relationship was observed [1,27].

These studies demonstrate that the analysis of tandem repetitive sequences could be a sensitive method for the detection of germline mutations transmitted to the next generation and caused by long-term and/or low-dose environmental exposure. However, very little is currently known about germline mutations induced at hypervariable tandem repeat sequences by specific chemicals. Two monofunctional alkylating agents, ethylnitrosourea (ENU) and isopropyl methanesulphonate, and the anti-cancer drug etoposide have already been investigated and led to elevated ESTR mutation rates in the germline of male mice [28]. Although these results demonstrate that tandem repeat sequences can be used to monitor germline mutation induction, the effects of exposure to environmental or dietary mutagens other than radiation on germline mutation induction at tandem repeat loci in rodents and humans clearly merits further evaluation.

\section{Small-pool PCR}

Small-pool PCR (SP-PCR), which is derived from DNA fingerprinting of minisatellites, can also be used as a germ cell mutagenicity test [29-31]. However, in contrast to DNA fingerprinting, the tandem repeats are amplified by PCR using allele-specific PCR primers directed at the polymorphic sites in minisatellite regions. This allows the analysis of mutant alleles in individual gametes. Consequently, this method can be used to map minisatellite length polymorphisms directly in the germ cell DNA [29-31]. SP-PCR uses amplification of small aliquots of sperm DNA to screen thousands of sperm cells from an individual in one PCR to detect changes in the repeat size of unstable minisatellite loci. Mutations detected by SP-PCR as products of altered length are counted and the rate of mutation expressed as a given number of events found in a given estimated number of sperm equivalents [32].

Quantitative SP-PCR methods were found to be appropriate for investigating the effects of chemotherapeutic mutagens and radiation on minisatellite mutation rates in human sperm [32-35]. The advantage of this approach is that relatively small increases in mutation rate can be detected in individual samples, which makes it a sensitive method. However, this technique also has several limitations that are predominantly related to interpretation of the data. First, this technique may potentially underestimate the true number of expansion events since PCR is known to favour the amplification of the smaller allele. Second, the variants detected in this assay may be PCR artefacts rather than variants in repeat size. Third, SP-PCR is less precise in controlling for the number of cell equivalents analysed. Consequently, considerable care should be taken in accurately diluting and pipetting the DNA samples for SP-PCR in order to minimize variation, as the number of cells in each pool is the denominator in determining the rates of change. Furthermore, the efficiency of amplification of all the cell equivalents within a pool may be $<100 \%$ [36].

In conclusion, SP-PCR seems less appropriate as a mutagenicity test than standard DNA fingerprinting of minisatellites and ESTRs. The disadvantages of this technique are mainly related to the use of PCR amplification, which causes misinterpretation of the results by PCR artefacts. 


\section{Single-molecule PCR}

In addition to SP-PCR, single-molecule PCR (SM-PCR) has been developed as a method for detecting new mutations in both the germline and somatic tissues [35]. This method has been used to quantify the in vivo mutation frequency at the Ms6-hm locus in somatic and germ cells and to determine whether mutation induction by environmental exposure and ionizing radiation can be detected in pedigrees as well as directly in sperm DNA $[35,37]$. This is an important addition to the pedigree approach for tandem repeat analysis because mutations in sperm are not necessarily transferred to the offspring and, vice versa, mutations in the offspring do not necessarily originate from the gametes, but can be induced during early embryogenesis. For this SM-PCR method, DNA samples are digested outside the ESTR array and distal to the PCR primer sites prior to amplification to render genomic DNA fully soluble prior to dilution. Digested DNA is serially diluted and amplified with flanking primers [38]. PCR products are analysed by electrophoresis followed by hybridization with specific probes. The approximate number of amplifiable ESTR molecules in each dilution is estimated by Poisson analysis of the number of positive and negative reactions for ESTR-PCR products. Subsequently, a new set of PCRs is seeded with each containing a mean of approximately one amplifiable ESTR molecule. PCR products are subsequently separated on an agarose gel, followed by hybridization and scoring of the allele lengths. A band shift of at least $1 \mathrm{~mm}$ relative to the internal size marker indicates a mutation; smaller changes cannot be scored reliably [35].

SM-PCR has several advantages. First, experimental time might be reduced because mating and birth is unnecessary (it has been shown in laboratory mice that mutation rates in the offspring were indistinguishable from the rates in sperm DNA [35]). Second, SM-PCR was found to be useful for studying mutation induction at low-dose exposures [35] and the majority of mutations were small changes in repeat copy number. These advantages allow a more thorough investigation of chemicals with different modes of action. Furthermore, using SM-PCR circumvents the requirement of sub-cloning. Yauk et al. [35] showed that SM-PCR can provide robust estimates of the frequency of ESTR mutations in somatic and sperm cells of irradiated and control male mice.

In addition to the limited number of in vivo results, in vitro studies have also shown that SM-PCR is a useful method for detecting mutations. Polyzos et al. $[37,39]$ described the same method for the in vitro detection of de novo mutations in cultures of embryonic cells and noted that cells treated with ENU, B[a]P and etoposide showed a significant increase of the mutation frequency compared to untreated cells. They also indicated a similarity in mutation response between embryonic fibroblasts in culture and somatic and germ cells in vivo at the ESTR locus [39].

In conclusion, SM-PCR methods are appropriate for the detection of germline mutations at the ESTR locus Ms6-hm. The reduction in time and costs make this method particularly suitable for screening large numbers of agents. A similar approach developed for minisatellites would be very useful for studying mutation frequencies in humans, but such methods are currently lacking.

\section{Do differences between rodent and human spermatogenesis affect germline mutation induction?}

The advantage of the methods described above is that they can be used to detect germline mutations in rodents and humans. This is essential because until recently extrapolation of animal data was necessary for assessing potential genetic risks in the human population. Nonetheless, extrapolation might still be very useful in certain situations. Human exposure to genotoxic chemicals usually involves chronic exposure to low doses, 
making it much more difficult to study mutagenicity during spermatogenesis. In theory, this could lead to a misinterpretation of the effects due to the differences in spermatogenesis between rodents and humans (reviewed by Ehmcke et al. [40] and summarized in Figure 4). There are differences in type of stem cell and in mitotic expansion. Finally, it must also be remembered that the vulnerability of germ cells towards genotoxins is known to alter during spermatogenesis due to cell turnover, differentiation and changes in DNA repair activity [41].

\begin{tabular}{|c|c|c|c|c|c|c|}
\hline \multirow{2}{*}{$\begin{array}{l}\text { Location } \\
\text { Cell type }\end{array}$} & \multicolumn{5}{|c|}{ TESTIS } & \multirow{2}{*}{$\begin{array}{l}\text { EPIDIDYMIS } \\
\text { SPERMATOZOA }\end{array}$} \\
\hline & \multicolumn{2}{|c|}{\begin{tabular}{|l:l|l|} 
STEM & PROG \\
CELLS & CELLS & SPERMATOGONIA \\
\end{tabular}} & \multicolumn{2}{|c|}{ SPERMATOCYTES } & SPERMATIDS & \\
\hline $\begin{array}{r}\text { Mouse } \\
\text { Primate }\end{array}$ & (19) छ) & ${ }_{B}$ & & $\frac{f_{x}}{\text { late }}$ & $\rightarrow$ & \\
\hline \multirow{2}{*}{$\begin{array}{l}\text { \# of cells } \begin{array}{r}\text { Mouse } \\
\text { Primate }\end{array} \\
\text { Cell division }\end{array}$} & \begin{tabular}{|cc|c|}
1 & & $2 \rightarrow 256$ \\
& 1 & 1 \\
\end{tabular} & $\begin{array}{c}512 \\
2\end{array}$ & $\begin{array}{c}1024 \\
4\end{array}$ & $\begin{array}{c}2048 \\
8\end{array}$ & $\begin{array}{c}4096 \\
16\end{array}$ & $\begin{array}{c}4096 \\
16\end{array}$ \\
\hline & \multicolumn{2}{|l|}{ MITOSIS } & \multicolumn{2}{|c|}{ MEIOSIS } & \multicolumn{2}{|c|}{ POST-MEIOSIS } \\
\hline Cell division & \multicolumn{3}{|c|}{ DIPLOID } & \multicolumn{3}{|c|}{ HAPLOID } \\
\hline \multirow{2}{*}{$\begin{array}{l}\text { DNA synthesis } \\
\text { DNA repair }\end{array}$} & YES & & \multicolumn{4}{|c|}{ NO } \\
\hline & \multicolumn{4}{|c|}{ REPAIR PROFICIENT } & \multicolumn{2}{|c|}{ REPAIR DEFICIENT } \\
\hline
\end{tabular}

Figure 4: Schematic overview of spermatogenesis in mice and humans. This scheme shows the characteristics of different cell stages during spermatogenesis that are important for the formation of mutations in germ cells at different stages. Differences in sperm cell expansion between mice and humans are predominantly at the level of stem/progenitor cells and the number of differentiating cells after mitotic divisions. Abbreviations: Prog, progenitor.

\section{Analysis of germline mutations: where do they come from and where do they take us?}

Both RAPD-PCR and the analysis of repetitive sequences might increase our understanding of how best to extrapolate from rodents to humans. However, important concerns are (i) the mechanisms through which the mutations arise are unknown and (ii) their biological relevance for the health of offspring is not clear.

\section{Mechanisms leading to mutations}

Alterations in RAPD-PCR profiles may originate from genomic alterations, DNA lesions that block the polymerase and secondary structures within the PCR product [13]. Therefore, studying the origin of RAPD-PCR detectable mutations from a mechanistic viewpoint will be difficult because multiple types of mutations can be involved. Gains or losses of tandem repeats are possibly easier to interpret, as the underlying mechanism might be the same. ESTR mutations have been observed after exposure to radiation but were also induced by chemical carcinogens that induce strand breaks or bulky DNA lesions $[28,37,42]$. Although this non-specific detection of mutations induced by different types of DNA damage might be advantageous for the sensitivity of the assays, it complicates the mechanistic interpretation of the data. Therefore, more dedicated in vitro and in vivo experiments are needed to provide a definitive characterization of the mechanistic basis 
for this type of mutation analyses. Moreover, these mutations may also be the consequence of genomic destabilization during early embryogenesis, which is supported by the observation that an increased number of mutations can arise in the maternal allele of the offspring of irradiated males and unexposed mothers [43]. Therefore, mutations in both sperm and offspring should be observed so that the two processes can be differentiated. There is evidence that indirect mechanisms are involved in the induction of tandem repeat mutations; for instance recent findings indicate a potential role for epigenetic alterations [44]. Since the epigenome can be transferred to subsequent generations, this mechanism might also be relevant for exposed populations.

Transcriptomics could contribute to this mechanistic understanding of germline mutagenesis by comparing gene expression in testes of exposed fathers. Despite the obvious difficulties in obtaining mRNA from human testes, gene expression can be studied in mRNA obtained from ejaculates. The presence of mRNA in an ejaculate was discovered by Pessot et al. [45] and is thought to reflect gene expression during spermatogenesis [46]. Therefore, pathways involved in the induction of tandem repeat mutations may also be identifiable in humans. Studies in humans seem to be necessary to avoid problems with interspecies extrapolation. However, variability in the susceptibility towards genotoxic compounds may complicate the interpretation of the data and so controlled studies with laboratory animals are still required. Moreover, the use of genetically modified animals may allow further elucidation of mechanisms in germline mutagenesis.

\section{Biological significance of mutations detected}

It is almost impossible to predict the biological impact of germline mutations for offspring health. In principle, the RAPD-PCR assay can scan the entire genome including coding DNA regions, which can be identified by cloning and sequencing the altered PCR products (new PCR products or PCR products that disappeared due to exposure). However, most of the mutations will probably be found in non-coding DNA. No studies to date have linked an increased mutational load, as assessed by RAPD-PCR, to an actual phenotypic alteration. Furthermore, it is still unclear whether tandem repeat mutations reflect effects in coding regions or provide a measure of other heritable genomic outcomes. Although the tandem repeat loci do not confer any observed phenotypes, many tandem repeats are known to be related to transcribed genes and instability within these repetitive sequences has been shown to influence the function of these genes [47-50]. For example, expansions within tandem repeat sequences are associated with 20 well-characterized developmental and degenerative diseases [47]. Nevertheless, mutations assessed by RAPD-PCR or tandem repeat analysis can be considered as biomarkers of adverse genetic events.

\section{Future perspectives}

The new approaches described are needed to test germline mutagenicity in humans exposed to environmental and dietary mutagens [51]. Efforts need to be made to use new molecular techniques to overcome the limitations of classical tests with respect to time, costs and the number of animals needed for germline mutagenicity testing. Further these tests should fit in a broad range of applications; genomic alterations should be measurable in humans, animals and their offspring, in multiple organs and at different stages during spermatogenesis.

Table II provides an overview of the advantages and disadvantages of RAPD-PCR and DNA fingerprinting of tandem repetitive DNA sequences compared to classical germ cell assays. The two new methods fulfill most of the demands, including their applicability 
in humans, but still require further technical validation. Too few experiments have been performed to confirm the suitability of these methods for detecting germline mutations. In addition, not enough is known about how tandem repeat mutations are formed and the type of mutations analysed by RAPD-PCR. Therefore, the biological consequences of these mutations for the offspring are unknown. However, the improved sensitivity, which results in the use of small sample sizes and consequently lower costs, means that these methods are promising for the testing of low doses of mutagens and long-term exposure to mutagens on germline mutations and heritable effects.

Table II: Comparison of the characteristics of germ cell assays

\begin{tabular}{l|c|c|c}
\hline Characteristics & DNA fingerprinting & RAPD-PCR & $\begin{array}{c}\text { Classical germ cell } \\
\text { assays }\end{array}$ \\
\hline Validation & - & - & + \\
Reproducibility & + & $+1-$ & + \\
Costs & + & ++ & - \\
Time & + & ++ & - \\
Number of animals required & + & + & - \\
Sensitivity & + & ++ & + \\
Applicable to humans & ++ & - & + \\
Coding DNA & - & - & - \\
Phenotypic effects & - & - & + \\
Defined mechanism of mutation & -
\end{tabular}

'+' indicates favourable and '-' indicates unfavourable

DNA fingerprinting for repetitive sequences is the most promising new method for mutagenicity testing, while RAPD-PCR can be considered as a semi-quantitative screening method. Furthermore, DNA fingerprinting is a sensitive method for detecting germline mutations in sperm and for establishing whether these mutations can be transmitted to the progeny after long-term, low-dose exposure to pollutants in experimental animals, free-living animals and humans.

\section{Funding}

Cefic Long-Range Research Initiative Innovative Science award 2004 to R.W.L.G.; EU Integrated Project NewGeneris, 6th Framework Programme, Priority 5: Food Quality and Safety (FOOD-CT-2005 016320). 


\section{References}

1. Dubrova, Y. E., Nesterov, V. N., Krouchinsky, N. G., Ostapenko, V. A., Neumann, R., Neil, D. L. and Jeffreys, A. J. (1996) Human minisatellite mutation rate after the Chernobyl accident. Nature, 380, 683-686.

2. Yauk, C. L., Fox, G. A., McCarry, B. E. and Quinn, J. S. (2000) Induced minisatellite germline mutations in herring gulls (Larus argentatus) living near steel mills. Mutat. Res., 452, 211-218.

3. Somers, C. M., Yauk, C. L., White, P. A., Parfett, C. L. and Quinn, J. S. (2002) Air pollution induces heritable DNA mutations. Proc. Natl Acad. Sci. USA, 99, 15904-15907.

4. Yauk, C. L. and Quinn, J. S. (1996) Multilocus DNA fingerprinting reveals high rate of heritable genetic mutation in herring gulls nesting in an industrialized urban site. Proc. Natl Acad. Sci. USA, 93, 12137-12141.

5. Somers, C. M., McCarry, B. E., Malek, F. and Quinn, J. S. (2004) Reduction of particulate air pollution lowers the risk of heritable mutations in mice. Science, 304, 1008-1010.

6. Trasler, J. M. and Doerksen, T. (1999) Teratogen update: paternal exposures-reproductive risks. Teratology, 60, 161-172.

7. Sobels, F. H. (1989) Models and assumptions underlying genetic risk assessment. Mutat. Res., 212, 77-89.

8. Adler, I. D. (1996) Future research directions to study genetic damage in germ cells and estimate genetic risk. Environ. Health Perspect., 104 (Suppl. 3), 619-624.

9. Singer, T. M., Lambert, I. B., Williams, A., Douglas, G. R. and Yauk, C. L. (2006) Detection of induced male germline mutation: correlations and comparisons between traditional germline mutation assays, transgenic rodent assays and expanded simple tandem repeat instability assays. Mutat. Res., 598, 164-193.

10. Williams, J. G., Kubelik, A. R., Livak, K. J., Rafalski, J. A. and Tingey, S. V. (1990) DNA polymorphisms amplified by arbitrary primers are useful as genetic markers. Nucleic Acids Res., 18, 6531-6535.

11. Welsh, J. and McClelland, M. (1990) Fingerprinting genomes using PCR with arbitrary primers. Nucleic Acids Res., 18, 7213-7218.

12. Caetano-Anolles, G. (1993) Amplifying DNA with arbitrary oligonucleotide primers. PCR Methods Appl., 3, 85-94.

13. Atienzar, F. A. and Jha, A. N. (2006) The random amplified polymorphic DNA (RAPD) assay and related techniques applied to genotoxicity and carcinogenesis studies: a critical review. Mutat. Res., 613, 76-102.

14. Valentini, A., Timperio, A. M., Cappuccio, I. and Zolla, L. (1996) Random amplified polymorphic DNA (RAPD) interpretation requires a sensitive method for the detection of amplified DNA. Electrophoresis, 17, 1553-1554.

15. Atienzar, F. A., Cheung, V. V., Jha, A. N. and Depledge, M. H. (2001) Fitness parameters and DNA effects are sensitive indicators of copper induced toxicity in Daphnia magna. Toxicol. Sci., 59, 241-250.

16. Becerril, C., Ferrero, M., Sanz, F. and Castano, A. (1999) Detection of mitomycin C-induced genetic damage in fish cells by use of RAPD. Mutagenesis, 14, 449-456.

17. Atienzar, F. A., Venier, P., Jha, A. N. and Depledge, M. H. (2002) Evaluation of the random amplified polymorphic DNA (RAPD) assay for the detection of DNA damage and mutations. Mutat. Res., 521, 151-163.

18. Jones, C. and Kortenkamp, A. (2000) RAPD library fingerprinting of bacterial and human DNA: applications in mutation detection. Teratog. Carcinog. Mutagen., 20, 49-63.

19. Russell, P. J. (2002) iGenetics. San Francisco, CA, Pearson Education, Inc.

20. Benter, T., Papadopoulos, S., Pape, M., Manns, M. and Poliwoda, H. (1995) Optimization and reproducibility of random amplified polymorphic DNA in human. Anal. Biochem., 230, 92-100.

21. Savva, D. (1998) Use of DNA fingerprinting to detect genotoxic effects. Ecotoxicol. Environ. Saf., 41, $103-106$.

22. Atienzar, F. A. and Jha, A. N. (2004) The random amplified polymorphic DNA (RAPD) assay to determine DNA alterations, repair and transgenerational effects in B(a)P exposed Daphnia magna. Mutat. Res., 552, 125-140.

23. Weinberg, H. S., Korol, A. B., Kirzhner, V. M. et al. (2001) Very high mutation rate in offspring of Chernobyl accident liquidators. Proc. Biol. Sci., 268, 1001-1005.

24. Jeffreys, A. J. and Dubrova, Y. E. (2001) Monitoring spontaneous and induced human mutation by RAPD-PCR: a response to Weinberg et al. (2001). Proc. Biol. Sci., 268, 2493-2494.

25. Yauk, C. L. (2004) Advances in the application of germline tandem repeat instability for in situ monitoring. Mutat. Res., 566, 169-182. 
26. Jeffreys, A. J., Royle, N. J., Wilson, V. and Wong, Z. (1988) Spontaneous mutation rates to new length alleles at tandem-repetitive hypervariable loci in human DNA. Nature, 332, 278-281.

27. Dubrova, Y. E., Nesterov, V. N., Krouchinsky, N. G., Ostapenko, V. A., Vergnaud, G., Giraudeau, F., Buard, J. and Jeffreys, A. J. (1997) Further evidence for elevated human minisatellite mutation rate in Belarus eight years after the Chernobyl accident. Mutat. Res., 381, 267-278.

28. Vilarino-Guell, C., Smith, A. G. and Dubrova, Y. E. (2003) Germline mutation induction at mouse repeat DNA loci by chemical mutagens. Mutat. Res., 526, 63-73.

29. Buard, J., Collick, A., Brown, J. and Jeffreys, A. J. (2000) Somatic versus germline mutation processes at minisatellite CEB1 (D2S90) in humans and transgenic mice. Genomics, 65, 95-103.

30. May, C. A., Jeffreys, A. J. and Armour, J. A. (1996) Mutation rate heterogeneity and the generation of allele diversity at the human minisatellite MS205 (D16S309). Hum. Mol. Genet., 5, 1823-1833.

31. Jeffreys, A. J., Tamaki, K., MacLeod, A., Monckton, D. G., Neil, D. L. and Armour, J. A. (1994) Complex gene conversion events in germline mutation at human minisatellites. Nat. Genet., 6, 136-145.

32. Armour, J. A., Brinkworth, M. H. and Kamischke, A. (1999) Direct analysis by small-pool PCR of MS205 minisatellite mutation rates in sperm after mutagenic therapies. Mutat. Res., 445, 73-80.

33. May, C. A., Tamaki, K., Neumann, R., Wilson, G., Zagars, G., Pollack, A., Dubrova, Y. E., Jeffreys, A. J. and Meistrich, M. L. (2000) Minisatellite mutation frequency in human sperm following radiotherapy. Mutat. Res., 453, 67-75.

34. Zheng, N., Monckton, D. G., Wilson, G., Hagemeister, F., Chakraborty, R., Connor, T. H., Siciliano, M. J. and Meistrich, M. L. (2000) Frequency of minisatellite repeat number changes at the MS205 locus in human sperm before and after cancer chemotherapy. Environ. Mol. Mutagen., 36, 134-145.

35. Yauk, C. L., Dubrova, Y. E., Grant, G. R. and Jeffreys, A. J. (2002) A novel single molecule analysis of spontaneous and radiation-induced mutation at a mouse tandem repeat locus. Mutat. Res., 500, 147-156.

36. Crawford, D. C., Wilson, B. and Sherman, S. L. (2000) Factors involved in the initial mutation of the fragile $X$ CGG repeat as determined by sperm small pool PCR. Hum. Mol. Genet., 9, 2909-2918.

37. Polyzos, A., Parfett, C., Healy, C., Douglas, G. R. and Yauk, C. L. (2006) Instability of expanded simple tandem repeats is induced in cell culture by a variety of agents: N-Nitroso-N-ethylurea, benzo(a)pyrene, etoposide and okadaic acid. Mutat. Res., 598, 73-84.

38. Jeffreys, A. J., Neumann, R. and Wilson, V. (1990) Repeat unit sequence variation in minisatellites: a novel source of DNA polymorphism for studying variation and mutation by single molecule analysis. Cell, 60, 473485.

39. Polyzos, A., Parfett, C., Healy, C., Douglas, G. and Yauk, C. (2006) A single-molecule PCR approach to the measurement of induced expanded simple tandem repeat instability in vitro. Mutat. Res., 594, 93-100.

40. Ehmcke, J., Wistuba, J. and Schlatt, S. (2006) Spermatogonial stem cells: questions, models and perspectives. Hum. Reprod. Update, 12, 275-282.

41. Adler, I. D. (1996) Comparison of the duration of spermatogenesis between male rodents and humans. Mutat. Res., 352, 169-172.

42. Dubrova, Y. E. (2005) Radiation-induced mutation at tandem repeat DNA loci in the mouse germline: spectra and doubling doses. Radiat. Res., 163, 200-207.

43. Niwa, O. and Kominami, R. (2001) Untargeted mutation of the maternally derived mouse hypervariable minisatellite allele in F1 mice born to irradiated spermatozoa. Proc. Natl Acad. Sci. USA, 98, 1705-1710.

44. Yauk, C., Polyzos, A., Rowan-Carroll, A. et al. (2008) Germ-line mutations, DNA damage, and global hypermethylation in mice exposed to particulate air pollution in an urban/industrial location. Proc. Natl Acad. Sci. USA, 105, 605-610.

45. Pessot, C. A., Brito, M., Figueroa, J., Concha, I. I., Yanez, A. and Burzio, L. O. (1989) Presence of RNA in the sperm nucleus. Biochem. Biophys. Res. Commun., 158, 272-278.

46. Ostermeier, G. C., Goodrich, R. J., Diamond, M. P., Dix, D. J. and Krawetz, S. A. (2005) Toward using stable spermatozoal RNAs for prognostic assessment of male factor fertility. Fertil. Steril., 83, 1687-1694.

47. Gatchel, J. R. and Zoghbi, H. Y. (2005) Diseases of unstable repeat expansion: mechanisms and common principles. Nat. Rev. Genet., 6, 743-755.

48.Dubrova, Y. E., Jeffreys, A. J. and Malashenko, A. M. (1993) Mouse minisatellite mutations induced by ionizing radiation. Nat. Genet., 5, 92-94. 
49. Dubrova, Y. E., Plumb, M., Brown, J., Fennelly, J., Bois, P., Goodhead, D. and Jeffreys, A. J. (1998) Stage specificity, dose response, and doubling dose for mouse minisatellite germ-line mutation induced by acute radiation. Proc. Natl Acad. Sci. USA, 95, 6251-6255.

50. Kelly, R., Gibbs, M., Collick, A. and Jeffreys, A. J. (1991) Spontaneous mutation at the hypervariable mouse minisatellite locus Ms6-hm: flanking DNA sequence and analysis of germline and early somatic mutation events. Proc. Biol. Sci., 245, 235-245.

51. Wyrobek, A. J., Mulvihill, J. J., Wassom, J. S. et al. (2007) Assessing human germ-cell mutagenesis in the Postgenome Era: a celebration of the legacy of William Lawson (Bill) Russell. Environ. Mol. Mutagen., 48, 71-95. 



\section{EVALUATION OF RANDOMLY AMPLIFIED POLYMORPHIC DNA (RAPD)-PCR AS METHODOLOGY TO ASSESS} MUTATION FREQUENCIES

Manuscript in preparation

Joost O. Linschooten

Sabine A.S. Langie

Nicole Verhofstad

Danielle Pachen

Lou Maas

Roland K. Chiu

Fredrik J. van Schooten

Roger W.L. Godschalk 


\section{Abstract}

Various methodologies have been developed to analyze mutation induction after exposure to genotoxic agents. These assays preferably need to be easy and quick to perform, versatile and cheap. One promising assay to detect mutations is Randomly Amplified Polymorphic DNA (RAPD)-PCR, but it needs further validation. This method has the potential to detect a wide range of mutations, but it may also lack reproducibility. To further evaluate this method in assessing mutations, it was compared with the well established HPRT mutation analysis in vitro. For this purpose, two cell types were exposed to benzo[a]pyrene-diol-epoxide (BPDE); A549 cell lines stably expressing ubiquitin either in its Wild type-form (WT-Ub) or as Lys63-mutants (K63R-Ub). The latter blocks ubiquitin chain formation through K63, forcing DNA damage avoidance pathways into the errorprone translesion synthesis resulting in increased BPDE-induced mutagenicity. RAPDPCR data indeed showed a significant dose-dependent change in the PCR-product intensity, but there were no new PCR-products and no differences between WT-Ub and K63R-Ub cells. However, using the HPRT assay, the dose-dependent increase in pointmutations was significantly higher in the K63R-Ub compared to the WT-Ub cells. These data suggest that RAPD-PCR is not reliably reflecting the induction of point-mutations. Furthermore, a significant relation was observed between levels of endogenous DNA damage and the alterations as detected by the RAPD-PCR, indicating that this assay may be sensitive for Taq polymerase blockage. We therefore conclude that the RAPD-PCR is not reliable for the analysis of genetic alterations in vitro. 


\section{Introduction}

It is now generally accepted that cancer is a multi-step process that comprises some critical steps to produce irreversible changes in the genetic material; i.e. mutations [1]. When these mutations already occur in germ cells, the offspring seems to be more susceptible for the development of cancer [2]. With respect to effects of specific exposures and the effects on next generations, it is therefore needed to detect these genetic alterations in both parents and offspring. An overview of several methodologies to detect germline mutations was presented by Verhofstad et al. [3]. One of the assays to potentially detect germline mutations, which still need further validation, is the Random Amplified Polymorphic DNA-PCR (RAPD-PCR). In this simple technique genomic DNA is amplified with single primers of arbitrary nucleotide sequence [4]. With the RAPDPCR it is possible to produce genetic maps or detect genomic alterations without prior information about the loci [3]. Each PCR reaction produces multiple fragments and the various amplification products are revealed by agarose gel electrophoresis [5] or capillary electrophoresis [6]. In theory, the RAPD-PCR method has the potential to detect a wide range of mutations (point mutations and large rearrangements). However, it has also been reported that this assay lacks reproducibility, because of DNA damage (e.g. polymerase blocking by DNA adducts or DNA breaks) [7]. In general, the amplification using a set of random primers results in a primer-specific profile in samples that are related to each other (parents vs. offspring or cell clones). A genetic alteration can result in a deletion of a primer binding site or creation of an extra primer binding site, which respectively leads to extra PCR products or the loss of products. This theoretical outcome is unfortunately not a reflection of the practical outcome, since most studies did not report new bands or band disappearance; an overall change in band intensities was more often discovered [8], which is indicative for DNA damage related blockage of the Taq polymerase affecting amplification efficiency [9], or could be attributed to conformational DNA changes possibly improving the access of primers [10]. The sensitivity of this assay was also questioned, since Jones and Kortenkamp showed that the RAPD-PCR can detect mutations only if they occur in at least $2 \%$ of the DNA [5]. Another disadvantage is that the use of random primers can result in amplification of any kind of DNA, either coding or non-coding. If mutations are detected, the effects of these mutations are difficult to extrapolate, since the mutations can also occur in a non-coding part of the DNA and might not have any effect on the phenotype. Thus, the RAPD-PCR seems a fairly quick and simple technique, but it has some drawbacks in the interpretation of the results.

Therefore, to further investigate the usefulness of this methodology in assessing mutations, it was compared with the validated hypoxanthine-guanine phosphoribosyl transferase (HPRT) mutation analysis. It was already reported that the HPRT assay is probably more sensitive than the RAPD-PCR in mammalian cell lines [5], but further comparisons are needed to establish the usefulness of RAPD-PCR. To this end, two cell types were exposed to various concentrations of the known DNA damaging compound benzo[a]pyrene-7,8-dihydrodiol-9,10-epoxide (BPDE) [11]. We applied previously established A549 cell lines stably expressing ubiquitin either in its WT-form (WT-Ub) or as Lys63-mutants (K63R-Ub) which blocks further ubiquitination through K63 [12]. Chiu et al. showed that PCNA is poly-ubiquitinated after BPDE-treatment and therefore disruption of K63-polyUb chain formation increased BPDE-induced mutagenicity is in these mutant cells [12]. 


\section{Materials \& Methods}

\section{Cell strains and cultures}

A549 cells (human epithelial lung carcinoma cells) were stably transfected as described by Langie et al. [13] in order to retrieve two cell lines, WT-Ub-GFP and K63R-Ub-GFP. Both cell lines were cultured in a humidified atmosphere at $37^{\circ} \mathrm{C}(5 \% \mathrm{CO} 2)$, in DMEM (Sigma, St. Louis) supplemented with $10 \%$ heat inactivated FCS (Gibco Invitrogen, Scotland, UK). Cells were routinely grown in $75 \mathrm{~cm}^{2}$ cell-culture flasks and were passaged twice a week until experimental use between passage 20 and 25. Both cell lines, A549 WT-Ub and K63R-Ub, were used before to determine effects of exposure to BPDE, since polyubiquitination is blocked in the mutant cell line. Therefore, DNA damage avoidance is 'forced' into translesion synthesis by error-prone Y-family polymerases in the K63R-Ub cells.

\section{Cell treatments}

Before BPDE-exposure, medium was aspirated and cells were washed with sterile HBSS (-Ca/-Mg) (Gibco Invitrogen, Scotland, UK). BPDE (NCI Chemical Carcinogen Reference Standard Repository, Midwest Research Institute, Kansas City, MO) was dissolved in anhydrous dimethyl sulfoxide (DMSO, Merck, Darmstadt, Germany) at a concentration of $20 \mathrm{mM}$. This stock solution was diluted in culture medium to the desired concentrations of $0.1-1 \mu \mathrm{M}$ and immediately added to the cells (see figure 1). The final DMSO concentration was always $0.5 \%$ [14]. After 30 min of incubation at $37^{\circ} \mathrm{C}$, medium containing BPDE was replaced by fresh culture medium.

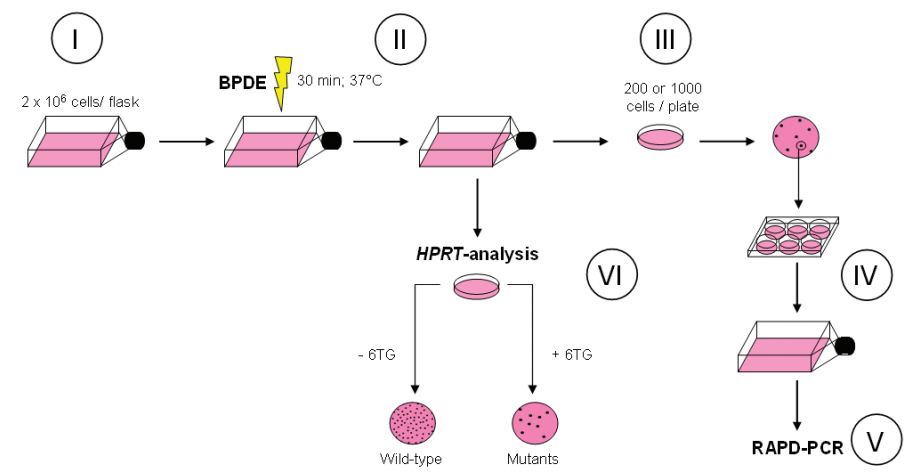

Figure 1: Exposure protocol of A549 WT-Ub and K63R-Ub. Cell culture conditions were always $37^{\circ} \mathrm{C}$ and $5 \% \mathrm{CO} 2$. Cells were cultured to $2 \times 10^{6}$ cells per flask (I). Cells were exposed to medium with or without BPDE (resp. 0, 0.1, 0.5 or $1.0 \mu \mathrm{M}$ ) for $30 \mathrm{~min}$ at $37^{\circ} \mathrm{C}$ after which the medium was replaced (II). Cells were trypsinized and cell suspensions were plated out in either 200 or 1000 cells per $60 \mathrm{~mm}$ dish to obtain single colonies (III). Isolated colonies were picked and expanded to a confluent T-75 culture flask per colony (IV). The final number of colonies grown to confluence differs in all exposure conditions, since not every colony succeeded in growing after exposure. From these confluent flasks DNA was isolated and used for RAPD-PCR analysis (V). Cell suspensions were also plated out with $1 \times 10^{6}$ cells per $100 \mathrm{~mm}$ dish and cultured with or without $6-\mathrm{TG}$ in the medium (VI). Only mutated cells that are 6-TG resistant will form colonies. In parallel, cells were plated (200 cells/100 mm dish) in medium lacking 6-TG to determine the plating efficiency at the time of selection. 
Subsequently, cells were diluted and seeded at a density 200 or 1000 cells/60 mm dish (Falcon, Le Pont De Claix, France). Dishes were cultivated for $\sim 14$ days to supply enough time for the cells to form colonies. After the incubation time, colonies on the dishes were selected which were growing separately from other colonies. Those colonies were scraped off using a pipette tip with a small volume of culture medium, and the scraped colony was directly resuspended in fresh culture medium. The cell material was transferred to 96-wells plates (Corning Inc., Corning, NY, USA) and grown to confluency and in this way grown to confluent $75 \mathrm{~cm}^{2}$ cell-culture flasks that provide enough cellmaterial for DNA isolation. Confluent culture flasks $\left(75 \mathrm{~cm}^{2}\right)$ were trypsinized and cell suspensions were centrifuged 5 min $300 \mathrm{~g}$. Supernatant was removed and cell pellets were stored at $-20^{\circ} \mathrm{C}$ until use.

\section{HPRT-mutation analysis}

HPRT-mutation analysis was performed as described by Langie et al. [13]. For the determination of HPRT-mutant frequencies in K63R-Ub and WT-Ub expressing cells, cells were seeded at $1 \times 10^{6}$ cells per $100 \mathrm{~mm}$ dish (Falcon, Le Pont De Claix, France) and cultured in hypoxanthine, aminopterin, and thymidine (HAT) supplemented culture medium for one week, to eliminate background HPRT mutations. Subsequently, cells were exposed to the indicated concentrations of BPDE $\left(30 \mathrm{~min}, 37^{\circ} \mathrm{C}\right)$ and were maintained for one week to allow for phenotypic expression of the acquired mutations. Cells carrying mutated HPRT were then selected in gentamicin-containing medium supplemented with $30 \mu \mathrm{M}$ 6-thioguanine (6-TG). After $\sim 14$ days of culture, cells were fixed and stained with $2 \%$ bromophenol blue in $70 \%$ ethanol. 6-TG resistant colonies consisting of 50 or more cells were counted. In parallel, cells were plated (200 cells/100 mm dish) in medium lacking 6-TG to determine the plating efficiency at the time of selection. Mutation frequency for each treatment was calculated as follows; mutation frequency = \# colonies/ (plating efficiency $\times \#$ cells seeded).

\section{DNA isolation}

Cell pellets were lysed in $400 \mu$ l lysis buffer $(50 \mathrm{mM} \mathrm{NaCl}, 18.75 \mathrm{mM}$ EDTA, $15 \mathrm{mM}$ TrisHCl $\mathrm{pH} 8.5$ and $0,5 \% \mathrm{SDS}$ ) and $50 \mu \mathrm{l}$ proteinase $\mathrm{K}(10 \mathrm{mg} / \mathrm{ml})$, and incubated overnight at $37^{\circ} \mathrm{C}$. DNA was extracted sequentially with phenol: chloroform: isoamylalcohol (25:24:1, $\mathrm{v} / \mathrm{v} / \mathrm{v})$ and chloroform: isoamylalcohol $(24: 1, \mathrm{v} / \mathrm{v})$. DNA was precipitated with 2 volumes of ice-cold $100 \%$ ethanol and $10 \% 3 \mathrm{M} \mathrm{NaAc}$ (pH 5.2). Pelleted DNA was washed with $80 \%$ ethanol, dried under nitrogen and dissolved in $\mathrm{mQ}$-water and stored at $-20^{\circ} \mathrm{C}$ until use. Concentrations and purity of all samples were determined spectrophotometrically.

\section{RAPD-PCR}

PCR reactions were performed on Whatman Biometra TProfessional Thermocyclers using the conditions as mentioned in table 1 in a total volume of $25 \mu$, with one of the random primers per reaction. For all primers (Eurofins MWG Operon, Edersberg, Germany, sequences in table 2) thermal cycling parameters consisted of 35 cycles: 1 min denaturation at $95^{\circ} \mathrm{C}$ (except for the first cycle: $4 \mathrm{~min}$ ), $1 \mathrm{~min}$ annealing at either $40^{\circ} \mathrm{C}$ or $48^{\circ} \mathrm{C}$, and 1 min extension at $72^{\circ} \mathrm{C}$ (except for the last cycle: $3 \mathrm{~min}$ ). All PCR reagents were from Invitrogen (Invitrogen Ltd, Paisley, UK) except when otherwise mentioned. PCR amplification products were electrophoresed in 1.5\% agarose gels at $170 \mathrm{~V}$ for $45 \mathrm{~min}$, stained with ethidium bromide and visualized under UV light. A photograph was taken 
using GeneSnap 5.00 (SynGene, Cambridge, UK) and analyzed using AIDA Image Analyzer V3.50 (Raytest GmbH, Straubenhardt, Germany) to calculate band intensities.

Table 1: Overview of PCR parameters, including sequences of the 10 -mer primers $\left(5^{\prime} \rightarrow 3^{\prime}\right)$ used in this study. Each PCR reaction was performed with only one of the single random primers. PCR conditions were similar for primers 1,2 \& 3 , as well as for primers 4,5 and 6 .

\begin{tabular}{|c|c|c|c|c|c|c|}
\hline & \multicolumn{3}{|c|}{ Primers $1,2 \& 3$} & \multicolumn{3}{|c|}{ Primers 4,5 \& 6} \\
\hline \multirow[t]{3}{*}{ Primer sequences } & \multicolumn{3}{|c|}{ RAPD-1: TGGGCATCTG (10) } & \multicolumn{3}{|c|}{ RAPD-4: AGCTGCCGGG (10) } \\
\hline & \multicolumn{3}{|c|}{ RAPD-2: AAGGCTAGCG (10) } & \multicolumn{3}{|c|}{ RAPD-5: CGGCCCCTGT (10) } \\
\hline & \multicolumn{3}{|c|}{ RAPD-3: AGGCATTCCC (10) } & \multicolumn{3}{|c|}{ RAPD-6: CAGGCCCTTC (10) } \\
\hline PCR buffer & \multicolumn{3}{|c|}{$1 \times$} & \multicolumn{3}{|c|}{$1 \times$} \\
\hline $\mathrm{MgCl}_{2}$ & \multicolumn{3}{|c|}{$4 \mathrm{mM}$} & \multicolumn{3}{|c|}{$6 \mathrm{mM}$} \\
\hline dNTPs & \multicolumn{3}{|c|}{$0.2 \mu \mathrm{M}$ each } & \multicolumn{3}{|c|}{$0.2 \mu \mathrm{M}$ each } \\
\hline Primer concentration & \multicolumn{3}{|c|}{$0.6 \mu \mathrm{M}$} & \multicolumn{3}{|c|}{$0.6 \mu \mathrm{M}$} \\
\hline Taq Polymerase & \multicolumn{3}{|c|}{$0.10 \mathrm{U} / \mu \mathrm{l}$} & \multicolumn{3}{|c|}{$0.08 \mathrm{U} / \mu \mathrm{l}$} \\
\hline DNA & \multicolumn{3}{|c|}{$1.0 \mathrm{ng} / \mu \mathrm{l}$} & \multicolumn{3}{|c|}{$1.0 \mathrm{ng} / \mu \mathrm{l}$} \\
\hline \multicolumn{7}{|l|}{ PCR conditions } \\
\hline Denaturation & \multicolumn{3}{|c|}{$95^{\circ} \mathrm{C} ; 1 \mathrm{~min}$} & \multicolumn{3}{|c|}{$95^{\circ} \mathrm{C} ; 1 \mathrm{~min}$} \\
\hline Annealing & \multicolumn{3}{|c|}{$40^{\circ} \mathrm{C} ; 1 \mathrm{~min}$} & \multicolumn{3}{|c|}{$48^{\circ} \mathrm{C} ; 1 \mathrm{~min}$} \\
\hline Extension & \multicolumn{3}{|c|}{$72^{\circ} \mathrm{C} ; 1 \mathrm{~min}$} & \multicolumn{3}{|c|}{$72^{\circ} \mathrm{C} ; 1 \mathrm{~min}$} \\
\hline Cycles & \multicolumn{3}{|c|}{35} & \multicolumn{3}{|c|}{35} \\
\hline & RAPD-1 & RAPD-2 & RAPD-3 & RAPD-4 & RAPD-5 & RAPD-6 \\
\hline No. of visible bands & 15 & 14 & 10 & 13 & 17 & 13 \\
\hline
\end{tabular}

\section{Determination of 8-OHdG}

High performance liquid chromatography with electrochemical detection (HPLC-ECD) of 8-OHdG was based on a method described earlier [15]. Briefly, $30 \mu \mathrm{g}$ DNA was digested to deoxyribonucleosides by treatment with $6 \mu \mathrm{l} 0.5 \mathrm{M} \mathrm{NaAc}, 9 \mu \mathrm{l} 10 \mathrm{mM} \mathrm{ZnCl}$ and 1.5 $\mu \mathrm{l}$ nuclease P1 (stock: $1 \mathrm{U} / \mu \mathrm{l}$ ), and incubation for $90 \mathrm{sec}$ at $37^{\circ} \mathrm{C}$. Subsequently, $30 \mu \mathrm{l}$ $0.5 \mathrm{M}$ Tris- $\mathrm{HCl}(\mathrm{pH} 7.4)$ and $1.5 \mu \mathrm{l}$ alkali phosphatase $(0.014 \mathrm{U} / \mu \mathrm{l})$ was added followed by incubation at $37^{\circ} \mathrm{C}$ for $45 \mathrm{sec}$. The digest was then analysed by HPLC-ECD, using a Supelcosil ${ }^{\mathrm{TM}}$ LC-18S column $(250 \times 4.6 \mathrm{~mm})$ (Supelco Park, Bellefonte, PA) and a DECADE electrochemical detector (Antec, Leiden, The Netherlands). The ECD-signal was first stabilized with mobile phase $\left(94 \mathrm{mM} \mathrm{KH}_{2} \mathrm{PO}_{4}, 13 \mathrm{mM} \mathrm{K}_{2} \mathrm{HPO}_{4}, 26 \mathrm{mM} \mathrm{KCl}\right.$ and $0.5 \mathrm{mM}$ EDTA, $10 \%$ methanol) for approximately 3 hours at a flow rate of $1 \mathrm{~mL} / \mathrm{min}$. After stabilization, 8-OHdG was detected at a potential of $400 \mathrm{mV}$ and $\mathrm{dG}$ was simultaneously monitored by UV absorption at $260 \mathrm{~nm}$.

\section{Statistical Analysis}

\section{$R A P D-P C R$}

Band intensities were analyzed for every band identifiable in each sample and from the representative peak patterns the area under the curve (AUC) was used as dimension for intensity of each band separately. In each individual sample, intensities of single PCR products were corrected for overall intensity of all products. Non-exposed samples of WT-Ub cells were used as control and AUC's of all exposed samples (WT-Ub and K63R- 
$\mathrm{Ub}$ ) were compared to these controls. Bands were identified as mutants when intensity changed more than average \pm 2 times standard deviation from control band intensity. This analysis was performed primer-specific and finally a total mutation frequency per exposure condition and cell-type for all primers was calculated.

\section{HPRT mutation analysis}

To examine differences in HPRT-mutation frequencies after exposure to various concentrations of BPDE versus the control ( $0 \mu \mathrm{M}$ BPDE), one-way ANOVA was used with subsequent Dunnett's-correction for multiple comparisons.

\section{Results}

\section{Amplification and visualization of RAPD-PCR products}

The RAPD-PCR uses random primers, amplifying random pieces of DNA. In this study, 6 different primers were used, all amplifying different products resulting in primer-specific patterns after gel electrophoresis. From each profile, band intensities were calculated and corrected for overall intensity of each individual sample. An average of 12 bands per primerset was scored (for more detailed information, see table 1). We observed differences in band intensities, which could not be ascribed to differences in DNA concentrations. Specific band intensities differed between samples, still showing the same primerspecific pattern (both decreased and increased intensities were observed).

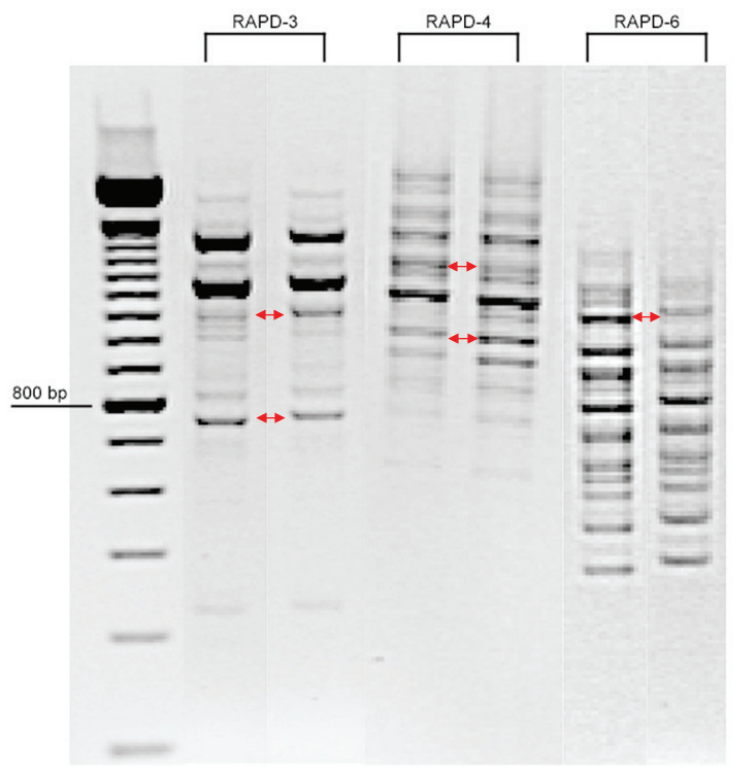

Figure 2: Representative patterns of the RAPD-PCR analysis using specific primers. No new bands appeared or existing bands disappeared after exposure to BPDE, but band intensities differed significantly (indicated by red arrows), which was not caused by differences in DNA concentrations. 


\section{Mutation frequencies as determined by RAPD-PCR and HPRT assay}

PCR-product intensities were quantified and fold changes between exposed and unexposed K63R-Ub and WT-Ub cells were calculated. Unexposed Wt-Ub were used as control samples (reference $=1.00$ ). Mutation frequencies at the HPRT locus were corrected for cell survival and calculated per 100,000 cells and compared to controls. Both assays show a dose-dependent increase in 'genetic alterations', as can be seen in table 2. Notably, exposure to $1 \mu \mathrm{M}$ BPDE resulted in a seven-fold increase in the PCR-product profile assessed by RAPD-PCR, but there were no differences between WT-Ub and K63R-Ub.

In the HPRT assay, the highest BPDE dose showed an increase from 0.00 to 16.7 HPRT-variants per $10^{5}$ cells in the WT-Ub cells, where the mutation frequency in the K63R$\mathrm{Ub}$ cells is almost 320 per $10^{5}$ cells $(p<0.001)$. Although the experiments are carried out in similar conditions, the RAPD-PCR lacked the ability to detect exposure-related genetic alterations between the cell lines.

Table 2: Genetic alterations in both cell lines as determined by both RAPD-PCR and HPRT-analysis.

\begin{tabular}{c|cc|cc}
\hline \multirow{2}{*}{ BPDE dose $[\mu \mathrm{M}]$} & \multicolumn{2}{|c|}{ RAPD-PCR $^{1}$} & \multicolumn{2}{c}{ HPRT-assay ${ }^{2}$} \\
\hline 0 & WT-Ub & K63R-Ub & WT-Ub & K63R-Ub \\
\hline 0.1 & 1.00 (= ref.) & 1.25 & 0.00 & 0.00 \\
0.5 & 5.18 & 5.59 & 0.23 & $7^{*}$ \\
1.0 & 6.06 & 6.66 & 2.92 & $2^{*}$ \\
& 7.71 & 7.98 & 16.74 & $319.96^{*}$ \\
\hline
\end{tabular}

${ }^{1}$ RAPD-PCR data are expressed as fold change compared to reference samples (0 $\mu \mathrm{M}$ BPDE in A549 WT-Ub). ${ }^{2} H P R T$ data are presented as mutation frequency per $10^{5}$ cells and corrected for survival rate. ${ }^{*} p<0.001, \mathrm{~K} 63 \mathrm{R}-$ Ub vs. WT-Ub

\section{Inhibition of polymerase activity by oxidative DNA damage}

Changes in band intensities by RAPD-PCR are most probably induced by blockage of the Taq polymerase. The processivity of the Taq polymerase can be affected by intrinsic inhibitory factors, one of which is DNA damage, which blocks the replication process. BPDE-exposure was 14 days before cell collection and the cells were expanded from a single colony to a full T-75 culture flask. Therefore, it was expected that Taq polymerase blockage in the PCR cannot be caused by BPDE-DNA adducts (these will be removed by DNA repair and diluted by cell divisions). Therefore, the amount of oxidative DNA damage was determined by 8-OHdG detection; although 8-oxo-dG is not a polymerase blocking lesion, it may reflect overall DNA damage by oxidative stress, including lesions that can block the polymerase. 8-OHdG levels were indeed related to the mutation frequencies as detected by RAPD-PCR, with a higher number of bands with altered intensity in those samples with relatively high $8-\mathrm{OHdG}$ levels (above median) $(p<0.05$, student's $t$-test) (figure 3). 


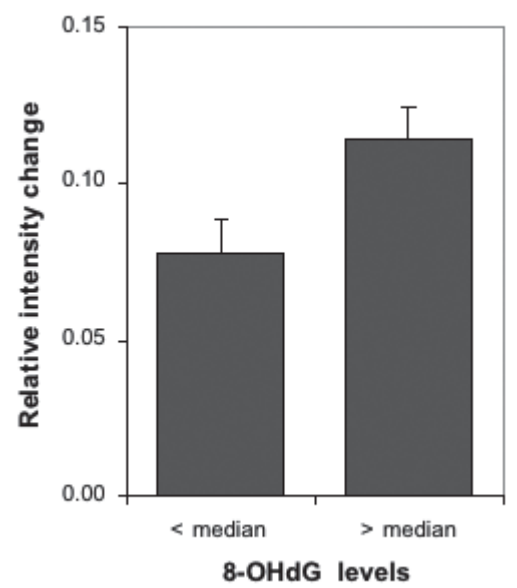

Figure 3: Changed PCR-product intensity as detected by RAPD-PCR was significantly increased in the subset of samples with 8-OHdG levels above the median. This suggests that differences in intensities are not only introduced by mutations, but that oxidative damage also plays a role. It inhibits PCR reactions by blockage of polymerases. ${ }^{*} p<0.05$

\section{Discussion}

The RAPD-PCR has been widely used for genetic mapping, but it could also be a valuable screening tool to assess the ability of chemicals to induce DNA alterations. However, the RAPD-PCR has been criticized for its reproducibility and 'mutations' observed as new PCR-product have seldomly been confirmed by independent methodologies. To further investigate the value of RAPD-PCR, two cell lines were exposed in vitro to BPDE to induce genetic alterations. In the A549 K63R-Ub cells, polyubiquitination of PCNA is disrupted and therefore BPDE induced mutagenicity is enhanced, compared to its WT-form (WT-Ub). After exposure, cells were plated in low concentrations resulting in clear colonies from small number of cells that could be picked easily. In this way, every colony originates from a single cell that was exposed to BPDE. In order to retrieve enough DNA for analysis, these colonies were grown separately to confluency in T-75 flasks. The amount of potential genetic alterations was determined using the RAPD-PCR assay. Changes in DNA sequences might lead to an increase or decrease of binding sites for the primers and thus changes in the number or intensity of bands after gel electrophoresis (as illustrated by Verhofstad et al. [3]). To further validate this assay, the HPRT assay was performed simultaneously.

Although the results from the RAPD-PCR show that there is a dose-dependent change in the PCR-product profile (i.e., band intensities), there was no difference between WT$\mathrm{Ub}$ and K63R-Ub. However, such a difference was expected because the HPRT assay showed a clear difference between these 2 cell lines. Since the HPRT assay is thought to reflect BPDE induced point-mutations [13], it can be concluded that the RAPD-PCR assay lacks the ability to detect point mutations.

The use of the RAPD-PCR to detect different DNA alterations was previously evaluated by Atienzar et al. [8]. In several studies, DNA modifications were able to introduce new bands in the pattern or loss of bands. However, in BPDE-modified DNA, mainly an overall decrease in band intensities starting in the highest molecular weight bands was observed. The explanation for these changes of band intensities was ascribed to altered processivity of the Taq polymerase. It is also known that conformational DNA 
changes or the presence of DNA adducts have an effect on the accessibility of the DNA for the primers $[7,9,10]$. We also observed differences in band intensities, but we did not detect any change in the number of bands. Based on the very high mutation frequencies as determined by the HPRT assay (up to 1 HPRT-mutant per 300 cells), at least a few changes in the amount of bands in the patterns were expected in the RAPDPCR gels. In our experimental setup cells were directly exposed to BPDE in order to induce mutations. After 30 minutes of exposure to BPDE, the cells were diluted and left to grown colonies and finally cultured to confluent T75 flasks. This will result in a dilution of BPDE-DNA adducts in one cell to a total of approximately $10^{7}$ cells in a confluent flask. Moreover, in both cell lines DNA repair systems are still effective, even though in the K63R-Ub translesion synthesis is inactive, which is important for the error-free processing of BPDE-DNA adducts $[16,17]$. Therefore, the level of persistent BPDE-DNA adducts will be too low to explain the observed differences in band intensities. Genetic alterations (i.e. insertions, deletions) will predominantly result in new bands or disappearing bands in the pattern, and therefore we assume that the differences as detected by the RAPDPCR, are more related to endogenous types of DNA damage. It was already reported that differences in band intensities could be the result of blockage of the polymerase reaction [18]. Although we only detected differences in band intensities, we were able to show that with both the RAPD-PCR and the HPRT mutation assay a dose-dependent increase in 'genetic' alterations was observed. We suggest that the changes in band intensities as detected by the RAPD-PCR are from a different origin as the alterations that caused the increase in the HPRT mutation analysis. Therefore, the amount of oxidative DNA damage in these samples was determined by measurement of $8-\mathrm{OHdG}$, which is a reliable marker for oxidative stress. There appeared to be a relation between $8-\mathrm{OHdG}$ levels and the changes in band intensities as detected by the RAPD-PCR. Therefore we suggest that if more oxidative damage is present, the PCR reaction is more often blocked, which will lead to larger differences in amplification. 8-OHdG by itself is not a polymerase blocking lesion, but it could be a marker for other endogenous lesions that can interfere with proper DNA amplification, which makes it even more difficult to interpret the outcomes of the RAPD-PCR in terms of actual genetic modifications, such as mutations. Interestingly, these data also indicate that a single in vitro exposure to BPDE might have long-lasting effects on oxidative DNA damage formation.

Several studies that used the RAPD-PCR to study genomic instability concluded that the RAPD-PCR assay is very complementary to existing DNA fingerprinting, such as micro- and minisatellite mapping [7]. The measurement of mutations at non-coding tandem repetitive DNA sequences (such as minisatellites) was suggested to be a most promising approach to quantify heritable genetic mutations $[19,20]$. It has already been shown that significant increases in tandem repeat mutation frequencies after relatively low doses of exposure of environmental mutagens [21] and mainstream tobacco smoke [22]. Since BPDE is one of the major mutagenic metabolites of benzo[a]pyrene, which is present in cigarette smoke, the analysis of repetitive sequences might deliver better data than RAPD-PCR.

Altogether, the RAPD-PCR is widely accepted as a reliable assay to produce genetic maps, but does not provide easy interpretable data with respect to mutation analysis. We did not detect the appearance or loss of bands, but we did detect differences in band intensities, which lead to a clear dose-dependent increase in quantities of PCR-products. It appeared that there is a relation with endogenous DNA damage and therefore, we assume that this assay is not able to pick up genetic alterations, such as point mutations, but rather is sensitive to Taq polymerase blocking lesions. The RAPD-PCR needs intensive optimization to obtain reliable interpretable data, where the number of false-positives is decreased to a minimum. 


\section{References}

1. Compton, P.J., K. Hooper, and M.T. Smith, Human somatic mutation assays as biomarkers of carcinogenesis. Environ Health Perspect, 1991. 94: p. 135-41.

2. Tamura, K., J. Utsunomiya, T. Iwama, J. Furuyama, T. Takagawa, N. Takeda, et al., Mechanism of carcinogenesis in familial tumors. Int J Clin Oncol, 2004. 9(4): p. 232-45.

3. Verhofstad, N., J.O. Linschooten, J. van Benthem, Y.E. Dubrova, H. van Steeg, F.J. van Schooten, et al., New methods for assessing male germ line mutations in humans and genetic risks in their offspring. Mutagenesis, 2008.

4. Williams, J.G., A.R. Kubelik, K.J. Livak, J.A. Rafalski, and S.V. Tingey, DNA polymorphisms amplified by arbitrary primers are useful as genetic markers. Nucleic Acids Res, 1990. 18(22): p. 6531-5.

5. Jones, C. and A. Kortenkamp, RAPD library fingerprinting of bacterial and human DNA: applications in mutation detection. Teratog Carcinog Mutagen, 2000. 20(2): p. 49-63.

6. Valentini, A., A.M. Timperio, I. Cappuccio, and L. Zolla, Random amplified polymorphic DNA (RAPD) interpretation requires a sensitive method for the detection of amplified DNA. Electrophoresis, 1996. 17(10): p. 1553-4.

7. Atienzar, F.A. and A.N. Jha, The random amplified polymorphic DNA (RAPD) assay and related techniques applied to genotoxicity and carcinogenesis studies: a critical review. Mutat Res, 2006. 613(2-3): p. 76-102.

8. Atienzar, F.A., P. Venier, A.N. Jha, and M.H. Depledge, Evaluation of the random amplified polymorphic DNA (RAPD) assay for the detection of DNA damage and mutations. Mutat Res, 2002. 521(1-2): p. 151-63.

9. Chary, P. and R.S. Lloyd, In vitro replication by prokaryotic and eukaryotic polymerases on DNA templates containing site-specific and stereospecific benzo[a]pyrene-7,8-dihydrodiol-9,10-epoxide adducts. Nucleic Acids Res, 1995. 23(8): p. 1398-405

10. Pietrasanta, L.I., B.L. Smith, and M.C. MacLeod, A novel approach for analyzing the structure of DNA modified by Benzo[a]pyrene diol epoxide at single-molecule resolution. Chem Res Toxicol, 2000. 13(5): p. 351-5.

11. Cheng, S.C., B.D. Hilton, J.M. Roman, and A. Dipple, DNA adducts from carcinogenic and noncarcinogenic enantiomers of benzo[a]pyrene dihydrodiol epoxide. Chem Res Toxicol, 1989. 2(5): p. 334-40.

12. Chiu, R.K., J. Brun, C. Ramaekers, J. Theys, L. Weng, P. Lambin, et al., Lysine 63-polyubiquitination guards against translesion synthesis-induced mutations. PLoS Genet, 2006. 2(7): p. e116.

13. Langie, S.A., A.M. Knaapen, C.H. Ramaekers, J. Theys, J. Brun, R.W. Godschalk, et al., Formation of lysine 63-linked poly-ubiquitin chains protects human lung cells against benzo[a]pyrene-diol-epoxide-induced mutagenicity. DNA Repair (Amst), 2007. 6(6): p. 852-62.

14. van Schooten, F.J., M.J. Hillebrand, E. Scherer, L. den Engelse, and E. Kriek, Immunocytochemical visualization of DNA adducts in mouse tissues and human white blood cells following treatment with benzo[a]pyrene or its diol epoxide. A quantitative approach. Carcinogenesis, 1991. 12(3): p. 427-33.

15. de Kok, T.M., F. ten Vaarwerk, I. Zwingman, J.M. van Maanen, and J.C. Kleinjans, Peroxidation of linoleic, arachidonic and oleic acid in relation to the induction of oxidative DNA damage and cytogenetic effects. Carcinogenesis, 1994. 15(7): p. 1399-404.

16. Ogi, T., Y. Shinkai, K. Tanaka, and H. Ohmori, Polkappa protects mammalian cells against the lethal and mutagenic effects of benzo[a]pyrene. Proc Natl Acad Sci U S A, 2002. 99(24): p. 15548-53.

17. Zhang, Y., X. Wu, D. Guo, O. Rechkoblit, N.E. Geacintov, and Z. Wang, Two-step error-prone bypass of the (+)- and (-)-trans-anti-BPDE-N2-dG adducts by human DNA polymerases eta and kappa. Mutat Res, 2002. 510(1-2): p. 23-35.

18. He, S., H. Ohm, and S. Mackenzie, Detection of DNA sequence polymorphisms among wheat varieties. Theoretical and Applied Genetics 1992. 84(5-6): p. 573-578.

19. Dubrova, Y.E., M. Plumb, J. Brown, and A.J. Jeffreys, Radiation-induced germline instability at minisatellite loci. Int J Radiat Biol, 1998. 74(6): p. 689-96.

20. Yauk, C.L., A. Polyzos, A. Rowan-Carroll, I. Kortubash, A. Williams, and O. Kovalchuk, Tandem repeat mutation, global DNA methylation, and regulation of DNA methyltransferases in cultured mouse embryonic fibroblast cells chronically exposed to chemicals with different modes of action. Environ Mol Mutagen, 2008. 49(1): p. 26-35.

21. Somers, C.M., C.L. Yauk, P.A. White, C.L. Parfett, and J.S. Quinn, Air pollution induces heritable DNA mutations. Proc Natl Acad Sci U S A, 2002. 99(25): p. 15904-7

22. Yauk, C.L., M.L. Berndt, A. Williams, A. Rowan-Carroll, G.R. Douglas, and M.R. Stampfli, Mainstream tobacco smoke causes paternal germ-line DNA mutation. Cancer Res, 2007. 67(11): p. 5103-6. 



\title{
CHAPTER 7 \\ PATERNAL LIFESTYLE AS A POTENTIAL SOURCE OF GERMLINE MUTATIONS TRANSMITTED TO OFFSPRING
} 103

Manuscript in preparation

\author{
Joost O. Linschooten \\ Nicole Verhofstad \\ Kristine Gutzkow \\ Gunnar Brunborg \\ Carole Yauk
}

Yvonne Oligschläger

Frederik J. van Schooten

Roger W.L. Godschalk 


\section{Abstract}

Minisatellites are a class of highly variable repetitive DNA sequences with a high frequency of germline mutations, especially after exposure to various mutagenic agents. In humans, analysis of minisatellites has predominantly been used to detect increases in mutation frequencies in offspring after parental exposure to radioactivity. The impact of general lifestyle factors on mutation frequencies remain uninvestigated. Therefore, two of the most common minisatellite probes (CEB1 and B6.7) were used to identify germline mutations in blood samples from complete mother - father - child triads from the Norwegian Mother and Child Cohort Study (MoBa) and lifestyle was assessed on basis of extensive questionnaires $(n=95)$. As both probes responded differently to lifestyle exposure data, they were analysed separately. Mutation rates at the B6.7 locus were mainly affected by alcohol consumption, but this did not reach statistical significance. No other factors could be identified on basis of the lifestyle questionnaires that affected the variability in B6.7 allele sizes. In contrast, at the CEB1 locus, a significant relation was found between low mutation rates and high gross year income $(p<0.05)$. These findings suggest that healthier lifestyles may contribute to lower germline mutation frequencies, because income was related to several lifestyle factors including smoking behaviour. CEB1 mutation rates derived from the paternal allele were indeed dose dependently increased when the father smoked in the 6 months before pregnancy $(p<0.05)$, and mutation rates increased with increased tobacco use. Finally, a strong protective effect was found for the consumption of unfiltered coffee by the father with significantly lower mutation rates in the offspring $(p<0.01)$ by frequent consumption ( 7 cups per week). These results suggest that inherited mutations are affected by paternal lifestyle. To our knowledge this is the first study reporting an effect of lifestyle on mutation rates in a human population with moderate paternal environmental exposures. 


\section{Introduction}

Minisatellites are highly unstable non-coding genetic elements that have success-fully been used to demonstrate that environmental factors can impact human and animal germline mutation rates [1-3]. Minisatellites consist of sequences with 10 to $>100 \mathrm{bp}$ repeat units, arranged in arrays ranging from 0.5 to $30 \mathrm{~kb}$ in length and are present throughout the whole eukaryotic genome [4]. Because of their instability, these tandem repetitive sequences have a high frequency of germline mutations and are therefore a potential sensitive tool for monitoring germline mutations after mutagenic exposure. These germline mutations at human minisatellites are the result of altered repeat copy number of the repetitive sequence caused predominantly by recombination and complex gene-conversion events [5]. The high mutation rates facilitate the assessment of induced mutations in a relatively small number of samples following environmentally relevant exposure [6]. As such, analysis of tandem repeat mutations, either directly by PCR analysis of sperm or by DNA fingerprinting in full families, is a proposed approach for the analysis fo the impact of environmental factors that may impact genetic disease in future generations [7].

There are several of these hypervariable loci in the DNA, which have a much higher mutation rate than unique sequence DNA. By using DNA fingerprinting techniques, several loci can be screened and thereby the probability of finding mutations is increased. This will result in both an increased power, as well as reduced time and costs for the analysis [3]. After digestion of DNA with restriction enzymes and electrophoresis, the DNA is transferred to nylon membranes by Southern blotting and subsequently hybridized with probes that are complementary to the hypervariable loci [4]. Each probe will result in a specific pattern and patterns between parents and offspring are easily compared, since each offspring band should also be present in one of the parents. For every hypervariable locus a specific probe needs to be designed in order to visualize two alleles per sample. The number of different specific probes is rather low, but still very efficient to provide mutational data, since mutations are easy to score.

Minisatellite mutation analysis has predominantly been applied to detect an increase in germline mutations in humans exposed to high levels of radioactivity [8]; for example, increased rates of paternally-inherited minisatellite mutations were found in children born to parents inhabiting the contaminated areas near the Chernobyl accident site relative to offspring conceived prior to the accident using this methodology [9]. No studies using this technique have been performed to investigate the effects of specific hazardous compounds people encounter in daily life, via for instance their diet. However, a number of animal studies on expanded simple tandem repeats (ESTRs), do show that it is possible to detect germline mutations after exposure to such compounds [7, 10-12], such as living in a heavily industrialized area. Since minisatellites and ESTRs are both unstable and predominantly non-coding DNA, ESTRs were initially classified as minisatellites, but are now recognized as a fundamentally different entity [13]. ESTRs consist of long arrays (up to $16 \mathrm{~kb}$ in length) of short $(<10 \mathrm{bp})$ repeat units. They show different mechanisms of mutation as compared to highly mutable GC-rich minisatellites and also exhibit high levels of somatic instability.

In this study we quantify mutation rates in human families for two of the most commonly used hypervariable minisatellite loci to identify germline mutations in the general population. CEB1 is the most hypermutable minisatellite characterized so far and has been widely used to study germline mutation [14, 15]. B6.7 is another very unstable human minisatellite $[2,16]$. For example, CEB1 and B6.7 have been used to demonstrate significant increased rates of heritable mutations arising in families exposed to high levels of radioactive contamination from various sources $[8,17]$. 
In general, we have little knowledge of the lifestyle choices or environmental variables that lead to mutations in gametes that are transmitted to children, or on transgenerational genetic instability. However, evidence is emerging to support the notion that specific exposures such as parental smoking, alcohol consumption or pesticide exposure may lead to effects in the offspring $[18,19]$. In the present study we investigate general lifestyle factors that may affect minisatellite germline mutations. To do this, blood samples from complete father - mother - child triads were made available from the large Norwegian Mother and Child Cohort Study 'MoBa' [20]. Lifestyle and general exposures were assessed on basis of extensive questionnaires.

\section{Materials \& Methods}

\section{Subjects and MoBa food frequency questionnaire}

The data set is part of the Norwegian Mother and Child Cohort Study (MoBa), initiated by and maintained at the Norwegian Institute of Public Health This study is presently the largest pregnancy cohort in the world with 107,000 pregnancies included since 1999 [20]. The women were asked to provide biological samples and to answer questionnaires covering a wide range of information, including education and work, diet and eating habits, health and lifestyle. The cohort database is linked to the Medical Birth Registry of Norway and other national health registries. The MoBa study has been approved by the Regional Committee for Ethics in Medical Research and the Data Inspectorate in Norway. A subgroup of 95 mothers was selected to participate in the current study, since paternal DNA was also available from this group. The MoBa food frequency questionnaire (FFQ) is a semi-quantitative FFQ designed specifically for assessing lifestyle and diet just before and during pregnancy from mother and father.

\section{DNA isolation}

Blood cell pellets were lysed overnight in $10 \mathrm{~mL}$ lysis buffer $(50 \mathrm{mM} \mathrm{NaCl}, 18.75 \mathrm{mM}$ EDTA, $15 \mathrm{mM}$ Tris HCl pH 8.5 and $0.5 \%$ SDS) and $50 \mu$ proteinase $\mathrm{K}$ [25 mg/ml] in a shaking water bath at $56^{\circ} \mathrm{C}$. Genomic DNA was extracted sequentially with phenol: chloroform: isoamylalcohol (25:24:1, v/v/v) and chloroform: isoamylalcohol (24:1, v/v). DNA was precipitated with 2 volumes of cold 100\% ethanol and $10 \% 3 \mathrm{M} \mathrm{NaAc}(\mathrm{pH}$ 5.2). Pelleted DNA was washed with $70 \%$ ethanol, dried under nitrogen and dissolved in $\mathrm{mQ}$-water. Concentrations of all samples were determined using a NanoDrop (IsogenLifescience).

\section{Minisatellite mutation analysis}

First, DNA $(10 \mu \mathrm{g})$ was digested overnight at $37^{\circ} \mathrm{C}$ to completion with 30 units Alul restriction enzyme (New England Biolabs), and digestions were checked for completion on a $40 \mathrm{~cm}$ long $0.8 \%$ Seakem LE agarose gel (Lonza, Basel, Switzerland) (2 h, 150V). DNA was size-fractionated in $40 \mathrm{~cm}$ long $0.8 \%$ Seakem LE agarose gels during $6 \mathrm{~h}$ of electrophoresis $(220 \mathrm{~V})$ at $4^{\circ} \mathrm{C}$. Although allele-sizes were not determined, all gels were run with $2 \mathrm{ng}$ of $1 \mathrm{~kb}$ ladder as size standard and for gel orientation. DNA was transferred to a nylon membrane (Hybond-XL, Amersham Pharmacia) by Southern blotting where it was fixed by ultra-violet (UV) cross-linking. DNA fingerprints were generated by 
sequential hybridization with ${ }^{32}$ P-labeled (Perkin-Elmer, Waltham, MA, USA) synthetic minisatellite probes B6.7 [2] and CEB1 [21], and were visualized by using FujiFilm imaging system FLA-3000 (Raytest, Straubenhardt, Germany). Scoring was performed without knowledge of exposure regimen and verified by a second observer. All scans of gels were processed to correct for slight differences in run time using the patterns of the $1 \mathrm{~kb}$ ladders and scans were all brought to the same frame size (A4). Next, parental alleles were marked and compared to the each corresponding offspring allele and when differences in offspring allele size were more than $1.5 \mathrm{~mm}$ larger or shorter, this was marked as a mutation. Smaller differences in length could be introduced by processing of the gels and scans, so these short differences were not considered true mutations for this analysis. Mutations included both increases and decreases in allele sizes compared to maternal and paternal alleles. Blots were completely stripped of probe DNA between hybridizations by boiling in $0.1 \%$ SDS and shaking for 10 minutes.

\section{Statistical analysis}

Since the main focus was on the mutations induced via the paternal side, only these mutations were included in the statistical analyses. Mutation rates were calculated as the number of mutant bands out of the total number of scored bands and mutation rates are presented for B6.7 and CEB1, both separately and combined. Families were subsequently divided into 2 groups according to the presence of germline mutations. Next, these two groups were screened for significant relations with FFQ outcomes using Chi-square tests. SPSS v. 15.0 was used for statistical analysis. A difference was considered significant at $p<0.05$.

\section{Results}

\section{Subjects and DNA isolation}

From all samples DNA was isolated and from the original 95 complete triads, only 81 triads had sufficient amounts of DNA in every sample for the analysis (i.e. > 10 $\mathrm{\mu g}$ per sample). Thus, samples with insufficient DNA for minisatellite analysis were excluded. The ages of the fathers and mothers were reported categorically and were on average between 30 and 34 years for fathers and between 25 and 29 for mothers. We acquired additional information on diet and smoking behaviour for all of the remaining 81 triads from the questionnaire.

\section{Minisatellite mutation analysis}

DNA fingerprints were made using two different probes: CEB1 and B6.7. Both CEB1 and B6.7 have shown to hybridize one single allele and appeared in mother, father and child, showing two bands if the subject was heterozygous or one band if homozygous. When no mutation was present, allele sizes in the child were comparable in size with those of their parents. However, mutations were called when there were clear instances where the allele size in the child's DNA differed from that seen in the parent (for an example see Figure 1). The intensity of some bands was too low to be detected and these samples therefore also had to be excluded for the statistical analysis of the specific probe. Furthermore, in some cases it was not possible to determine whether the mutation was caused by a deletion in 
the largest parental allele or an insertion in the smallest allele. Finally, samples in which mutations occurred in both probes were discarded from the analysis, because it could be questioned whether this was the corresponding biological father.

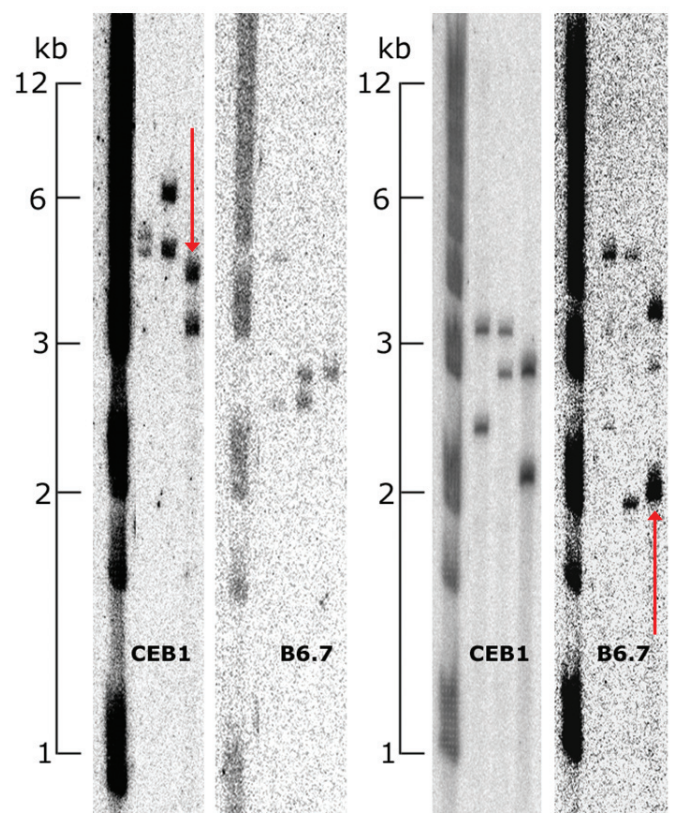

Figure 1: Representative picture of the CEB1 gel and corresponding B6.7 gel of two different families after hybridization with radioactively labelled probes, and scanned using a phosphoimager. The lanes from left to right contain: $1 \mathrm{~kb}$ ladder, maternal DNA, offspring DNA and paternal DNA, and orientation was kept identical on each separate gel. Paternal mutations, present at either the CEB1 allele or the B6.7 allele in a specific family, are indicated by the red arrows.

For both probes the number of mutant alleles was counted as well as the number of informative alleles (i.e., all usable alleles for scoring of mutations). Since some samples were excluded for statistical analysis, these numbers may vary per probe and between paternal and maternal alleles (table 1). A total number of 13 paternal mutations were found, originating from 5 mutations at B6.7 and 8 mutations at CEB1. Only 4 maternally derived mutations were detected, of which 1 was found for B6.7 and 3 for CEB1. Mutation frequencies were calculated by dividing the number of mutant alleles by the total number of observed bands (informative alleles). If both probes were taken together, the paternal mutation frequency was 0.08 ; the maternal mutation frequency was 0.03 . However, since these loci may respond differently to lifestyle or environmental variables, data for both probes were analysed separately. 
Table 1: Germline DNA mutation rates in offspring for both alleles separately and combined for all families .

\begin{tabular}{l|c|c|c|c}
\hline & Alleles & $\begin{array}{c}\text { Absolute number of } \\
\text { mutations }\end{array}$ & $\begin{array}{c}\text { Number of } \\
\text { informative alleles }\end{array}$ & $\begin{array}{c}\text { Mutation } \\
\text { frequency (MF) }\end{array}$ \\
\hline Paternal & B6.7 & 5 & 75 & 0.07 \\
& CEB1 & 8 & 81 & 0.10 \\
\hline Maternal & Total & 13 & 156 & 0.08 \\
\hline & B6.7 & 1 & 69 & 0.01 \\
& CEB1 & 3 & 75 & 0.04 \\
& Total & 4 & 144 & 0.03 \\
\hline
\end{tabular}

\section{Relationship with lifestyle factors}

In most previous studies on minisatellites in human populations, mutation frequencies were calculated as the sum of mutations using all probes. However, spontaneous and radiation-induced mutation frequencies were found to differ between the various probes that were used. Therefore, in this study both probes were initially analysed separately to identify which environmental factors might induce mutations at a specific locus.

\section{Mutations at B6.7}

Only 5 paternal mutations were found at the minisatellite B6.7 locus and 1 maternal mutation. Screening for a significant role for any of the questionnaire variables, resulted in a potential role for alcohol consumption; drinking of more than 3 times per week in the period of 6 months before pregnancy resulted in more mutations compared to the group that drank less, but this difference did not reach statistical significance $(p=0.08)$. Although the number of observed mutations is low, those fathers of children who carried a mutation of paternal origin tended to drink more prior to pregnancy. However, confirmation of this would require additional studies in a larger population.

\section{Mutations at CEB1}

At the CEB1 locus a total number of 11 mutations were found, of which 8 mutations were paternal in origin (see table 1). Screening for possible paternal lifestyle effects on the occurrence of mutations, showed a possible role for smoking before pregnancy and an inverse correlation with gross year income and consumption of unfiltered coffee. As not all subjects did accurately answer all questions in the FFQ, some values were missing leading to different numbers of mutations per type of exposure as shown in table 2.

Gross year income significantly affected the occurrence of mutations at the CEB1 allele $(p=0.039)$. Subjects with an average income of 400.000 Kroner per year or less (approximately $€ 51.000$ per year) had significantly more mutations than the group of subjects that had an income of $400.000 \mathrm{Kr}$ per year or more, suggesting that high income stimulates a healthier lifestyle. Indeed, there was a strong significant correlation between the groups based on smoking behaviour and the two income groups ( $p=0.03$, data not shown), suggesting that people with higher incomes tend to live healthier.

Furthermore, a significant increase in paternally derived mutations was observed when the father smoked in the 6 month period before his partner became pregnant ( $p=$ 0.039), not taking into account the amount and frequency of smoking (table 2). This effect was dose dependent when the subjects were divided into three groups of non-smoking (5.3\% with mutation), irregularly (18.8\% with mutation) or daily smokers (33.3\% with mutation). 
Table 2: Mutation frequencies at the CEB1 allele in relation to 3 specific lifestyle factors. Furthermore, income height was significantly inversely correlated with smoking behaviour $(p<0.05)$, indicating that people with higher incomes have healthier lifestyles.

\begin{tabular}{|c|c|c|c|c|}
\hline & \multicolumn{3}{|c|}{ CEB1 } \\
\hline & & Mutants & No mutants & $\%$ \\
\hline \multirow{3}{*}{$\begin{array}{l}\text { What was your gross income } \\
\text { last year? } \\
(400.000 \mathrm{kr}=+/-€ 51.000,-)\end{array}$} & & 6 & 26 & 18.8 \\
\hline & $400.000 \mathrm{kr}$ or more & 2 & 44 & 4.3 \\
\hline & Total & 8 & 70 & $p=0.039$ \\
\hline \multirow{3}{*}{$\begin{array}{l}\text { Did you smoke in the six } \\
\text { months before your partner } \\
\text { became pregnant? }\end{array}$} & No & 3 & 54 & 5.3 \\
\hline & Yes & 4 & 15 & 21.1 \\
\hline & Total & 7 & 69 & $p=0.039$ \\
\hline \multirow{3}{*}{$\begin{array}{l}\text { How often do you drink } \\
\text { unfiltered coffee? (cafetiere } \\
\text { coffee, espresso or similar) }\end{array}$} & & 6 & 15 & 28.6 \\
\hline & 1 cup per day or more & 2 & 51 & 3.8 \\
\hline & Total & 8 & 66 & $p=0.002$ \\
\hline
\end{tabular}

Furthermore, a negative correlation was found between CEB1 mutation frequencies and the consumption of unfiltered coffee, as in espresso or cafetiere coffee. Subjects who consumed 1 unit of unfiltered coffee per week or more had significantly less mutations than people who did not drink this type of coffee $(p<0.01)$. Again, this suggests a possible role for lifestyle in the induction or protection against paternally induced mutations. However, it should also be noted that this type of coffee was mostly consumed by people with above average incomes.

\section{Discussion}

The analysis of tandem repetitive sequences has demonstrated to be a sensitive method for the detection of germline mutations transmitted to the next generation either caused by acute exposure to high doses of radiation in humans, or long-term low-dose environmental exposure in experimental animals. No studies are currently available in which the effects of environmental or dietary exposures on human germline mutagenesis is studied, and therefore it was previously suggested that such effects need further evaluation [4].

In the present study, we determined mutation frequencies in Norwegian families exposed to environmental agents that are influenced by lifestyle choices, to further understand how basal mutation rates in minisatellite DNA can be affected by environmental variables. The subjects were not exposed to a high dose of a specific type of exposure (e.g., radiation, pesticides); they were predominantly exposed to genotoxins that are present in our every day environment and diet. Exposure levels were estimated from an extensive questionnaire, filled in by the father during pregnancy of the mother. Mutation frequencies were assessed by analyzing DNA from fathers, mothers and their offspring to identify size changes in the offspring for two different minisatellite loci. Although many studies have used this assay to detect mutations after high levels of exposure $[8,9,16]$, no other study focused on the explanation of variation in background mutation rates in a human study population.

Usually, mutation frequencies are reported as the sum of all mutations at different minisatellite loci, which is subsequently correlated to exposure levels. Although high levels of exposure may induce mutations at all loci used in previous studies, it is very likely that mutation frequencies and mechanisms differ between loci [14]. As such, the loci may be affected differently by the exposures, a hypothesis that is supported in our study. 
Therefore, we studied both loci separately to elucidate which environmental parameters affect germline mutation rates in the general population.

Mutations at the B6.7 alleles were not significantly affected by lifestyle factors evaluated as part of the MoBa questionnaire. However, the number of mutant alleles for B6.7 was relatively low and therefore it is likely that this study was underpowered for this allele. For mutation frequencies at the CEB1 allele, stronger relationships were found for some specific exposure parameters. Gross yearly income was significantly related with CEB1 mutation frequencies, suggesting that lower mutation rates are a result of a healthier lifestyle (which is possible because of a higher income). Previous work has demonstrated that having a lower income increases risk of mortality in healthy US populations [22]. Furthermore, smoking behaviour was also strongly correlated with CEB1 mutation frequencies. We have recently confirmed that smoking may affect sperm DNA integrity [23], which could be involved in the induction of mutations. Studies regarding effects of parental smoking on offspring have shown relations with severe birth defects and malformations [24]. Furthermore, earlier studies suggest that paternal cigarette smoking could increase risk of childhood cancer in children from non-smoking mothers. Although the evidence for this suggestion is rather weak in some studies, it does emphasize the risk of passive smoking during and possibly before pregnancy $[19,25,26]$.

Our data also show that consumption of unfiltered coffee might have a protective effect on CEB1 related mutations, since the group that used less than six consumptions per week, had a significantly higher mutation frequency as compared to the group that consumed at least one cup of unfiltered coffee each day. Whether coffee consumption might have a possible protective effect on reproductive outcomes is less certain. It is known that coffee contains compounds that elicit anti-oxidant effects [27, 28], which may be involved in the protection of the germline. One study reported adverse health effects in a group of women that abstained coffee [29], but there are no reports on effects of paternal coffee consumption. In most cases it is difficult to examine the effects of coffee consumption solely and therefore no strong relationships can be found with reproductive endpoints [30, 31].

Altogether, these data suggest a possible role for moderate levels of exposure on germline mutations in the offspring, encountered in the general population. Lifestyle has been intensively studied, but most outcomes focus on either female or male reproductive parameters. Studies in which paternal exposure to lifestyle factors was determined, found effects mainly related to sperm quality, spermatozoal malformations, or fertility [32]. Although many studies focussed on reproductive success rates, it remains unclear what the effects of increased mutation rates will have on the development of the offspring. Reported effects in offspring after paternal exposure to therapeutic and recreational drugs and ionizing radiation vary from increases in congenital malformations, spontaneous abortions, low birth weight, increases in childhood cancers, or developmental and neurobehavioral abnormalities [33]. However, little is known about how lifestyle factors influence inherited DNA sequence mutations that may be associated with overall genetic integrity and detrimental effects on health effects in humans.

In conclusion, the minisatellite mutation analysis is considered to be a highly sensitive method, although a large number of samples are required for adequate analysis of mutation rates. It was shown before, in both human and animal studies, that high levels of exposure are able to increase offspring mutations rates, but these events are relatively uncommon in most human-populated areas [34, 35]. To our knowledge this is the first study reporting significant increased mutation rates in offspring to moderate exposure level to cigarette smoke and the possible important role for lifestyle factors. These data provide us more evidence about the existence of human germline mutagens and urges the need for further evaluation of the effects of these mutagens on future progeny. 


\section{References}

1. Bois, P. and A.J. Jeffreys, Minisatellite instability and germline mutation. Cell Mol Life Sci, 1999. 55(12): p. 1636-48.

2. Tamaki, K., C.A. May, Y.E. Dubrova, and A.J. Jeffreys, Extremely complex repeat shuffling during germline mutation at human minisatellite B6.7. Hum Mol Genet, 1999. 8(5): p. 879-88.

3. Yauk, C., Monitoring for induced heritable mutations in natural populations: application of minisatellite DNA screening. Mutat Res, 1998. 411(1): p. 1-10.

4. Verhofstad, N., J.O. Linschooten, J. van Benthem, Y.E. Dubrova, H. van Steeg, F.J. van Schooten, et al., New methods for assessing male germ line mutations in humans and genetic risks in their offspring. Mutagenesis, 2008.

5. Dubrova, Y.E., Monitoring of radiation-induced germline mutation in humans. Swiss Med Wkly, 2003. 133(3536): p. 474-8.

6. Jeffreys, A.J., N.J. Royle, V. Wilson, and Z. Wong, Spontaneous mutation rates to new length alleles at tandemrepetitive hypervariable loci in human DNA. Nature, 1988. 332(6161): p. 278-81.

7. Yauk, C.L. and J.S. Quinn, Multilocus DNA fingerprinting reveals high rate of heritable genetic mutation in herring gulls nesting in an industrialized urban site. Proc Natl Acad Sci U S A, 1996. 93(22): p. 12137-41.

8. Dubrova, Y.E., V.N. Nesterov, N.G. Krouchinsky, V.A. Ostapenko, R. Neumann, D.L. Neil, et al., Human minisatellite mutation rate after the Chernobyl accident. Nature, 1996. 380(6576): p. 683-6.

9. Dubrova, Y.E., G. Grant, A.A. Chumak, V.A. Stezhka, and A.N. Karakasian, Elevated minisatellite mutation rate in the post-chernobyl families from ukraine. Am J Hum Genet, 2002. 71(4): p. 801-9.

10. Yauk, C.L., M.L. Berndt, A. Williams, A. Rowan-Carroll, G.R. Douglas, and M.R. Stampfli, Mainstream tobacco smoke causes paternal germ-line DNA mutation. Cancer Res, 2007. 67(11): p. 5103-6.

11. Somers, C.M., B.E. McCarry, F. Malek, and J.S. Quinn, Reduction of particulate air pollution lowers the risk of heritable mutations in mice. Science, 2004. 304(5673): p. 1008-10.

12. Yauk, C., A. Polyzos, A. Rowan-Carroll, C.M. Somers, R.W. Godschalk, F.J. Van Schooten, et al., Germ-line mutations, DNA damage, and global hypermethylation in mice exposed to particulate air pollution in an urban/ industrial location. Proc Natl Acad Sci U S A, 2008. 105(2): p. 605-10.

13. Yauk, C.L., Advances in the application of germline tandem repeat instability for in situ monitoring. Mutat Res, 2004. 566(2): p. 169-82.

14. Vergnaud, G., D. Mariat, F. Apiou, A. Aurias, M. Lathrop, and V. Lauthier, The use of synthetic tandem repeats to isolate new VNTR loci: cloning of a human hypermutable sequence. Genomics, 1991. 11(1): p. 135-44.

15. Vergnaud, G. and F. Denoeud, Minisatellites: mutability and genome architecture. Genome Res, 2000. 10(7): p. 899-907.

16. Dubrova, Y.E., V.N. Nesterov, N.G. Krouchinsky, V.A. Ostapenko, G. Vergnaud, F. Giraudeau, et al., Further evidence for elevated human minisatellite mutation rate in Belarus eight years after the Chernobyl accident. Mutat Res, 1997. 381(2): p. 267-78.

17. Dubrova, Y.E., O.G. Ploshchanskaya, O.S. Kozionova, and A.V. Akleyev, Minisatellite germline mutation rate in the Techa River population. Mutat Res, 2006. 602(1-2): p. 74-82.

18. Anderson, D., Male-mediated developmental toxicity. Toxicol Appl Pharmacol, 2005. 207(2 Suppl): p. 506-13.

19. Secretan, B., K. Straif, R. Baan, Y. Grosse, F. El Ghissassi, V. Bouvard, et al., A review of human carcinogens-Part E: tobacco, areca nut, alcohol, coal smoke, and salted fish. Lancet Oncol, 2009. 10(11): p. 1033-4.

20. Magnus, P., L.M. Irgens, K. Haug, W. Nystad, R. Skjaerven, and C. Stoltenberg, Cohort profile: the Norwegian Mother and Child Cohort Study (MoBa). Int J Epidemiol, 2006. 35(5): p. 1146-50.

21. Davies, B.G., A. Hussain, S.M. Ring, J.M. Birch, T.O. Eden, M. Reeves, et al., New germline mutations in the hypervariable minisatellite CEB1 in the parents of children with leukaemia. Br J Cancer, 2007. 96(8): p. 126571.

22. Rehkopf, D.H., L.F. Berkman, B. Coull, and N. Krieger, The non-linear risk of mortality by income level in a healthy population: US National Health and Nutrition Examination Survey mortality follow-up cohort, 19882001. BMC Public Health, 2008. 8: p. 383. 
23. Sipinen, V., J. Laubenthal, A. Baumgartner, E. Cemeli, J.O. Linschooten, R.W. Godschalk, et al., In vitro evaluation of baseline and induced DNA damage in human sperm exposed to benzo[a]pyrene or its metabolite benzo[a]pyrene-7,8-diol-9,10-epoxide, using the comet assay. Mutagenesis, 2010. 25(4): p. 417-25.

24. Zhang, J., D.A. Savitz, P.J. Schwingl, and W.W. Cai, A case-control study of paternal smoking and birth defects. Int J Epidemiol, 1992. 21(2): p. 273-8.

25. Boffetta, P., J. Tredaniel, and A. Greco, Risk of childhood cancer and adult lung cancer after childhood exposure to passive smoke: A meta-analysis. Environ Health Perspect, 2000. 108(1): p. 73-82.

26. Ji, B.T., X.O. Shu, M.S. Linet, W. Zheng, S. Wacholder, Y.T. Gao, et al., Paternal cigarette smoking and the risk of childhood cancer among offspring of nonsmoking mothers. J Natl Cancer Inst, 1997. 89(3): p. 238-44.

27. Anese, M. and M.C. Nicoli, Antioxidant properties of ready-to-drink coffee brews. J Agric Food Chem, 2003. 51(4): p. 942-6.

28. Nicoli, M.C., M. Anese, M.T. Parpinel, S. Franceschi, and C.R. Lerici, Loss and/or formation of antioxidants during food processing and storage. Cancer Lett, 1997. 114(1-2): p. 71-4.

29. Windham, G.C., L. Fenster, and S.H. Swan, Moderate maternal and paternal alcohol consumption and the risk of spontaneous abortion. Epidemiology, 1992. 3(4): p. 364-70.

30. Curtis, K.M., D.A. Savitz, and T.E. Arbuckle, Effects of cigarette smoking, caffeine consumption, and alcohol intake on fecundability. Am J Epidemiol, 1997. 146(1): p. 32-41.

31. Maconochie, N., P. Doyle, S. Prior, and R. Simmons, Risk factors for first trimester miscarriage--results from a UK-population-based case-control study. Bjog, 2007. 114(2): p. 170-86.

32. Robbins, W.A., D.A. Elashoff, L. Xun, J. Jia, N. Li, G. Wu, et al., Effect of lifestyle exposures on sperm aneuploidy. Cytogenet Genome Res, 2005. 111(3-4): p. 371-7.

33. Friedler, G., Paternal exposures: impact on reproductive and developmental outcome. An overview. Pharmacol Biochem Behav, 1996. 55(4): p. 691-700.

34. Singer, T.M. and C.L. Yauk, Germ cell mutagens: risk assessment challenges in the 21st century. Environ Mol Mutagen, 2010. 51(8-9): p. 919-28.

35. Somers, C.M., C.L. Yauk, P.A. White, C.L. Parfett, and J.S. Quinn, Air pollution induces heritable DNA mutations. Proc Natl Acad Sci U S A, 2002. 99(25): p. 15904-7. 

Paternal exposure to high levels of certain genotoxic compounds can affect DNA integrity of germ cells, which may subsequently jeopardize the health of future generations. However, effects of moderate exposures to environmental levels of these compounds and their effects on the offspring are much more difficult to establish. Therefore, the aim of this thesis was to develop and test new biomarkers with which one could investigate whether environmental genotoxins are able to induce DNA damage in the sperm nucleus and whether such paternal exposure can lead to genetic alterations in the offspring.

Effects of exposure on male germ cells have already been intensively studied, as it is known that paternal genotoxic exposure might lead to altered sperm quality and consequently decreased fertility, but the consequences of these exposures for the offspring are less well characterized. To assess the effects of exposure to genotoxins in sperm, paternal smoking was used as an exposure model, because cigarette smoke is known to contain multiple genotoxic compounds, among which the genotoxic component $\mathrm{B}[\mathrm{a}] \mathrm{P}$. Several biomarkers were developed and tested for their ability to detect alterations in mature spermatozoa in smokers as compared to non-smokers. Germline mutations that can be inherited by the offspring of humans can be studied by analysis of repetitive sequences (so-called minisatellites), and is most often investigated in families exposed to high levels of radioactivity after the Chernobyl accident, but the effects of low dose exposures to environmental genotoxins due to the parent's lifestyle has not yet been investigated. Whereas, studies in animals indicate that these exposures could have a significant effect [1,2]. Therefore, several methodologies were critically reviewed and potential methods were selected and tested to determine germline DNA damage and mutations after paternal exposure to genotoxins.

\section{Paternal exposure and DNA damage in spermatozoa}

In our regular lifestyle, we are continuously exposed to a large variety of genotoxins, which are known to induce DNA damage, not only in somatic cells, but likely also in germ cells. Therefore it is thought that DNA damage in the mature spermatozoa after paternal exposure to these genotoxic compounds may contribute to the onset of diseases in their offspring $[3,4]$. However, it is complicated to determine to what extent damage was induced during the development of the male germ cells, since it would be highly invasive to take testis biopsies to isolate the various stages of maturating germ cells during spermatogenesis. Therefore, it is of importance to develop new biomarkers of male germ cell exposure that are less invasive, but delivers also valuable indications of exposure, preferably at earlier developmental stages because sperm cells are thought to be more sensitive for damaging agents at certain stages of their development. For instance, DNA repair activity is gradually lost during spermiogenesis [5]. The discovery of spermatozoal mRNA might provide new ways of biomonitoring exposure of spermatozoa [6]. During maturation these cells undergo several structural changes, in order to produce progressively motile sperm cells with a nucleus filled with paternal DNA to deliver to the oocyte. One of the modifications is the replacement of histones with protamines in the DNA structure, leading to a more compact package, as well as decreased accessibility of the DNA [7]. Because of this modification, it is thought that these cells are largely transcriptionally inactive [8] and thus, the mRNA profiles in mature spermatozoa may reflect processes that occurred in the testis after exposure, but before transcription was silenced. Gene expression profiles of mRNA in the mature sperm cells might therefore provide a retrospective view on cellular reactions that occurred in earlier phases of spermatogenesis. As exposure model, spermatozoal mRNA profiles from smokers were compared with non-smokers and gene expression analysis was performed using 
microarray technology (chapter 2). The list of genes that were differentially expressed in smokers as compared to the non-smokers and also correlated with the level of exposure (as assessed by cotinine levels in the seminal plasma), indicated that the germ cell specific transcription factor SALF was the highest up-regulated gene and the zinc finger encoding gene TRIM26 most down regulated. No altered pathways could be identified for the differentially expressed genes, but enrichment was observed for genes that are transcriptionally regulated by NF-kB, indeed indicating a stress response in these cells. These data were confirmed in a larger subsequent study (chapter 4), but the difference between smokers and non-smokers was not statistically significant, probably due to the much lower amount of cigarettes consumed in the second study. Furthermore, analysis of transcription factor networks suggested that apoptosis was inhibited in smokers. Altogether, our data indicated that gene-expression profiles in mature sperm are a feasible tool to elucidate gene-environment interactions in the male testis. Next to that, these data indicate that there is an exposure-related response in the maturating germ cells. Under normal conditions, DNA damage in spermatozoa might lead to apoptosis in order to deliver an intact genetic package to the oocyte [9]. If apoptosis is inhibited, cells containing high levels of DNA damage are not removed and will remain present in the ejaculate. Indeed, the number of strand breaks was significantly increased in the sperm cells as determined by the single cell gel electrophoresis assay (also known as comet assay).

One of the genotoxins of major presence in cigarette smoke is benzo[a]pyrene, which is a polycyclic aromatic hydrocarbon, known for its interaction with DNA after its metabolic activation to benzo[a]pyrene-7,8-dihydrodiol-9,10-epoxide (BPDE) [10]. This compound is also able to induce strand breaks after direct contact with the DNA, also in male germ cells, potentially putting future progeny at risk for developmental defects and diseases. Therefore, next to the study of spermatozoal mRNA profiles as biomarker of exposure in chapter 2, we have also studied the usefulness of sperm DNA damage as biomarker of exposure (chapter 3 ). We investigated cellular and molecular changes induced by B[a] $P$ in human sperm in vitro, again comparing smokers and non-smokers. Higher levels of DNA fragmentation were indeed observed in sperm from smokers, which was assessed using the alkaline comet assay. Furthermore, B[a]P related DNA adducts were detected at increased levels in smokers by immunostaining using antibodies against BPDE-DNA adducts, but surprisingly these adducts were not detectable by the ultrasensitive ${ }^{32} \mathrm{P}$ postlabelling assay. This suggests that the DNA lesions detected by immunostaining have a similar structure to the stable and covalent binding of BPDE to DNA (i.e. BPDEDNA adducts), but are not actual BPDE-DNA. Moreover, the metabolic precursor of BPDE, benzo[a]pyrene-7,8-diol, was not detected in incubations of mature sperm with $\mathrm{B}[\mathrm{a}] \mathrm{P}$, confirming that the metabolic formation of BPDE and the subsequent formation of BPDE-DNA adducts in vitro in mature sperm cells obtained from an ejaculate is unlikely. Still, B[a]P was able to induce in vitro DNA fragmentation in mature sperm, interestingly independent of addition of human liver S9 mix and also independent from the donor's smoking behavior. S9-mix contains a multitude of enzymes that are involved in the metabolism of $\mathrm{B}[\mathrm{a}] \mathrm{P}$, but increased DNA damage in absence of $\mathrm{S} 9$ mix suggests some unknown metabolism of $\mathrm{B}[\mathrm{a}] \mathrm{P}$ in ejaculates. In this regard, it is of importance to note that the in vitro mutagenicity of $\mathrm{B}[\mathrm{a}] \mathrm{P}$ was increased by addition of seminal plasma in the Ames bacterial mutagenicity-test for yet unknown reasons [11].

Since spermatozoa were not able to metabolize B[a]P into BPDE, but may in vivo still be exposed to this metabolite, because they are in the close proximity of other metabolically competent cells (for instance Sertoli cells), mature spermatozoa were also in vitro exposed to BPDE directly. BPDE induced dose-dependent DNA fragmentation, 
but only when formamidopyrimidine DNA glycosylase treatment (FPG-treatment) was part of the comet assay, which is an indicator for oxidative DNA damage. However, the levels of DNA fragmentation were rather low compared to the amounts of BPDE-DNA adducts as measured by ${ }^{32} \mathrm{P}$ postlabelling. Analysis by this method resulted in DNA adduct levels that were extremely high and far beyond what is considered to be physiologically relevant. Therefore, it seems unlikely that BPDE is a major source of increased levels of DNA fragmentation in vivo in mature spermatozoa in smokers as compared to nonsmokers. Altogether, the comet assay adapted to sperm in order to detect DNA damage, may be a useful tool for biomonitoring effects of direct exposure of sperm in vivo. Next to that, the presence of DNA adducts in sperm after in vitro $\mathrm{B}[\mathrm{a}] \mathrm{P}$ exposure suggests that mature sperm is susceptible to B[a]P induced DNA damage.

Several previously mentioned biomarkers of exposure were tested in a small set of samples. Therefore, these methodologies were applied to a larger set of samples. It is known that DNA damage in human spermatozoa is potentially associated with adverse health effects and fertility related problems. The origin of this damage to sperm, however, is still not fully understood and requires further investigation. Therefore, in chapter 4, sperm samples were obtained from 21 donors, who participated in the Rhea Cohort study in Crete (Greece) and these were grouped by smoking behavior, as smoking is known to induce DNA strand breaks in sperm (chapter 3). The high levels of DNA damage in the ejaculate could either be the result of formation of reactive oxygen species (ROS) [12], and / or via inhibition of apoptosis during spermatogenesis leading to accumulation of damaged cells in the ejaculate as suggested in chapter 2 of this thesis. In theory, an overwhelming production of ROS as a result of smoking might overrun the spermatozoal antioxidant defense systems leading to an accumulation of DNA damage. DNA damage levels in mature spermatozoa were measured by the comet assay and DNA damage was indeed significantly increased in sperm from smokers. Furthermore, higher levels of the vitamin $\mathrm{C}$ radical in the seminal plasma from smokers were detected by using electron spin resonance spectroscopy (ESR), as compared to non-smokers. The presence of vitamin $\mathrm{C}$ radicals in seminal plasma is considered to be indicative for an increased level of oxidative stress, but it could simultaneously protect the sperm cells, because vitamin $\mathrm{C}$ levels are very high in seminal plasma (up to $1 \mathrm{mM}$ ) and it efficiently traps hydroxylradicals. This protective role of vitamin $\mathrm{C}$ was further investigated by in vitro exposure of mature sperm to hydrogen peroxide in the presence of vitamin C; vitamin $\mathrm{C}$ protected against DNA damage induced by $\mathrm{H}_{2} \mathrm{O}_{2}$, but this protection was probably insufficient in vivo, since DNA damage was increased nonetheless. In these 21 sperm samples, also gene expression was assessed using real time-PCR and expression of a subset of antioxidant related genes was determined. In smokers, expression of antioxidant enzymes catalase and DDIT4 was higher, but expression of both genes was not related to DNA damage. Expression of both genes correlated significantly with the expression of the sperm-specific transcription factor $S A L F$, which was the most significant differentially regulated gene in our first study. Furthermore, CAT and DDIT4 expression were inversely related with sperm count, indicating that sperm cells experiencing high levels of oxidative stress during development may survive this assault due to increased expression of these potentially protective enzymes and eventually reach the ejaculate. As a consequence, these cells contain on average higher levels of DNA damage. Altogether, it could be concluded that spermatozoa from smokers encounter higher levels of oxidative stress. Antioxidant enzyme expression and the presence of vitamin $C$ in the semen were insufficient to provide full protection of spermatozoa against DNA damage. 


\section{Germline mutagenicity}

Germline mutations resulting from genotoxic exposures are a particular problem in toxicology as they affect not only the exposed generation but also an infinite number of generations thereafter. Germline mutations can be formed in spermatozoal stem cells, but it is also possible that mutations are formed in the early stages of the fertilized egg in which the damaged spermatozoal DNA is not properly repaired prior to division. In both cases, mutations will be present in all cells of their offspring. It is both technically and ethically difficult to directly investigate the effect of DNA damage in human sperm cells on birth outcomes. Therefore, in chapter 5 several methods were reviewed to assess germline mutations in humans and the genetic risks in their offspring. Several new molecular techniques (including analysis of tandem repeats and randomly amplified polymorphic DNA) now provide relatively quick and easy methods of assessing potential germline mutations that are transmittable to the offspring. However, these methods only determine mutations rates in specific regions in the DNA and the relevance of these non-coding regions for their relation with diseases (particularly cancer) is not always obvious. Therefore, it is assumed that increased mutation rates in these selected regions correlate with other more relevant parts of the genome and may thus act as a marker for the development of heritable mutations that may lead to an altered phenotype. This assumption needs further evaluation and more research is needed to link DNA alterations with changes in the phenotype. Furthermore, it was concluded that the use of tandem repeats and randomly amplified polymorphic DNA in transgenerational genotoxicity testing needs further validation.

In chapter 6 the random amplified polymorphic DNA PCR (RAPD-PCR) was further validated with respect to the use of this method in detecting genetic alterations in vitro. This method uses random primers to amplify random parts of the genome (may be coding and/ or non-coding) which are subsequently visualized as separate bands by gel-electrophoresis. In theory, this methodology has a great potential in detecting a wide range of mutations (point mutations as well as deletions and insertions). However, as it is a PCR based method and thus depending on amplification efficiency, reproducibility of this assay was questioned after indications of polymerase blockage leading to changes in band intensities [13, 14]. Therefore, to further evaluate this method in assessing mutations, it was compared with the validated hypoxanthine-guanine phosphoribosyl transferase (HPRT) mutation analysis. The HPRT assay is reported to be more sensitive than the RAPD-PCR for detecting mutations in vitro [15], but detection of mutations is limited to one genomic target and HPRT-mutation analysis is not suitable for studying germline mutations in human populations. For this comparison, two cell types were exposed to BPDE; A549 cell lines stably expressing ubiquitin either in its WT-form (WT-Ub) or as Lys63-mutants (K63R-Ub). The latter cell line is ultra-sensitive for BPDE induced mutations, because the Lys63 variant blocks polyubiquitination of PCNA, which is relevant for error-free damage avoidance during cell replication [15, 16]. Although a dose-dependent increase in band intensity alterations was detected in the RAPDPCR data, there was no difference observed between WT-Ub and K63R-Ub. No new or disappearing PCR-products were detected, which would have been indicative for the occurrence of mutations. In contrast, in the HPRT assay a strong significant increase in mutation frequency was found predominantly in the K63R-Ub cells. Changes in band intensities are most probably caused by blockage of Taq polymerase during PCR. Interestingly, RAPD-PCR 'mutation frequencies' were significantly related with 8-OHdG levels, indicating that exposure to BPDE probably not affect mutation frequencies, but exposure had lead to increased levels of oxidative DNA damage which lead to polymerase 
blockage and decreased polymerase efficiency. Although 8-OHdG is not a polymerase blocking lesion by itself, it may reflect the levels of other oxidative stress related DNA lesions that do block the polymerase. Interestingly, these data also indicate that in vitro BPDE exposure might have long lasting transgenerational effects in vitro, since a dosedependent alteration in PCR-profiles was found over two weeks after the initial single exposure of single cells that were allowed to expand to full culture flasks.

Overall, we assumed that the RAPD-PCR method is not sufficiently sensitive to detect mutations in vitro, and is too strongly influenced by endogenous types of DNA damage to be applicable as a mutation detection tool in human populations.

In chapter 5 it was concluded that the use of tandem repeats could be of great potential for detecting germline mutations in human populations. The use of tandem repeats, or minisatellites, is a complex, but also promising method in the determination of transgenerational effects, as these repetitive sequences have relatively high germline mutation frequencies after mutagenic exposure $[17,18]$. In chapter 7 , two of the most commonly used minisatellite probes (CEB1 and B6.7) were applied to identify germline mutations induced by paternal common lifestyle factors. In most studies using this methodology, the type of exposure was clearly defined and was very specific, such as high levels of radioactivity $[19,20]$ and significant increases in germline mutations in the exposed group as compared to the control group were reported. However, mutations were also detected in the control subjects of these studies, which indicate that other environmental triggers may have an impact on these 'background' mutations. Therefore, in this chapter we related detectable germline mutations with paternal lifestyle as assessed by a Food Frequency Questionnaire. From the Norwegian Mother and Child Cohort Study (MoBa) cohort, blood samples from a total of 81 complete father - mother - child triads were available including questionnaire data regarding dietary and environmental exposures, such as smoking. Mutation frequencies at both alleles appeared to react differently on lifestyle exposure data and were therefore analyzed separately. Although this may limit the power of the study, mutation frequencies at the CEB1 locus were found to be significantly related with gross year income, showing lower mutation rates when the gross year income was above the country's average; high income is often related to healthier lifestyle. In this particular case, high income was significantly inversely related with paternal smoking. Paternal smoking in the 6 months before pregnancy was indeed significantly related with increased CEB1 mutation frequencies in offspring. Moreover, consumption of unfiltered coffee could also contribute to this healthy lifestyle effect, as the paternal consumption of 1 cup per day significantly decreased mutation rates at the CEB1 locus (even if the father was a smoker). These data from a relative small group of samples showed that a healthy lifestyle appeared to decrease mutation frequencies at the CEB1 locus. The effect of paternal cigarette smoking is in line with the results of the first part of this thesis, in which smoking was identified as a risk factor for the genetic integrity of the paternal genome as it is transmitted to the offspring. Furthermore, these data indicate that even in a relatively small set of samples, heritable mutations were detected by the use of minisatellite analysis after low dose exposures, emphasizing that the analysis of tandem repetitive sequences is a sensitive method for the detection of germline mutations, which needs further attention. 


\section{Overall conclusion}

In conclusion, these data indicate that genotoxic exposure is able to induce damage to male germ cells which subsequently increases mutation frequencies in offspring. In this thesis, paternal smoking is identified as a type of exposure which affected DNA damage in sperm and led to the induction of mutations that were transmitted to the offspring. The health effects of these mutations are still not clear, but one could speculate that other parts of the genome may be affected as well. Paternal smoking induced DNA fragmentation in sperm, which could be due to direct exposure of spermatozoa to reactive oxygen species, but may also be the result of inhibited apoptosis in the presence of high levels of DNA damage. Bulky lesions were less likely to be the result of the effects of smoking, because (I) bulky DNA adducts were not detected in spermatozoa in vitro exposed to B[a]P and (II) DNA fragmentation was only seen at high exposure levels to BPDE. It is more likely that DNA fragmentation in spermatozoa is induced by reactive oxygen species, because a significant increase in the presence of the vitamin $\mathrm{C}$ radical was detected in smokers. Furthermore, expression of several antioxidant enzymes was inversely correlated with sperm cell count in the ejaculate, indicating that spermatozoa with high expression of protective enzymes are able to survive from high levels of oxidative stress, which was induced by smoking. Still, DNA damage was significantly increased, thus protection of the DNA in mature sperm cells against the genotoxic assaults from cigarette smoking might be insufficient. In combination with promoted anti-apoptotic pathways, this will lead to increased numbers of spermatozoa containing high levels of DNA damage in the ejaculate, as illustrated in figure 1.

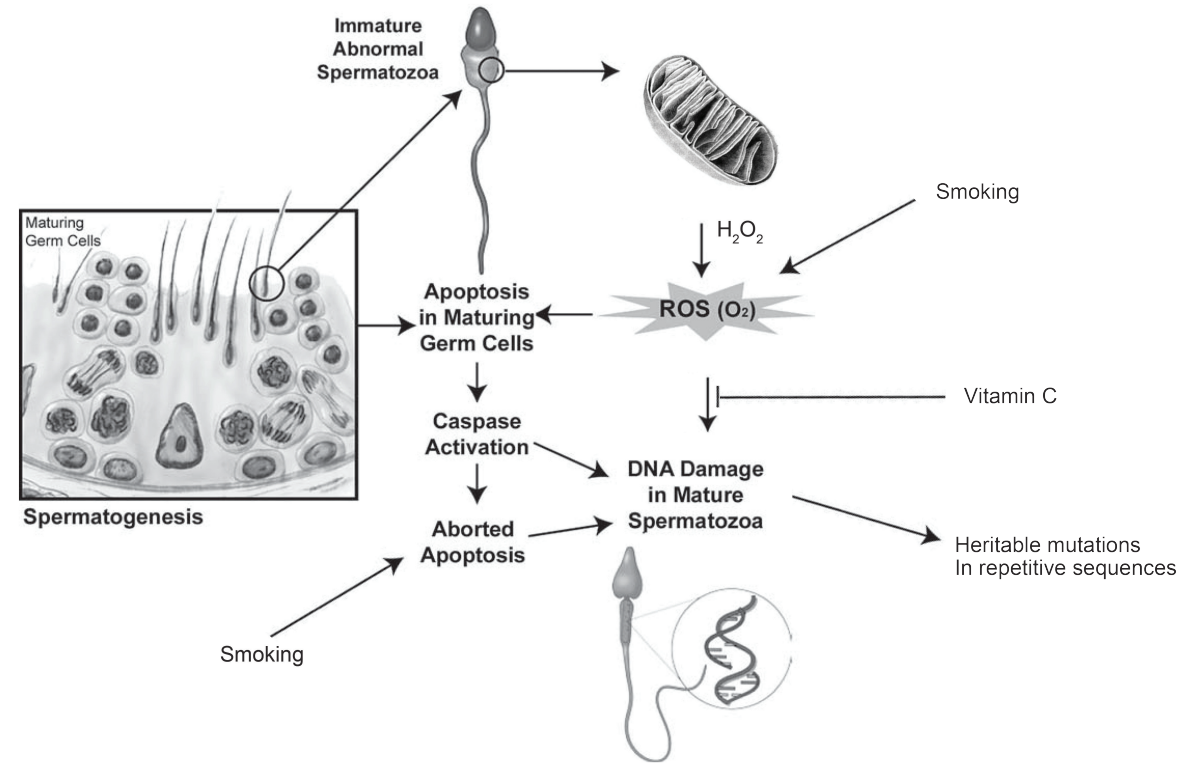

Figure 1: The effects of genotoxic exposure, in particular cigarette smoking, on mature sperm and subsequently on the offspring can be summarized as shown in this illustration. Several types of exposure might affect the genetic integrity of mature spermatozoa, which can lead to either increased inhibition of apoptosis in maturing sperm cells or increased levels of DNA damage in mature sperm in the ejaculate. These increased levels of DNA damage in mature sperm are a potential source of increased mutation frequencies in the offspring. (Adapted from Cocuzza et al. [21]) 
Increased levels of DNA damage in spermatozoa of smokers, raises the question whether this will have an impact on the number of germline mutations and the health of their offspring. To this end, we analyzed mutations in the highly variable minisatellites and indeed identified smoking, next to some other lifestyle factors, as a potential source of increased mutation frequencies in the offspring. Altogether, these data indicate that lifestyle has a large effect on the paternal contribution to genetic integrity of the offspring. Future studies should expand the number of sperm samples as well as the number of triads analyzed to further evaluate the role of the exposed father in the offspring's health. 


\section{References}

1. Yauk, C., A. Polyzos, A. Rowan-Carroll, C.M. Somers, R.W. Godschalk, F.J. Van Schooten, et al., Germ-line mutations, DNA damage, and global hypermethylation in mice exposed to particulate air pollution in an urban/ industrial location. Proc Natl Acad Sci U S A, 2008. 105(2): p. 605-10.

2. Yauk, C.L., M.L. Berndt, A. Williams, A. Rowan-Carroll, G.R. Douglas, and M.R. Stampfli, Mainstream tobacco smoke causes paternal germ-line DNA mutation. Cancer Res, 2007. 67(11): p. 5103-6.

3. Marchetti, F. and A.J. Wyrobek, Mechanisms and consequences of paternally-transmitted chromosomal abnormalities. Birth Defects Res C Embryo Today, 2005. 75(2): p. 112-29.

4. Aitken, R.J. and G.N. De luliis, On the possible origins of DNA damage in human spermatozoa. Mol Hum Reprod, 2010. 16(1): p. 3-13.

5. Olsen, A.K., B. Lindeman, R. Wiger, N. Duale, and G. Brunborg, How do male germ cells handle DNA damage? Toxicol Appl Pharmacol, 2005. 207(2 Suppl): p. 521-31.

6. Pessot, C.A., M. Brito, J. Figueroa, Concha, II, A. Yanez, and L.O. Burzio, Presence of RNA in the sperm nucleus. Biochem Biophys Res Commun, 1989. 158(1): p. 272-8.

7. Holstein, A.F., W. Schulze, and M. Davidoff, Understanding spermatogenesis is a prerequisite for treatment. Reprod Biol Endocrinol, 2003. 1: p. 107.

8. Ostermeier, G.C., D.J. Dix, D. Miller, P. Khatri, and S.A. Krawetz, Spermatozoal RNA profiles of normal fertile men. Lancet, 2002. 360(9335): p. 772-7.

9. Aitken, R.J. and A.J. Koppers, Apoptosis and DNA damage in human spermatozoa. Asian J Androl, 2011. 13(1): p. 36-42.

10. Godschalk, R.W., F.J. Van Schooten, and H. Bartsch, A critical evaluation of DNA adducts as biological markers for human exposure to polycyclic aromatic compounds. J Biochem Mol Biol, 2003. 36(1): p. 1-11.

11. Rivrud, G.N., Mutagenicity testing of seminal fluid: seminal fluid increases the mutagenicity of the precursor mutagen benzo[a]pyrene in the presence of S9 mix. Mutat Res, 1988. 208(3-4): p. 195-200.

12. Saleh, R.A., A. Agarwal, R.K. Sharma, D.R. Nelson, and A.J. Thomas, Jr., Effect of cigarette smoking on levels of seminal oxidative stress in infertile men: a prospective study. Fertil Steril, 2002. 78(3): p. 491-9.

13. Chary, P. and R.S. Lloyd, In vitro replication by prokaryotic and eukaryotic polymerases on DNA templates containing site-specific and stereospecific benzo[a]pyrene-7,8-dihydrodiol-9,10-epoxide adducts. Nucleic Acids Res, 1995. 23(8): p. 1398-405.

14. Pietrasanta, L.I., B.L. Smith, and M.C. MacLeod, A novel approach for analyzing the structure of DNA modified by Benzo[a]pyrene diol epoxide at single-molecule resolution. Chem Res Toxicol, 2000. 13(5): p. 351-5.

15. Chiu, R.K., J. Brun, C. Ramaekers, J. Theys, L. Weng, P. Lambin, et al., Lysine 63-polyubiquitination guards against translesion synthesis-induced mutations. PLoS Genet, 2006. 2(7): p. e116.

16. Langie, S.A., A.M. Knaapen, C.H. Ramaekers, J. Theys, J. Brun, R.W. Godschalk, et al., Formation of lysine 63-linked poly-ubiquitin chains protects human lung cells against benzo[a]pyrene-diol-epoxide-induced mutagenicity. DNA Repair (Amst), 2007. 6(6): p. 852-62.

17. Jeffreys, A.J., N.J. Royle, V. Wilson, and Z. Wong, Spontaneous mutation rates to new length alleles at tandemrepetitive hypervariable loci in human DNA. Nature, 1988. 332(6161): p. 278-81.

18. Yauk, C.L. and J.S. Quinn, Multilocus DNA fingerprinting reveals high rate of heritable genetic mutation in herring gulls nesting in an industrialized urban site. Proc Natl Acad Sci U S A, 1996. 93(22): p. 12137-41.

19. Dubrova, Y.E., V.N. Nesterov, N.G. Krouchinsky, V.A. Ostapenko, R. Neumann, D.L. Neil, et al., Human minisatellite mutation rate after the Chernobyl accident. Nature, 1996. 380(6576): p. 683-6.

20. Dubrova, Y.E., G. Grant, A.A. Chumak, V.A. Stezhka, and A.N. Karakasian, Elevated minisatellite mutation rate in the post-chernobyl families from ukraine. Am J Hum Genet, 2002. 71(4): p. 801-9.

21. Cocuzza, M., S.C. Sikka, K.S. Athayde, and A. Agarwal, Clinical relevance of oxidative stress and sperm chromatin damage in male infertility: an evidence based analysis. Int Braz J Urol, 2007. 33(5): p. 603-21. 

SAMENVATTING \& ALGEMENE DISCUSSIE $\mid 125$ 
Een hoge mate van paternale blootstelling aan bepaalde genotoxische verbindingen, kan de DNA-integriteit van geslachtscellen beïnvloeden, hetgeen vervolgens een gevaar zou kunnen opleveren voor toekomstige generaties. Echter, het effect van een gemiddelde mate van blootstelling - vergelijkbaar met die in het dagelijks leven - aan deze verbindingen en de mogelijke effecten op het nageslacht, zijn moeilijker te bepalen. Het doel van het onderzoek in dit proefschrift is om nieuwe biomarkers te ontwikkelen en te testen, waarmee men kan bepalen of deze omgevings-genotoxinen DNA-schade kunnen induceren in de celkern van de spermacel en daarmee te onderzoek of deze paternale blootstelling kan leiden tot genetische afwijkingen in het nageslacht.

Effecten van blootstelling op mannelijke geslachtscellen zijn al uitgebreid onderzocht, het is immers bekend dat paternale genotoxische blootstelling kan leiden tot verminderde kwaliteit van het sperma en daarmee ook de vruchtbaarheid negatief kan beïnvloeden. De consequenties van dit type blootstelling op het nageslacht zijn veel minder uitgebreid bestudeerd.

Om de effecten van genotoxische blootstelling op sperma te bepalen, is bij de vader roken als model voor blootstelling gekozen. Sigarettenrook bestaat uit een verscheidenheid aan genotoxische verbindingen, waaronder het genotoxine benzo[a]pyreen (B[a]P). Verschillende biomarkers zijn reeds ontwikkeld en getest op het vermogen om veranderingen in volgroeide spermatozoa van rokers te detecteren, vergeleken met niet-rokers. Erfelijke kiemlijn mutaties in nageslacht kunnen in mensen bestudeerd worden aan de hand van repeterende sequenties (oftewel: mini-satellieten). Dit is een veelgebruikte methode om de effecten te bepalen na extreem hoge blootstelling, zoals dit bijvoorbeeld werd gedaan met blootstelling aan radioactiviteit na de Tsjernobyl ramp. De effecten op het nageslacht van blootstelling aan lage doses genotoxische stoffen uit de dagelijkse omgeving als gevolg van de leefstijl van de ouders, is daarentegen nog in veel mindere mate onderzocht. Proefdierstudies hebben reeds aangetoond dat dit soort blootstelling significante effecten kan hebben [1, 2]. Daarom zijn verschillende methoden kritisch bekeken en potentiële methoden geselecteerd om kiemlijn DNA schade na paternale blootstelling aan genotoxinen te meten.

\section{Paternale blootstelling en DNA schade in spermatozoa}

In onze huidige leefstijl worden we continu blootgesteld aan een grote variëteit aan genotoxinen, waarvan bekend is dat deze niet alleen DNA-schade kunnen veroorzaken in somatische cellen, maar ook in kiemcellen. Daarom wordt verondersteld dat DNA-schade in volgroeide spermatozoa na paternale blootstelling aan deze genotoxische verbindingen een bijdrage levert aan de ontwikkeling van ziekten in het nageslacht [3, 4]. Dee mate van schade die is geïnduceerd tijdens de ontwikkeling van de geslachtscel is echter moeilijk te bepalen, omdat de methode waarbij spermatozoa in verschillende rijpingsstadia uit testisbiopten geïsoleerd worden, erg invasief is. Daarom is het belangrijk om nieuwe biomarkers te ontwikkelen die minder invasief zijn, maar toch een waardevolle indicatie van de blootstelling opleveren en bij voorkeur in vroege ontwikkelingsstadia. Vermoedelijk zijn spermatozoa in bepaalde fasen van ontwikkeling gevoeliger voor schadelijke componenten. DNA-herstel neemt bijvoorbeeld geleidelijk af gedurende de spermatogenese [5]. De ontdekking van mRNA in spermatozoa leidt mogelijk tot nieuwe inzichten in de ontwikkeling van biomarkers voor blootstelling van deze cellen [6]. Gedurende de rijping ondergaan spermatozoa verschillende structurele veranderingen, die resulteren in gezond bewegende spermacellen met het genetisch materiaal van de vader in de celkern, 
dat afgeleverd kan worden bij de oocyt. Een van deze modificaties is de vervanging van histonen door protamines in de DNA-structuur, waardoor het DNA meer compact verpakt kan worden. Het DNA wordt daardoor ook minder toegankelijk [7]. Vanwege deze modificatie wordt verondersteld dat DNA transcriptie in spermatozoa grotendeels inactief is [8] en dat mRNA-profielen uit deze volgroeide cellen een reflectie zijn van processen die eerder hebben plaatsgevonden in de testis na blootstelling, maar vóórdat transcriptie werd stilgelegd. Genexpressieprofielen van mRNA in volgroeide spermacellen bieden daarom mogelijk een retrospectief beeld van cellulaire reacties in eerdere fasen van de spermatogenese. Als blootstellingsmodel is ervoor gekozen om mRNA-profielen uit spermacellen van rokers te vergelijken met die van niet-rokers en de genexpressie te analyseren met behulp van microarray technologie. (hoofdstuk 2). De lijst met genen die significant verschillend gereguleerd zijn in rokers, vergeleken met niet-rokers, die tevens correleerden met de mate van blootstelling (bepaald door de cotinine concentratie in het seminale plasma), indiceert dat de geslachtscel-specifieke transcriptie factor SALF het meest omhoog gereguleerd is. Het zinkvinger coderende gen TRIM26 is het meest omlaag gereguleerd. Er konden geen pathways worden geïdentificeerd uit de verschillend gereguleerde genen, maar er was een verrijking zichtbaar in de genen die transcriptioneel gereguleerd wordt door NF-kB, wat een stressreactie in deze cellen indiceert. Deze data werden later bevestigd in een grotere vervolgstudie (hoofdstuk 4), maar het verschil tussen rokers en niet-rokers was niet significant, waarschijnlijk ten gevolge van lagere aantallen sigaretten dat gerookt werd door de participanten in de tweede studie. Uit de analyse van transcriptiefactor-netwerken kan worden afgeleid dat apoptose geremd is in rokers. Samenvattend kan worden gesteld dat onze data een indicatie geven voor het gebruik van de analyse van genexpressieprofielen van volgroeide spermacellen, als een bruikbare methode om gen-omgevings interacties in de testis aan te kunnen tonen. Daarnaast indiceren deze data dat er een blootstellingsgerelateerde reactie is in rijpende mannelijke geslachtscellen. Onder normale condities leidt DNA-schade in spermatozoa tot apoptose om op deze manier een intact genetisch pakket af te leveren bij de oocyt [9]. Als apoptose geremd is, zullen cellen met veel DNA schade niet verwijderd worden en aanwezig blijven in het ejaculaat. Dit wordt inderdaad bevestigd door de significante toename van DNA-strengbreuken in de spermacellen van rokers, gemeten met de comet assay.

Een van de genotoxische stoffen die veelvuldig aangetroffen wordt in sigarettenrook is benzo[a]pyreen, een polycyclische aromatische koolwaterstof (PAK), die bekend staat om zijn interactie met DNA na metabolische activatie tot benzo[a]pyreen-7,8-dihydrodiol-9,10-epoxide (BPDE) [10]. Deze component is in staat om DNA-strengbreuken te induceren na direct contact met het DNA, ook in mannelijke geslachtscellen, hetgeen mogelijk een risico vormt voor het nageslacht, in de zin van het ontwikkelen van ziektes en embryonale groeidefecten. Daarom wordt naast de studie naar mRNA-profielen van spermacellen als biomarker van blootstelling in hoofdstuk 2, ook het gebruik van spermatozoale DNA-schade als biomarker bestudeerd (hoofdstuk 3). Cellulaire en moleculaire veranderingen die door $\mathrm{B}[\mathrm{a}] \mathrm{P}$ worden geïnduceerd in menselijke spermacellen zijn in vitro bestudeerd, wederom gebruik makend van de vergelijking tussen rokers en niet-rokers. Met de alkalische comet assay werd in sperma van rokers inderdaad meer DNA-fragmentatie gevonden. Daarnaast werden ook B[a]P gerelateerde DNA adducten in verhoogde mate aangetroffen in rokers, door immunostaining met BPDE-DNA adduct antilichamen, terwijl deze adducten niet te detecteren waren met de zeer gevoelige ${ }^{32} \mathrm{P}$ postlabelling methode. Dit suggereert dat de DNA laesies die gedetecteerd werden met immunostaining, een structuur hebben die gelijk is aan de stabiele en covalente binding van BPDE aan het DNA (bijvoorbeeld BPDE-DNA adducten), maar in werkelijkheid 
geen BPDE-DNA adducten zijn. De eerder gevormde metaboliet, benzo[a]pyreen-7,8diol, werd eveneens niet aangetroffen na incubatie van volgroeide spermacellen met B[a] $P$, hetgeen bevestigt dat het onwaarschijnlijk is dat in vitro in volgroeide spermacellen (verkregen uit een ejaculaat) metabolisme plaatsvindt, waarbij BPDE en daaropvolgende vorming van BPDE-DNA adducten gevormd zouden kunnen worden. Echter, in vitro bleek $\mathrm{B}[\mathrm{a}] \mathrm{P}$ in staat om DNA fragmentatie te induceren in volgroeide spermacellen, interessant genoeg onafhankelijk van de toevoeging van S9-mix alsook van het rookgedrag van de donor. Deze S9-mix is samengesteld uit een groot aantal enzymen die betrokken zijn bij $\mathrm{B}[\mathrm{a}] \mathrm{P}$ metabolisme, maar verhoogde DNA-schade in afwezigheid van S9-mix duidt dus op een onbekend metabolisme van $\mathrm{B}[\mathrm{a}] \mathrm{P}$ in ejaculaten. In dit opzicht is het belangrijk om te vermelden dat de in vitro mutageniteit van $\mathrm{B}[\mathrm{a}] \mathrm{P}$ toenam na toevoeging van seminaal plasma in de Ames bacteriële mutageniteitstest, waarvan de onderliggende redenen tot op heden onbekend zijn [11].

Omdat spermacellen B[a]P niet om kunnen zetten in BPDE, maar mogelijk in vivo wel degelijk blootgesteld worden aan deze metaboliet (door de nabijheid van metabool actieve cellen, zoals Sertoli-cellen), zijn volgroeide spermacellen ook in vitro direct blootgesteld aan BPDE. Dit leidde tot dosis-afhankelijke DNA-fragmentatie, maar alleen wanneer formamidopyrimidine DNA-glycosylase behandeling (FPG-behandeling) onderdeel was van de comet assay, hetgeen een indicator is voor oxidatieve DNA schade. Echter, de mate van DNA fragmentatie was relatief laag in vergelijking met de aantallen BPDE-DNA adducten die gemeten werden met behulp van ${ }^{32} \mathrm{P}$ postlabelling. Deze analyse gaf extreem hoge DNA adduct niveaus, zelfs veel hoger dan wat gezien wordt als fysiologisch relevant. Daarom lijkt het erg onwaarschijnlijk dat BPDE de voornaamste bron is van toegenomen DNA-fragmentatie in vitro in spermacellen van rokers, ten opzichte van nietrokers. De comet assay als methode om DNA-schade in sperma te meten, lijkt hiermee een bruikbaar middel te zijn om effecten te monitoren van directe blootstelling op sperma in vivo. Daarnaast duidt de aanwezigheid van DNA adducten in sperma na in vitro blootstelling aan $\mathrm{B}[\mathrm{a}] \mathrm{P}$ erop dat volgroeide spermacellen wel degelijk gevoelig zijn voor $\mathrm{B}[\mathrm{a}]$ $P$ geïnduceerde DNA schade.

Enkele van de eerdergenoemde biomarkers van blootstelling zijn getest in een kleine sub-set van monsters. Vervolgens zijn deze methoden toegepast op een grotere groep proefpersonen. Het is bekend dat DNA schade in humane spermacellen mogelijk geassocieerd is met negatieve gezondheidseffecten en vruchtbaarheidsproblemen. De oorsprong van deze schade aan het sperma is echter nog steeds niet volledig bekend en behoeft verder onderzoek. In hoofdstuk 4 zijn sperma-monsters verkregen van 21 donoren uit de Rhea Cohort Study op Kreta, Griekenland. Deze zijn gegroepeerd op basis van rookgedrag (omdat van roken bekend is dat het DNA-strengbreuken kan induceren, zoals beschreven in hoofdstuk 3). De hoge niveaus DNA-schade in het ejaculaat kunnen ontstaan door óf de formatie van reactieve zuurstofdeeltjes (ook wel ROS genoemd), óf door remming van apoptose gedurende de spermatogenese hetgeen leidt tot een toename van beschadigde cellen in het ejaculaat (zoals beschreven in hoofdstuk 2 van dit proefschrift). In theorie zou een overweldigende productie van ROS, als gevolg van roken, het spermatozoale anti-oxidant afweersysteem teniet kunnen doen en dat kan resulteren in een toename van DNA-schade. Met de comet assay is de hoeveelheid DNA schade in volgroeide spermacellen bepaald en deze was inderdaad significant verhoogd bij rokers. Daarnaast werden met behulp van Electron Spin Resonance spectroscopy (ESR) ook hogere niveaus vitamine $\mathrm{C}$ radicaal aangetroffen in het seminaal plasma van rokers, in vergelijking met niet-rokers. De aanwezigheid van vitamine $\mathrm{C}$ radicalen in het seminaal plasma wordt gezien als indicator voor een toename van oxidatieve stress, maar het kan tegelijkertijd een bescherming zijn voor spermacellen. Vitamine $\mathrm{C}$ niveaus 
zijn relatief hoog in seminaal plasma (tot $1 \mathrm{mM}$ ) en kunnen daardoor veel hydroxyl-radicalen wegvangen. Dit beschermende effect van vitamine $\mathrm{C}$ is verder onderzocht door middel van blootstelling van in vitro volgroeide spermacellen aan waterstofperoxide, in aanwezigheid van vitamine $\mathrm{C}$. Vitamine $\mathrm{C}$ bood bescherming tegen $\mathrm{H} 2 \mathrm{O} 2$ geïnduceerde DNA-schade; dit beschermingmechanisme was in vivo waarschijnlijk onvoldoende, omdat er toch een verhoging van DNA-schade werd gemeten. In deze 21 monsters is ook genexpressie gemeten met behulp van real time-PCR en er werd expressie van een sub-set van antioxidant gerelateerde genen bepaald. In rokers was de expressie van de enzymen katalase en DDIT4 hoger, maar de expressie van beide genen kon niet worden gerelateerd aan DNA-schade. Expressie van beide genen correleerde wel significant met de expressie van de sperma-specifieke transcriptie-factor $S A L F$, het significant verschillend gereguleerde gen in onze eerste studie. De expressie van CAT en DDIT4 was omgekeerd gerelateerd aan het aantal spermacellen. Dit doet vermoeden dat spermacellen die sterk blootgesteld zijn aan oxidatieve stress tijdens rijping, deze aanslag mogelijk overleven door de toegenomen expressie van deze potentieel beschermende genen en dus mogelijk in het ejaculaat terecht komen. De consequentie hiervan is dat deze cellen waarschijnlijk meer DNA-schade hebben. Concluderend kan worden gesteld dat spermacellen van rokers blootstaan aan meer oxidatieve stress dan cellen van niet-rokers. De expressie van anti-oxidatieve enzymen en de aanwezigheid van vitamine $C$ in het ejaculaat zijn onvoldoende om volledige bescherming te bieden aan spermacellen tegen DNA-schade.

\section{Kiemlijn mutageniteit}

Kiemlijn mutaties als gevolg van genotoxische blootstelling zijn een op zichzelf staand probleem binnen de toxicologie, omdat deze niet alleen de blootgestelde generatie beïnvloeden maar ook een onbekend aantal volgende generaties. Deze kiemlijn mutaties kunnen gevormd worden in spermatozoale stamcellen, maar het is ook mogelijk dat mutaties gevormd worden in vroege fasen van de bevruchting van een eicel. Indien de DNA-schade in de spermatozoon niet volledig is opgeruimd door de eicel voordat de eerste celdeling plaatsvindt, kan er ook sprake zijn van kiemlijn mutatie. In beide gevallen blijven mutaties aanwezig in alle cellen van het nageslacht. Het is zowel technisch als ethisch gezien onmogelijk om een direct effect te bepalen van DNA schade in spermacellen op het nageslacht. Daarom zijn er in hoofdstuk 5 verschillende methoden nader bestudeerd om op indirecte wijze kiemlijn mutaties te bepalen in mensen en het genetische risico in hun nageslacht. Verschillende nieuwe moleculaire technieken (inclusief analyse van tandem repeats en randomly amplified polymorphic DNA) zijn relatief snel en gemakkelijk om potentiële overerfelijke kiemlijn mutaties te bepalen. Echter, deze methoden bepalen alleen mutatiefrequenties in specifieke delen van het DNA, maar de relevantie van deze niet-coderende delen in relatie tot ziekten (met name kanker) is niet altijd overduidelijk. Daarom wordt aangenomen dat verhoogde mutatie frequenties in deze specifieke gebieden correleren met andere relevante delen van het genoom en dus mogelijk als marker kunnen dienen voor de ontwikkeling van overerfelijke mutaties, die kunnen leiden tot een verandering in het fenotype. Deze aanname moet uitgebreider worden bestudeerd en meer onderzoek is nodig om veranderingen in het DNA te koppelen aan veranderingen in het fenotype. Tevens kan worden geconcludeerd dat ook het gebruik van tandem repeats en randomly amplified polymorphic DNA als testen voor transgenerationele genotoxiciteit verder gevalideerd dient te worden. 
In hoofdstuk 6 is de random amplified polymorphic DNA PCR (RAPD-PCR) verder gevalideerd met betrekking tot het gebruik van deze methode om genetische veranderingen in vitro te detecteren. Deze methode gebruikt primers om willekeurige delen van het genoom te amplificeren (coderend en niet-coderend), die vervolgens als separate bandjes gevisualiseerd worden door gelelektroforese. In theorie heeft deze methode de potentie om een grote variëteit aan mutaties te detecteren (puntmutaties, deleties en inserties). Het is echter een PCR gebaseerde methode en daarmee dus afhankelijk van de efficiëntie van amplificatie, waardoor de reproduceerbaarheid ter discussie werd gesteld. Dit naar aanleiding van indicaties dat blokkering van polymerase kon leiden tot veranderingen in intensiteit van de bandjes [13, 14]. Om deze methode daarom verder te valideren, is deze vergeleken met de gevalideerde hypoxanthine-guanine phosphoribosyl transferase (HPRT) mutatie analyse. Beschreven is dat de HPRT assay sensitiever is dan de RAPD-PCR, in de detectie van in vitro mutaties [15]. Echter, deze detectie is gelimiteerd tot slechts één gedeelte van het genoom en daarnaast is de HPRT-mutatie analyse niet bruikbaar om kiemlijn mutaties in humane populaties te meten. Voor deze vergelijking zijn twee celtypen blootgesteld aan BPDE; A549 cellen met stabiele ubiquitine expressie als wild-type (WT-Ub) of als Lys63-mutanten (K63R-Ub). Deze laatste cellijn is uitermate gevoelig voor BPDE geïnduceerde mutaties, omdat de Lys63 variant polyubiquitinatie van PCNA blokkeert, hetgeen relevant is voor het fout-vrij omzeilen van schade tijdens cel replicatie $[15,16]$. Ondanks de dosis-afhankelijke toename in veranderingen in bandintensiteit in de RAPD-PCR data, was er geen verschil waarneembaar tussen de WT-Ub en K63R-Ub cellen. Er konden geen nieuwe of verdwenen bandjes worden gedetecteerd, wat een indicatie zou zijn geweest voor de aanwezigheid van mutaties. In tegenstelling tot de HPRT assay, waarin een sterk significante toename in mutatiefrequenties gemeten werd in met name de K63R-Ub cellen. Veranderingen in intensiteit van bandjes is zeer waarschijnlijk veroorzaakt door blokkering van Taq polymerase tijdens PCR. Het was opmerkelijk dat de RAPD-PCR mutatie-frequenties significant correleerden met 8-OHdG niveaus. Dit impliceert dat blootstelling aan BPDE niet direct leidt tot hogere mutatiefrequenties, maar dat door blootstelling meer oxidatieve DNA-schade ontstaat, hetgeen polymerase blokkeert en daarmee de polymerase efficiëntie vermindert. 8-OHdG is zelf geen polymerase blokkerende laesie, maar het reflecteert wellicht wel de mate waarin andere oxidatieve stress gerelateerde DNA-laesies polymerase kunnen blokkeren. Uit deze data kan ook worden afgeleid dat in vitro BPDE blootstelling mogelijk lang aanhoudende transgenerationele effecten heeft, omdat een dosisafhankelijke verandering in PCR-profielen waarneembaar was, ruim twee weken na de eenmalige blootstelling van aparte cellen die later, per blootgestelde cel, uitgroeiden tot compleet gevulde kweekflessen.

Over het algemeen hebben we aangenomen dat de RAPD-PCR methode niet voldoende sensitief is om in vitro mutaties te detecteren en daarnaast té sterk beïnvloed wordt door endogene DNA schade, om bruikbaar te zijn in humane populaties voor het detecteren van mutaties.

In hoofdstuk 5 werd geconcludeerd dat de analyse van repeterende sequenties mogelijk een zeer bruikbare methode is om kiemlijn mutaties te meten in humane populaties. Het gebruik van repeterende sequenties, of minisatellieten, is een complexe, maar ook veelbelovende methode om transgenerationele effecten te bepalen, te meer omdat deze repeterende sequenties vaak hoge kiemlijn mutatie frequenties bevatten na mutagene blootstelling $[17,18]$. In hoofdstuk 7 worden twee van de meest gebruikte minisatelliet probes (CEB1 en B6.7) gebruikt om kiemlijn mutaties te bepalen die mogelijk geïnduceerd zijn door factoren zoals aanwezig in een gemiddelde leefstijl van de vader. In de meeste studies die deze methode gebruiken, kon de bron van blootstelling vaak nauwkeurig 
worden gedefinieerd, zoals extreme blootstelling aan radioactiviteit [19, 20], waarmee een significante toename in kiemlijn mutaties in de blootgestelde groep gemeten werd ten opzichte van een controle groep. Echter, in deze studies werden in de controlegroepen ook mutaties gevonden, zogenaamde 'achtergrond' mutaties, die mogelijk geïnduceerd werden door andere omgevingsfactoren. In dit hoofdstuk zijn daarom de gedetecteerde kiemlijn mutaties gerelateerd aan de levensstijl van de vader, die vastgesteld is aan de hand van een voedingsvragenlijst. Bloedmonsters zijn verkregen van in totaal 81 complete 'vader - moeder - kind-trio's' uit het 'Norwegian Mother and Child Cohort Study' (MoBa) cohort, aangevuld met data van vragenlijsten met betrekking tot blootstelling ten gevolge van dieet en omgeving, zoals rookgedrag. De mutatiefrequenties zoals bepaald op beide allelen (CEB1 en B6.7) bleken allebei verschillend te reageren op blootstellingen door leefstijl en daarom zijn beide apart geanalyseerd, ook al verlaagt dit wellicht de power van de studie.

De mutatiefrequenties op het CEB1 locus waren significant gerelateerd aan bruto jaarinkomen, waarbij lagere mutatieratio's gevonden werden bij een bovengemiddeld bruto jaarinkomen. Een hoog inkomen is al vaker gerelateerd aan een gezondere levensstijl, ook in dit geval was een hoog inkomen significant omgekeerd evenredig met rookgedrag van de vader. Bij vaders die rookten in de 6 maanden voor bevruchting, werden inderdaad significant hogere CEB1 mutatiefrequenties in het nageslacht gemeten. Daarnaast kan ook de consumptie van ongefilterde koffie een bijdrage leveren aan dit effect van gezonde leefstijl, want de consumptie van 1 kop per dag door de vader, verlaagt significant de mutatie ratio's op het CEB1 locus (zelfs als de vader rookt). Deze data uit een relatief kleine groep proefpersonen geven aan dat een gezonde levensstijl blijkbaar de mutatie frequenties op het CEB1 locus kunnen verlagen. Het effect van roken door de vader is in lijn met de eerder beschreven resultaten in het eerste deel van dit proefschrift, waarin roken een risicofactor bleek te zijn voor de genetische integriteit van het paternale genoom dat overgedragen wordt aan het nageslacht. Daarnaast blijkt dat het mogelijk is om, zelfs in een relatief kleine groep proefpersonen, overerfelijke mutaties te detecteren door analyse van minisatellieten na relatief lage blootstelling doses. Dit geeft aan dat de analyse van repeterende sequenties een gevoelige methode is om kiemlijn mutaties te detecteren en dat deze methode nader onderzocht dient te worden.

\section{Algemene conclusie}

Er kan worden geconcludeerd dat bovengenoemde data erop wijze dat genotoxische blootstelling schade kan veroorzaken in mannelijke geslachtscellen, hetgeen vervolgens leidt tot verhoogde mutatiefrequenties in het nageslacht. In dit proefschrift is het rookgedrag van de vader geïdentificeerd als een type blootstelling dat DNA-schade in sperma kan beïnvloeden en mutaties induceerde die werden overgebracht op het nageslacht. De effecten van deze mutaties op de gezondheid zijn nog altijd niet duidelijk, maar we kunnen speculeren dat dit ook invloed heeft op andere delen van het genoom. Roken door de vader induceerde DNA-fragmentatie in het sperma. Dit wordt enerzijds mogelijk veroorzaakt door directe blootstelling van spermatozoa aan ROS, anderzijds als gevolg van remming van apoptose door de aanwezigheid van een overmaat aan DNA-schade, of een combinatie van beide. Omvangrijke laesies zijn waarschijnlijk minder het gevolg van effecten van roken, omdat (I) omvangrijke DNA-adducten niet gedetecteerd werden in spermatozoa die in vitro werden blootgesteld aan B[a]P en (II) DNA-fragmentatie werd alleen gevonden na hoge blootstelling aan BPDE. Het is waarschijnlijker dat DNA-frag- 
mentatie veroorzaakt wordt door reactieve zuurstof deeltjes, omdat een significante toename van vitamine $\mathrm{C}$ radicaal werd gevonden in rokers. Daarnaast was de expressie van verschillende antioxidant enzymen omgekeerd gecorreleerd aan het aantal spermacellen in het ejaculaat. Dit geeft aan dat spermatozoa waarin beschermende enzymen hoog tot expressie komen beter beschermd zijn tegen oxidatieve stress ten gevolge van roken. DNA-schade was echter significant verhoogd, dus de bescherming van het DNA in volgroeide spermacellen tegen genotoxische aanslagen door het roken van sigaretten is wellicht onvoldoende. In combinatie met de stimulatie van anti-apoptotische pathways, zal dit leiden tot een toename in het ejaculaat van spermacellen met veel DNA-schade, zoals afgebeeld in afbeelding 1.

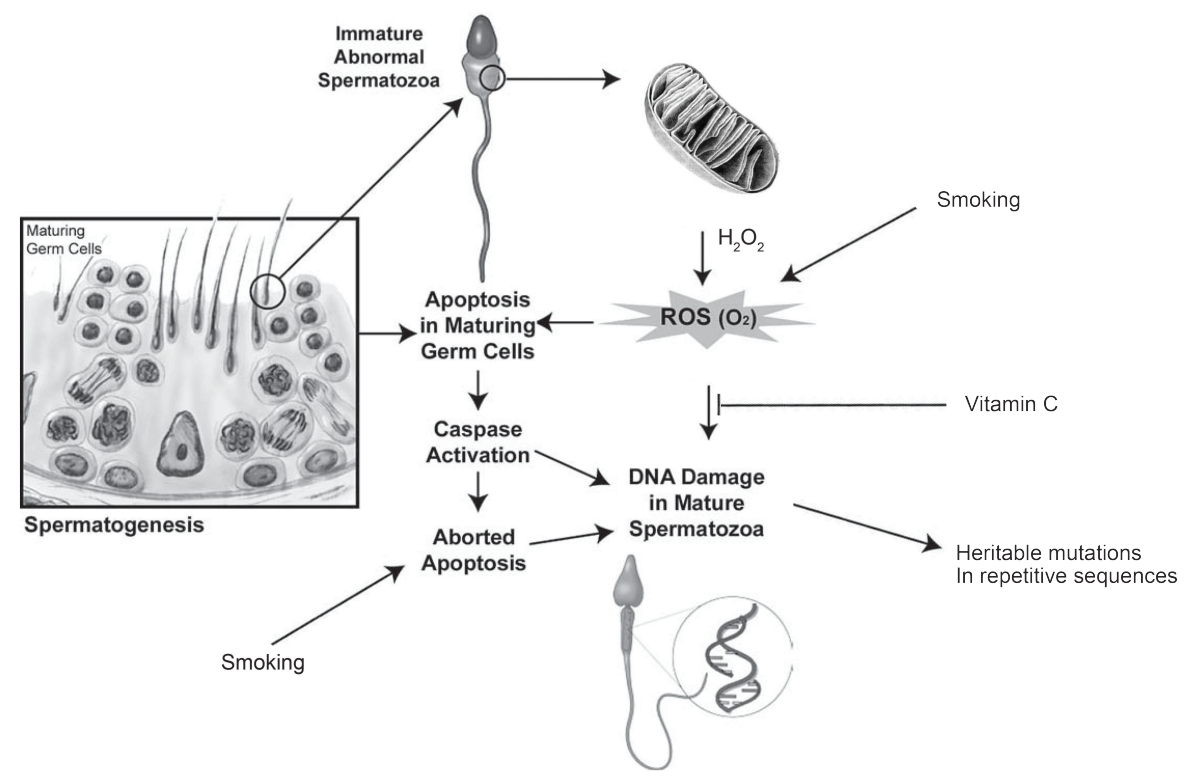

Figuur 1: De effecten van genotoxische blootstelling, met name het roken van sigaretten, op volgroeide spermacellen en vervolgens op het nageslacht kunnen worden samengevat zoals afgebeeld in deze illustratie. Verschillende typen blootstelling beïnvloeden mogelijk de genetische integriteit van de volgroeide spermacellen, wat vervolgens kan leiden tot enerzijds een afname in activatie van apoptose, en anderzijds een toename van DNA schade in volgroeide spermacellen in het ejaculaat. Deze verhoogde DNA schade niveaus in volgroeide spermacellen zijn een mogelijke oorzaak van de toename in mutatiefrequenties in het nageslacht. (Gebaseerd op Cocuzza v. [21])

Een toename van DNA-schade in de spermatozoa van rokende mannen roept de vraag op of dit invloed zal hebben op het aantal kiemlijn mutaties en op de gezondheid van hun nageslacht. Hiertoe hebben we mutaties geanalyseerd in de zeer variabele minisatellieten en konden we inderdaad 'roken' identificeren, naast enkele andere leefstijlfactoren, als potentiele oorzaak van een toename in mutatiefrequenties in het nageslacht. Er kan worden geconcludeerd dat deze data indiceren dat leefstijl van grote invloed is op de bijdrage van de vader aan de genetische integriteit van het nageslacht. Verdere studies zouden zowel het aantal spermamonsters als het aantal trio's moeten vergroten om de rol van de blootgestelde vader op de gezondheid van het kind verder te evalueren. 


\section{References}

1. Yauk, C., A. Polyzos, A. Rowan-Carroll, C.M. Somers, R.W. Godschalk, F.J. Van Schooten, et al., Germ-line mutations, DNA damage, and global hypermethylation in mice exposed to particulate air pollution in an urban/ industrial location. Proc Natl Acad Sci U S A, 2008. 105(2): p. 605-10.

2. Yauk, C.L., M.L. Berndt, A. Williams, A. Rowan-Carroll, G.R. Douglas, and M.R. Stampfli, Mainstream tobacco smoke causes paternal germ-line DNA mutation. Cancer Res, 2007. 67(11): p. 5103-6.

3. Marchetti, F. and A.J. Wyrobek, Mechanisms and consequences of paternally-transmitted chromosomal abnormalities. Birth Defects Res C Embryo Today, 2005. 75(2): p. 112-29.

4. Aitken, R.J. and G.N. De luliis, On the possible origins of DNA damage in human spermatozoa. Mol Hum Reprod, 2010. 16(1): p. 3-13.

5. Olsen, A.K., B. Lindeman, R. Wiger, N. Duale, and G. Brunborg, How do male germ cells handle DNA damage? Toxicol Appl Pharmacol, 2005. 207(2 Suppl): p. 521-31.

6. Pessot, C.A., M. Brito, J. Figueroa, Concha, II, A. Yanez, and L.O. Burzio, Presence of RNA in the sperm nucleus. Biochem Biophys Res Commun, 1989. 158(1): p. 272-8.

7. Holstein, A.F., W. Schulze, and M. Davidoff, Understanding spermatogenesis is a prerequisite for treatment. Reprod Biol Endocrinol, 2003. 1: p. 107.

8. Ostermeier, G.C., D.J. Dix, D. Miller, P. Khatri, and S.A. Krawetz, Spermatozoal RNA profiles of normal fertile men. Lancet, 2002. 360(9335): p. 772-7.

9. Aitken, R.J. and A.J. Koppers, Apoptosis and DNA damage in human spermatozoa. Asian J Androl, 2011. 13(1): p. 36-42.

10. Godschalk, R.W., F.J. Van Schooten, and H. Bartsch, A critical evaluation of DNA adducts as biological markers for human exposure to polycyclic aromatic compounds. J Biochem Mol Biol, 2003. 36(1): p. 1-11.

11. Rivrud, G.N., Mutagenicity testing of seminal fluid: seminal fluid increases the mutagenicity of the precursor mutagen benzo[a]pyrene in the presence of S9 mix. Mutat Res, 1988. 208(3-4): p. 195-200.

12. Saleh, R.A., A. Agarwal, R.K. Sharma, D.R. Nelson, and A.J. Thomas, Jr., Effect of cigarette smoking on levels of seminal oxidative stress in infertile men: a prospective study. Fertil Steril, 2002. 78(3): p. 491-9.

13. Chary, P. and R.S. Lloyd, In vitro replication by prokaryotic and eukaryotic polymerases on DNA templates containing site-specific and stereospecific benzo[a]pyrene-7,8-dihydrodiol-9,10-epoxide adducts. Nucleic Acids Res, 1995. 23(8): p. 1398-405.

14. Pietrasanta, L.I., B.L. Smith, and M.C. MacLeod, A novel approach for analyzing the structure of DNA modified by Benzo[a]pyrene diol epoxide at single-molecule resolution. Chem Res Toxicol, 2000. 13(5): p. 351-5.

15. Chiu, R.K., J. Brun, C. Ramaekers, J. Theys, L. Weng, P. Lambin, et al., Lysine 63-polyubiquitination guards against translesion synthesis-induced mutations. PLoS Genet, 2006. 2(7): p. e116.

16. Langie, S.A., A.M. Knaapen, C.H. Ramaekers, J. Theys, J. Brun, R.W. Godschalk, et al., Formation of lysine 63-linked poly-ubiquitin chains protects human lung cells against benzo[a]pyrene-diol-epoxide-induced mutagenicity. DNA Repair (Amst), 2007. 6(6): p. 852-62.

17. Jeffreys, A.J., N.J. Royle, V. Wilson, and Z. Wong, Spontaneous mutation rates to new length alleles at tandemrepetitive hypervariable loci in human DNA. Nature, 1988. 332(6161): p. 278-81.

18. Yauk, C.L. and J.S. Quinn, Multilocus DNA fingerprinting reveals high rate of heritable genetic mutation in herring gulls nesting in an industrialized urban site. Proc Natl Acad Sci U S A, 1996. 93(22): p. 12137-41.

19. Dubrova, Y.E., V.N. Nesterov, N.G. Krouchinsky, V.A. Ostapenko, R. Neumann, D.L. Neil, et al., Human minisatellite mutation rate after the Chernobyl accident. Nature, 1996. 380(6576): p. 683-6.

20. Dubrova, Y.E., G. Grant, A.A. Chumak, V.A. Stezhka, and A.N. Karakasian, Elevated minisatellite mutation rate in the post-chernobyl families from ukraine. Am J Hum Genet, 2002. 71(4): p. 801-9.

21. Cocuzza, M., S.C. Sikka, K.S. Athayde, and A. Agarwal, Clinical relevance of oxidative stress and sperm chromatin damage in male infertility: an evidence based analysis. Int Braz J Urol, 2007. 33(5): p. 603-21. 

DANKWOORD $\left.\right|^{135}$ 
Het voelt nog steeds een beetje onwerkelijk dat ik nu dan toch echt ben aangekomen bij het schrijven van het dankwoord. Alle andere hoofdstukken staan op papier en dit stukje is het laatste wat nog rest.

Het dankwoord staat zoals gebruikelijk achterin, terwijl dit vaak voor velen het beginpunt is van het lezen van een proefschrift. Toch wil ik jullie aanraden om ook de andere hoofdstukken van dit boekje door te lezen, misschien steek je er nog wat van op! Ik kan zelf niet anders zeggen dan dat ik de laatste jaren een heel stuk wijzer ben geworden. Lang geleden begon ik als stagiaire bij GRAT, een afdeling waar ik me snel thuis voelde. Marie-Claire herinnerde me nog vaak aan het moment dat ik enigszins nerveus voor mijn sollicitatie op het secretariaat binnen kwam lopen. De jaren daarna vlogen voorbij waarin ik steeds dieper dook in mijn onderzoek, af en toe even wakker geschud door een congres of onderwijsgroep. Nu is het moment om echt alles af te ronden en voilà, dit is het resultaat van al die jaren pipetteren, epjes schrijven, labellen, lezen, gels runnen, project meetings, schrijven, presentaties en blotten. Ik vind het zelf een mooie thesis geworden, maar ik ben misschien wel wat ge-biased. Zoals je zal begrijpen heb ik dit zeker niet alleen kunnen doen, maar ben ik hierbij geholpen door een aantal mensen die ik hierbij graag wil bedanken.

Allereerst wil ik mijn begeleiders, Prof. dr. van Schooten en Dr. Godschalk, bedanken voor de erg plezierige samenwerking. Frederik-Jan, ons overleg verliep altijd heel ontspannen, terwijl je toch kritisch de lijn en inhoud van dit proefschrift in de gaten hield. Roger, jouw kennis en enthousiasme inspireerde me telkens weer en ik vond het fijn dat je deur altijd open stond voor vragen of een korte brainstorm om weer met nieuwe ideeën aan de slag te gaan. Het was fijn om jullie als begeleiders te hebben.

Leden van de beoordelingscommissie, Prof. dr. J. de Mey, Dr. J. van Benthem, Prof. dr. G. Schoeters, Prof. dr. M. Zeegers: bedankt voor het beoordelen van mijn proefschrift.

Mijn PhD-project was een onderdeel van het grotere 'NewGeneris' project, waardoor ik de kans gekregen heb om kennis te maken met veel collega's door heel Europa. Hiervoor wil ik graag Prof. dr. Jos Kleinjans bedanken en daarbij ook het projectteam, Rene, Rob en Anneloes: bedankt voor alle ondersteuning en gezelligheid tijdens de verschillende NewGeneris meetings.

I also would like to thank the WP3 members with whom I collaborated over the last few years. Diana, thank you for leading our workpackage and making others aware of the importance of our work. Eduardo, Adi, Julian and Maggy, thanks for all your cooperation! Eleni, thank you so much for providing us with the Crete sperm samples! Gunnar and Ville, thank you for the nice cooperation and for all the good discussions! Last but not least I would also like to thank Kristine Gutzkow for her assistance on getting the MoBa triad samples! Thanks to the colleagues in Norway, I was able to perform the analyses as described in chapter 7 .

Furthermore, I would like to thank Carole Yauk for inviting us at your lab at Health Canada. Thanks to your experience and step-by-step walkthrough of the minisatellite assay, we finally got the assay working in our lab as well.

Mijn dank gaat ook uit naar alle anonieme donoren, waardoor ik vooral in de eerste jaren steeds weer kon blijven testen. Met lood in mijn schoenen moest ik op zoek naar mannelijke vrijwilligers, maar gelukkig waren er altijd mannen bereid om me te voorzien van monsters.

De afdeling GRAT bestaat inmiddels niet meer als zodanig, maar in mijn tijd waren we nog één groep en daarom wil ik ook iedereen van GRAT bedanken voor de zeer 
prettige samenwerking! Marie-Claire, jou wil ik in het bijzonder bedanken voor al je hulp gedurende mijn AiO-schap, zeker ook bij de laatste loodjes. Alle analisten wil ik bedanken voor hun hulp (en zeker ook de gezelligheid!) tijdens de vele uren op het lab. Met name Danielle Pachen (voor al je RAPD-PCR werk), Ralph Gottschalk en Marcel van Herwijnen (voor jullie hulp op het array lab), Edwin Moonen (voor de HPLC analyses), Lucien Beckers (voor je hulp bij het post-labellen) en last but not least Lou Maas (voor al je hulp bij het labellen en de minisatellite assay)! Lou, de radio blijft voortaan op StuBru staan! Daarnaast wil ik ook graag Jacco Briedé bedanken voor je enthousiaste hulp bij het ESR-en!

Mijn mede-AiO's hebben er zeker ook toe bijgedragen dat ik een erg leuke tijd bij GRAT heb gehad! In het bijzonder mijn kamergenoten van de beruchte AiO-kamer: Dennie, Joyce, Marieke en Linda. Dank jullie wel voor alle nodige ontspanning (die ik hier maar verder niet ga specificeren...) tussen de drukke werkzaamheden door! Karen en Sabine, samen met jullie (en alle pizza, kabouters en filmpjes op het lab), hebben we volgens mij best wat leuke activiteiten georganiseerd! Kevin, bedankt voor je gezelligheid tijdens de verschillende uitstapjes die we voor NewGeneris mochten maken!

Op het moment van schrijven wonen we inmiddels ook niet meer in Maastricht, waardoor we het leven in deze fijne stad moeten missen, ondanks dat ik er nog bijna dagelijks kom. Richard, Marieke, Jeantine, Mijke, Rutger, dank jullie wel voor alle ontspanning en gezelligheid! Gelukkig is onze verhuizing geen belemmering gebleken om elkaar nog regelmatig te zien!

Mark, Merel, Doret, Sander, Bas, Femke, Dorien, Frank, Paul en Marjon, dank jullie wel voor al jullie steun en interesse! De logeerweekendjes in het zuiden waren altijd erg gezellig, maar gelukkig wonen we nu weer wat dichterbij, waardoor we weer wat makkelijker en sneller een drankje kunnen doen.

Mijn paranimfen, terwijl ik jullie pas heel laat de vraag stelde of jullie achter me wilden staan, had ik in mijn hoofd al lang geleden bedacht dat ik me geen andere paranimfen kon wensen! Nicole, dank je wel voor al je hulp en Brabantse gezelligheid op het lab! Ik heb veel van je geleerd tijdens de vele momenten dat we hebben samengewerkt. Door jouw hulp kreeg ik het eindelijk voor elkaar om de minisatellite assay werkend te krijgen, met misschien wel als belangrijkste stap onze trip naar Canada! Richard, ik schrok even toen je me vertelde dat jullie al op korte termijn naar Aruba zouden gaan, maar ik ben blij dat jullie er straks op deze dag bij kunnen zijn. Het is fijn dat we ons allebei met iets anders bezighouden, zodat we het op de boot of de fiets niet over werk hoeven te hebben (in tegenstelling tot onze vrouwen :-) ). Ondanks dat de inhoud van dit boekje misschien wat minder duidelijk voor je zal zijn, is de lay-out echt heel gaaf geworden! Het is fijn om te weten dat we soms aan een half woord genoeg hebben!

Papa en mama, dank jullie wel voor alles! Dankzij jullie heb ik het zover kunnen schoppen dat ik straks dit boekje sta te verdedigen. Als ik weer met nietszeggende lijsten met genen aan kwam zetten, of mijn frustraties uitte over een niet-werkende assay, jullie toonden altijd interesse. Het is een steun om te weten dat jullie altijd achter me staan en weten hoe het met me gaat.

Lieve Marjolijn, zonder jou was dit nooit gelukt! Ik ben blij dat ik destijds heb besloten naar jou in Maastricht te verhuizen, waardoor we daar samen een heerlijke tijd hebben gehad! Ik kon altijd rekenen op je hulp of kritische blik, of om het onderzoek even vanuit een ander perspectief te bekijken. Inmiddels hebben we onze plek gevonden in Den Bosch en help je me ook met de laatste loodjes. Héél erg bedankt voor álles! Je bent een schat! 

\begin{tabular}{r|r} 
CURRICULUM VITAE & 139 \\
JOOST O LINSCHOOTEN &
\end{tabular} 


\section{Joost Olaf Linschooten}

Joost Olaf Linschooten was born on August 31 1982 in Apeldoorn, The Netherlands. He graduated from his secondary school at the Zwijsen College in Veghel in 2001. In the same year, he started studying food science and technology at the HAS Den Bosch, with dairy technology and product- and process development as sub specialism. He obtained his Bachelor's degree in 2005 and in the same year he started his Masters's course on Metabolism and Nutrition at Maastricht University. After an internship at the department of Health Risk Analysis and Toxicology (GRAT) at Maastricht University, he received his master's degree in 2006. From September 2006 until November 2010, he worked as a PhD student at this department on the project entitled: 'Paternal impact on genetic integrity in newborns', under the supervision of Prof. Frederik-Jan van Schooten and Dr. Roger Godschalk. The research performed during this period is described in this thesis, which was part of the EU FP6 Project NewGeneris (Newborns and Genotoxic exposure risks). During this research period he obtained the license to work with radioactive material (level of competence 5b, as accredited by the Dutch government) and received funding to participate in the Cascade-course in Reproductive and developmental Toxicology. Furthermore, he won a poster price at the European Environmental Mutagen Society Conference (2007) for his study entitled: 'The use of spermatozoal mRNA profiles as exposure marker for human germ cells'. He was awarded with another poster price for the same research on the 2008 NewGeneris Annual Meeting. He is currently working as Clinical Safety Specialist for Medtronic at the Bakken Research Center in Maastricht, The Netherlands. 



\section{LIST OF PUBLICATIONS $\left.\right|^{143}$}




\section{List of publications}

Use of spermatozoal mRNA profiles to study gene-environment interactions in human germ cells

Mutation Research (2009) Jul 10;667(1-2):70 - 76

Joost O. Linschooten, Frederik J. van Schooten, Adolf Baumgartner, Eduardo Cemeli, Joost van Delft, Diana Anderson, Roger W.L. Godschalk

In vitro evaluation of baseline and induced DNA damage in human sperm exposed to benzo[a]pyrene or its metabolite benzo[a]pyrene-7,8-diol-9,10-epoxide, using the comet assay

Mutagenesis (2010) 25 (4): $417-425$

Ville E. Sipinen, Julian Laubenthal, Adolf Baumgartner, Eduardo Cemeli, Joost 0. Linschooten, Roger W.L. Godschalk, Frederik J. van Schooten, Diana Anderson, Gunnar Brunborg

Incomplete protection of genetic integrity of mature spermatozoa against oxidative stress Reproductive Toxicology (2011) Jul;32(1):106 - 11

Joost O. Linschooten, Julian Laubenthal, Eduardo Cemeli, Adolf Baumgartner, Diana Anderson, Ville E. Sipinen, Gunnar Brunborg, Guido R. Haenen, Eleni Fthenou, Jacob J. Briedé, Frederik J. van Schooten,

Roger W.L. Godschalk

New methods for assessing male germline mutations in humans and genetic risks in their offspring

Mutagenesis (2008) Jul;23(4):241 - 247

Nicole Verhofstad, Joost O. Linschooten, Jan van Benthem, Yuri E. Dubrova, Harry van Steeg, Frederik J. van Schooten, Roger W.L. Godschalk

Evaluation of Randomly Amplified Polymorphic DNA (RAPD)-PCR as methodology to assess mutation frequencies

Manuscript in preparation

Joost O. Linschooten, Sabine A.S. Langie, Nicole Verhofstad, Danielle Pachen, Lou Maas, Roland K. Chiu, Frederik J. van Schooten, Roger W.L. Godschalk

Paternal lifestyle as a potential source of germline mutations transmitted to offspring Manuscript in preparation

Joost O. Linschooten, Nicole Verhofstad, Kristine Gutzkow, Gunnar Brunborg, Carole Yauk, Yvonne Oligschläger, Frederik J. van Schooten, Roger W.L. Godschalk 